\title{
The Impacts of Temperature and Thermal Properties on Municipal Solid Waste Stabilization
}

by

Courtney Berquist, B.Eng.

\author{
A thesis submitted to the \\ Faculty of Graduate and Postdoctoral Affairs \\ in partial fulfillment of the requirements for the degree of
}

Master of Applied Science in Environmental Engineering

Ottawa-Carleton Institute for Environmental Engineering

Department of Civil and Environmental Engineering

Carleton University

Ottawa, Ontario

(C) Copyright

Courtney Berquist, 2017 


\section{Abstract}

Instrument bundles placed within the Ste. Sophie landfill (Quebec, Canada) have been collecting temperature, settlement, and oxygen data since 2009. The temperature and settlement of the landfill were modelled using the finite element software COMSOL Multiphysics. The COMSOL optimization module was utilized to determine the thermal conductivity and specific heat of the waste as a function of time and depth. An anaerobic heat generation coefficient was employed to decrease the overall heat generated in the domain and a new latent heat value was assumed. The concept of total expended energy was used to replace the time-dependent biodegradation-induced settlement term with a temperaturedependent biodegradation-induced settlement term. The new term better accounts for the delayed biodegradation process observed in cold climate wastes. The model was in good agreement with the temperature and settlement data collected from the Ste. Sophie landfill. A simulation was run in order to study the effects of placement conditions on waste settlement and stabilization. It was found that waste placement temperature has an impact on overall settlement at the landfill. By strategically placing waste throughout the year, more waste can be placed during the filling stages of the landfill, simultaneously bringing increased revenues to landfill operators while decreasing the environmental burden of landfills. 


\section{Acknowledgments}

I would like to thank my supervisor, Dr. Paul Van Geel, for his patience and support, and for the endless knowledge he has provided me with over the past 2 years. I would also like to thank James Doyle for answering my countless questions, and Rob McDonald for his help along the way.

Mom, Dad, Melissa and Justin- thank you for loving me through the stresses and headaches of my many, many years of university education.

Last but not least, I would like to thank Marcel for his support, encouragement, and endless love, and for keeping a smile on my face throughout my undergraduate and graduate degrees. 


\section{Table of Contents}

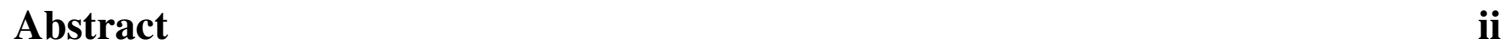

Acknowledgments iii

Table of Contents iv

List of Tables $\quad$ viii

$\begin{array}{ll}\text { List of Figures } & \text { ix }\end{array}$

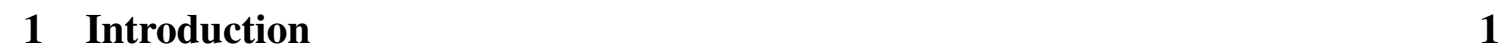

1.1 Problem Definition $\ldots \ldots \ldots \ldots$. . . . . . . . . . . . . . 1

1.2 Scope of Research $\ldots \ldots \ldots \ldots$. . . . . . . . . . . . . 2

1.3 Organization of Research $\ldots \ldots \ldots$. . . . . . . . . . 3

\begin{tabular}{|lll}
\hline 2 & Literature Review & 5
\end{tabular}

$2.1 \quad$ Introduction to Landfills $\ldots \ldots \ldots \ldots$. . . . . . . . . . 5

$2.1 .1 \quad$ Landfill Pre-Closure . . . . . . . . . . . . . . . . 6

2.1 .2 Landfill Post-Closure . . . . . . . . . . . . . . . . . . . . 9

2.2 Waste Stabilization . . . . . . . . . . . . . . . 10 
$2.2 .1 \quad$ Phases of Waste Stabilization $\ldots \ldots \ldots \ldots$

2.2 .2 Factors Impacting Waste Stabilization $\ldots \ldots \ldots \ldots$

2.3 Heat Transfer in Landfills . . . . . . . . . . . . . . . . . . . . . . . 15

2.3 .1 Conduction $\ldots \ldots \ldots \ldots \ldots \ldots \ldots$

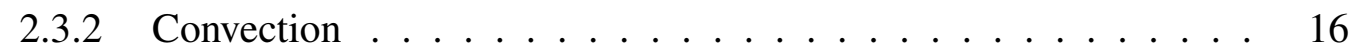

2.3 .3 Radiation . . . . . . . . . . . . . . . . . . . 17

2.3 .4 Thermal Conductivity $\ldots \ldots \ldots \ldots \ldots$

2.3 .5 Specific Heat Capacity . . . . . . . . . . . . . . . . 23

$2.3 .6 \quad$ Latent Heat of Phase Change. . . . . . . . . . . . . . . . 25

$2.3 .7 \quad$ Heat Generation $\ldots \ldots \ldots \ldots \ldots \ldots$

2.4 Landfill Settlement . . . . . . . . . . . . . . . . . . . . . 35

2.5 MSW Temperature Modelling $\ldots \ldots \ldots \ldots$

\begin{tabular}{|ll|}
\hline & Field Setup and Data Acquisition \\
\hline
\end{tabular}

$3.1 \quad$ Instrument Bundles $\ldots \ldots \ldots \ldots \ldots$. . . . . . . . . . . . 44

3.2 Field Data Analysis $\ldots \ldots \ldots \ldots \ldots \ldots \ldots \ldots \ldots$

$3.2 .1 \quad$ Temperature Data $\ldots \ldots \ldots \ldots \ldots \ldots \ldots$

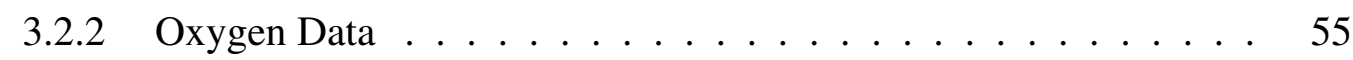

3.2 .3 Settlement Data . . . . . . . . . . . . . . . . . . . 56

\begin{tabular}{|lll}
4 & Ste. Sophie Heat Budget Model & 58
\end{tabular}

4.1 Model Development and Overview . . . . . . . . . . . . 58 
$4.2 \quad$ Initial Model Parameters $\ldots \ldots \ldots$. . . . . . . . . . . . . 62

$4.2 .1 \quad$ Conduction from Underlying Soil $\ldots \ldots \ldots$

4.2 .2 Surface Heat Flux $\ldots \ldots \ldots \ldots \ldots$

4.2 .3 Aerobic Heat Generation . . . . . . . . . . . . . . . . . . 63

$4.2 .4 \quad$ Latent Heat of Phase Change. . . . . . . . . . . . . . . . 64

4.2 .5 Anaerobic Heat Generation Coefficient . . . . . . . . . . 64

4.2 .6 Thermal Conductivity $\ldots \ldots \ldots \ldots$

4.2 .7 Specific Heat . . . . . . . . . . . . . . . . . . . 65

4.3 Methodology $\ldots \ldots \ldots \ldots \ldots \ldots$

4.4 Results and Discussion . . . . . . . . . . . . . . . . . . . . . . . . 69

4.4.1 Anaerobic Heat Generation Coefficient and Latent Heat _. . . 71

4.4 .2 Thermal Conductivity $\ldots \ldots \ldots \ldots$

4.4 .3 Specific Heat . . . . . . . . . . . . . . . . . . 77

4.5 Heat Budget $\ldots \ldots \ldots \ldots \ldots \ldots \ldots \ldots \ldots \ldots \ldots$

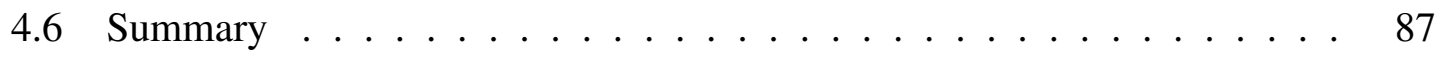

$\begin{array}{|lll|}5 & \text { Temperature-Dependent Biodegradation-Induced Settlement Model } & 89\end{array}$

$5.1 \quad$ Introduction . . . . . . . . . . . . . . . . . . . . . 89

5.2 Methodology . . . . . . . . . . . . . . . . . . . . . 90

5.3 Results and Discussion . . . . . . . . . . . . . . 96

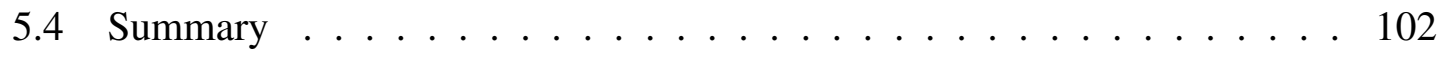


\begin{tabular}{|lll}
\hline 6 & Simulation of Strategic Waste Lift Placement & 104
\end{tabular}

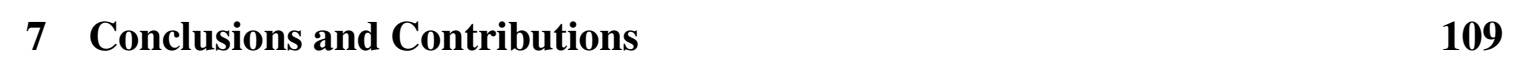

\begin{tabular}{ll}
\hline List of References & 113
\end{tabular} 


\section{List of Tables}

2.1 Geo-environmental and socio-economic considerations for siting a landfill. 6

2.2 Summary of thermal conductivities and specific heat capacities cited in literature. ............................ 19

2.3 Parameters used by Megalla et al. [2016) to model heat generation at Ste. Sophie landfill. ................... 31

$3.1 \quad$ Instruments used to collect data at the Ste. Sophie landfill. . . . . . . . . 48

3.2 Date in which data collection began for each bundle. . . . . . . . . . . 49

$4.1 \quad$ Modelled simulation times and cumulative waste lift heights. . . . . . . . 59

4.2 Conditions specified when using COMSOL Multiphysics. . . . . . . . . 61

4.3 Percentage increase in sum of squared differences in comparison to the Megalla et al. (2016) model. . . . . . . . . . . . . 70

4.4 Simulated heat budget results $\ldots \ldots \ldots \ldots$. . . . . . . . . . 83

$5.1 \quad$ Best fit $/$ Marques et al. (2003) parameters determined by Van Geel \& Mur-

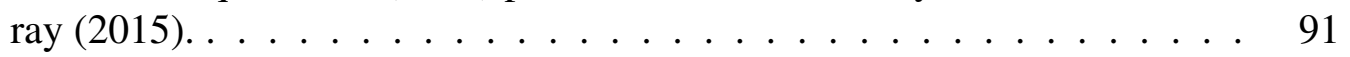




\section{List of Figures}

2.1 Thermal conductivity variance with depth and time used by Megalla et al.

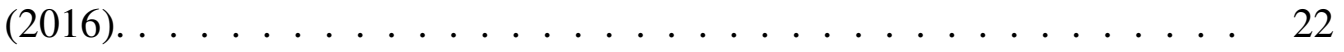

2.2 Dual-ramped anaerobic heat generation function used by Hanson et al. (2013) and quadratic fit used by Megalla et al.(2016). . . . . . . . . . 32

2.3 Heat generation as a function of expended energy proposed by Hanson et al.(2013) and 6th order polynomial applied by Megalla et al.(2016). . . . 33

2.4 3D function used by Megalla et al. (2016) to model the anaerobic heat generation at the Ste. Sophie landfill. . . . . . . . . . . . . . . 34

3.1 Aerial view of Zone 4 where the instrument bundles and instrument shed are located. . . . . . . . . . . . . . . . . 45 45

3.2 Lift placement dates and heights. . . . . . . . . . . . . . . . 46

3.3 Instrument bundle used for data collection at the Ste. Sophie landfill. . . . $\quad 47$

3.4 Bundle placement locations and elevations. . . . . . . . . . . . . . 50

3.5 Temperature variations with time at bundles 1 through $12 . \quad$. . . . . . . 51

3.6 Percent oxygen with time at bundles 1 through $12 . \quad \ldots \ldots$. . . . . . 54

$3.7 \quad$ Settlement with time at bundles 1 through 12. . . . . . . . . . . . . 57

4.1 Optimized modelled temperature results. . . . . . . . . . . . . 71

4.2 Optimized thermal conductivity (K) results for each simulation period (for example, K1 represents the thermal conductivity solution for simulation

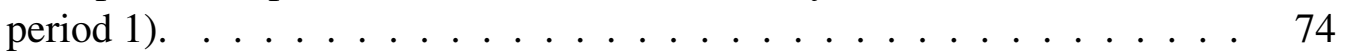


4.3 Upper and lower bounds specified during optimization of thermal conductivity. ........................... 75

4.4 Optimized heat capacity (C) results for each simulation period (for example, C1 represents the specific heat solution for simulation period 1). . . . 78

4.5 Upper and lower bounds specified during optimization of heat capacity for periods 1 through $3 . \ldots \ldots \ldots 79$

4.6 Upper and lower bounds specified during optimization of heat capacity for periods 4 through 7. . . . . . . . . . . . . 80

5.1 Conceptual plots to demonstrate temperature-dependent heat generation model proposed by Hanson et al.|(2013). . . . . . . . . . . . . . . . . . . 94

5.2 Simulated expended energy as a function of time for all bundles. . . . . . 95

5.3 Simulated temperature-dependent biodegradation-induced settlement at bundle $3 . \ldots \ldots \ldots \ldots$. . . . . . . . . . . . . . . . . . . . .

5.4 Simulated temperature-dependent biodegradation-induced settlement at

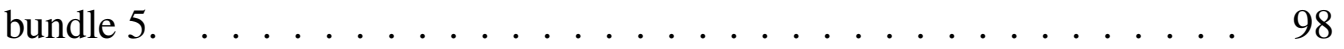

5.5 Simulated temperature-dependent biodegradation-induced settlement at bundle $7 . \ldots \ldots \ldots \ldots \ldots$

5.6 Simulated temperature-dependent biodegradation-induced settlement at bundle $9 . \ldots \ldots \ldots . \ldots \ldots 9 . \ldots \ldots \ldots$

5.7 Simulated temperature-dependent biodegradation-induced settlement at

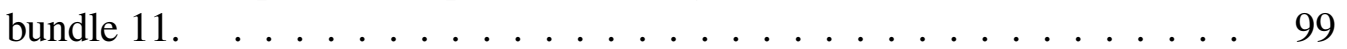

6.1 Comparison of actual waste lift sequence simulated temperatures with warm lift 2 waste lift sequence simulated temperatures . . . . . . . . . . 105

6.2 Regular waste lift sequence modelled expended energies. . . . . . . . . . 106

6.3 Warm waste lift 2 sequence modelled expended energies. . . . . . . . . . 106

6.4 Comparison of simulated expended energies for actual waste lift sequence

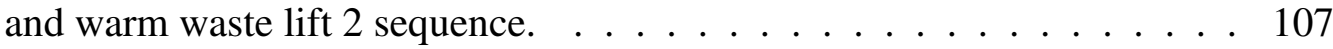




\section{Chapter 1}

\section{Introduction}

\subsection{Problem Definition}

Waste management is becoming an increasingly important challenge to tackle in light of the fact that the global population is expected to surpass 8 billion by the year 2050 (Lutz \& Samir, 2010). With increasing population and economic growth, waste production and resource consumption are expected to continue increasing (Statistics Canada, 2012).

In 2010, Canadians disposed of approximately 25 million tonnes of non-hazardous waste, which corresponds to an annual per capita waste disposal rate of $729 \mathrm{~kg}$ (Giroux, 2014). Only one third of waste was diverted away from landfills, still leaving a significant amount of waste to be disposed of (Giroux, 2014). Approximately 3\% of waste which is not diverted is incinerated, and the remaining 97\% ends up in landfills (Giroux, 2014). This sheds light on the continued need for environmentally friendly, safe and efficient landfill systems to manage our waste. 


\subsection{Scope of Research}

Canada's cold climate poses a significant challenge for the management of municipal solid waste (MSW). When MSW is placed at the curbside during winter months, the liquid fraction within the waste freezes. As a result, a significant amount of energy is needed to heat the waste to an optimum biodegradation temperature of approximately 35 degrees to enhance waste stabilization. This may take several months to years to occur, depending on the operating and climatic conditions at the site. The overall objective of this research is to better understand and optimize the waste stabilization and biodegradation processes for landfills operating in Northern climates. Waste stabilization is important because it can reduce the contaminating lifespan of the waste and impact pre- and post-closure activities at the site. Waste stabilization prior to placement of the final cover will increase waste settlement and the amount of usable airspace within the landfill for waste disposal; it will also increase the gas generation for recovery as a green energy source. Post-closure, waste stabilization will impact re-development options for the site.

A Waste Management landfill in Ste. Sophie, Quebec, Canada, has been instrumented with sensors to measure temperature, moisture content, settlement, overburden pressure, percent oxygen and leachate mounding. This thesis presents the temperature, settlement and oxygen data collected from the landfill since 2009. A finite element software program, COMSOL Multiphysics, was used to simulate the temperature and settlement of the landfill. Thermal conductivity and specific heat capacity were optimized in order to improve the fit of the model. The latent heat and heat generation rate were adjusted to further calibrate the model. The concept of waste expended energy was used to improve 
the biodegradation-induced settlement model by making the biodegradation-induced settlement rate temperature dependent rather than a function of time. A simulation was run in order to determine the benefit of strategically placing waste to avoid placing frozen waste above frozen waste.

\subsection{Organization of Research}

This thesis is divided into the following chapters:

Chapter 2 provides a literature search, explaining important background information, as well as summarizing previous relevant research efforts.

Chapter 3 explains the history of the field work, including the setup and instrumentation of the Ste. Sophie landfill in Quebec, Canada, and presents the temperature, settlement and oxygen data collected from the landfill.

Chapter 4 presents and explains the new parameters used in the 1D heat budget model of the Ste. Sophie landfill. Optimization of the thermal conductivity and specific heat capacity determined new relationships with time and depth for the landfill, and the anaerobic heat generation rate and latent heat value were adjusted by minimizing the sum of squared differences between the simulated and actual Ste. Sophie temperatures.

Chapter 5 presents the development of a temperature-dependent biodegradationinduced settlement term that accounts for the changing temperatures observed in cold 
climate landfills.

Chapter 6 presents the simulation of an alternative waste layer placement sequence to study the effects of placement conditions on overall waste stabilization.

Chapter 7 concludes the thesis and summarizes the research contributions of the author. 


\section{Chapter 2}

\section{Literature Review}

\subsection{Introduction to Landfills}

Landfilling is the final disposal option for 97\% of Canada's residual MSW (Giroux, 2014). A landfill is a physical facility used for the disposal of residual solid wastes at the surface of the earth. It differs from a 'dump' in that it uses engineered barrier systems in order to contain the waste and its resulting contaminants (leachate and landfill gas). In Ontario, landfills must be designed and operated in accordance with the Environmental Protection Act (EPA), specifically Ontario Regulation 232/98: Landfilling Sites. The Reasonable Use Guideline, mandated by the Ministry of the Environment (MOE), provides the basis for the maximum allowable contaminant concentration in the groundwater on properties adjacent to the landfill. The following section will outline the major design components of a landfill. 


\subsubsection{Landfill Pre-Closure}

\section{Situating the Landfill}

The first consideration in the design of a landfill is its location. There are many geoenvironmental factors and socio-economic factors which must be considered in locating a landfill. Some of these factors are listed in 2.1, followed by the main engineered components of a landfill.

Table 2.1: Geo-environmental and socio-economic considerations for siting a landfill.

\begin{tabular}{|c|c|}
\hline Geo-Environmental Factors & Socio-Economic Factors \\
\hline \hline Availability of land & Land use zoning \\
Site access & Distance to waste generation locations \\
Surface water hydrology & Development costs \\
Geologic conditions & Operation and Maintenance costs \\
Soil type/conditions & Public health and safety \\
Topography & \\
\hline
\end{tabular}

\section{Composite Liner System}

A liner system is placed at the bottom of the landfill in order to keep leachate from infiltrating the surrounding environment, and contaminating groundwater and/or drinking water. The design of the liner system ultimately depends on the specific site conditions of the landfill. Typically, a landfill will use either a compacted clayey liner (CCL), or a geosynthetic clay liner (GCL). In both cases, a geomembrane is used to provide an extra layer 
of protection from leachate infiltration. A CCL must have a minimum thickness of $0.6 \mathrm{~m}$ of compacted clay, and consist of at least four lifts of no more than $0.15 \mathrm{~m}$ in compacted thickness (Ontario Ministry of Environment, 1998). A GCL consists of a clay layer held between two geotextile fabrics. The clay layer is usually made of bentonite, which has a very low hydraulic conductivity and a significant swelling capacity.

\section{Leachate Collection System}

Leachate is the contaminated liquid which is expulsed from waste due to compaction and the weight of the waste itself. It is also generated by water which infiltrates the landfill and carries contaminants with it. Leachate consists of a number of dissolved and suspended components, such as salts, organic compounds and metals (El-fadel et al., 1997b; Rowe, 2005). Primarily, the leachate collection system (LCS) is used to control the leachate head which builds up above the liner system and secondly, it is used to remove the leachate, either for leachate recycle or to be treated and disposed of (Rowe, 2005).

\section{The Working Landfill}

Once the aforementioned composite liner system and LCS have been installed in a waste cell, operators can begin placing MSW in the landfill. The landfill is typically divided into waste cells, in which the waste can be placed over time. Waste is placed in layers (referred to as lifts) of about $3 \mathrm{~m}$ in thickness within the cells. Each waste lift is compacted to maximize the amount of waste which can be placed in the landfill. A daily cover is placed 
at the end of each day, usually consisting of approximately $15 \mathrm{~cm}$ of soil material, in order to reduce odours, keep vermin away from the waste and to keep the waste from blowing around.

\section{Landfill Gas Collection System}

Landfill gas (LFG) is composed mainly of methane (45-60\%) and carbon dioxide (40$50 \%$ ), and also contains trace amounts of nitrogen, oxygen, hydrogen, water vapor and volatile organic compounds (VOCs). The generation of LFG is affected by waste composition, moisture content, particle size, age, $\mathrm{pH}$ and temperature. Methane is a potent greenhouse gas, with a 100-year global warming potential (GWP) 25 times that of carbon dioxide (Cao \& Staszewska, 2013; United States Environmental Protection Agency, 2017). Methane (and therefore LFG) is also highly flammable, with a lower explosive limit of only 5\%. For these reasons, it is necessary to capture LFG before it can reach the atmosphere. LFG collection systems are mandatory in Ontario. The LFG collected can either be flared (burned) whereby the by-products are less harmful to the environment, or used to produce energy. The type of LFG collection system used is based on several factors such as expected LFG volume, and the type of waste. Horizontal LFG collection pipes are commonly installed as the landfill is being filled (that is, for an open landfill). Vertical gas collection wells may be placed after the landfill has closed, and a final cover has been placed. 


\section{Final Cover System}

The landfill cover system is used primarily to control the infiltration of water and the exfiltration of LFG. Two cover designs are generally employed: high infiltration or low infiltration. High infiltration is beneficial because it reduces the overall contaminating lifespan of the landfill by flushing out contaminants quickly and accelerating the biodegradation of waste. The cover system must contain at least $0.6 \mathrm{~m}$ of cover material, overlaid by at least $0.15 \mathrm{~m}$ of topsoil and finally a vegetative cover (Ontario Ministry of Environment, 1998).

\subsubsection{Landfill Post-Closure}

\section{Monitoring and Contingency}

Once a landfill has reached its capacity and a final cover has been placed, it must continue to be monitored in order to ensure that there is no contamination to the surrounding environment. This monitoring usually involves testing groundwater, surface water, soil and air for contamination resulting from the landfill. It is also necessary to monitor the landfill gas and leachate which is generated by the landfill even after closure.

\section{Development}

A closed, stabilized landfill has the potential to be utilized for many different uses. For example, a greenspace for public enjoyment or even for habitat restoration (Yun et al. 
2014). Some barriers to developing on a closed landfill include cost benefit, public perception, soil conditions, slope stability and landscape design (Yun et al., 2014).

\subsection{Waste Stabilization}

Waste stabilization is important because it can reduce the contaminating lifespan of the waste and impact pre- and post-closure activities at the site. Waste stabilization prior to placement of the final cover will increase waste settlement and the amount of usable airspace within the landfill for waste disposal; it will also increase the gas generation for recovery as a green energy source. Post-closure, waste stabilization will impact redevelopment options for the site.

\subsubsection{Phases of Waste Stabilization}

Solid waste decomposition and stabilization can be divided into two biodegradation stages: aerobic and anaerobic (El-fadel et al., 1997). Upon initial placement in a landfill, oxygen is present in the waste which allows aerobic decomposition to take place. Once the oxygen has been depleted, anaerobic biodegradation begins to take place. There are four phases which can be used to describe this biodegradation process, in which the organic waste fraction is converted to methane and carbon dioxide (Eq. 2.1) (El-fadel et al., 1997b; Rich et al. 2008). These are hydrolysis, acidogenesis, acetogenesis and methanogenesis. 


$$
\mathrm{C}_{6} \mathrm{H}_{12} \mathrm{O}_{6} \rightarrow 3 \mathrm{CO}_{2}+3 \mathrm{CH}_{4}
$$

\subsubsection{Factors Impacting Waste Stabilization}

\section{Waste Composition}

Waste composition will vary depending on the type of waste the landfill receives (MSW, industrial, commercial \& institutional or construction \& demolition wastes, for example). It may further vary within these categories based on economy, season, and cultural practices. The waste composition will impact the ratio of methane and carbon dioxide which are ultimately produced (El-Fadel, 1991). Size reduction can increase the decomposition rate by increasing the surface area of the waste (Lee, 1996).

\section{Nutrients}

Leachate recirculation can add nutrients back into the waste and accelerate the waste breakdown (Warith, 2003). Nutrients (including nitrogen and phosphorous, among others) are important for the anaerobic bacteria because they aid in the degradation of the waste. On the other hand, toxic heavy metals can impede the growth of bacteria and can result in a lower production rate of gas. Leachate recirculation can also help to further treat the leachate. 


\section{Bacteria}

Bacteria naturally exist in the soil and waste in the landfill. The addition of municipal sludge and/or waste water into the landfill will add more bacteria, aiding in biodegradation and methanogenesis (Alkaabi et al., 2009; Warith, 2003).

\section{Temperature}

Heat and landfill gas are the primary by-products of anaerobic biodegradation. Mesophilic and thermophilic bacteria are responsible for anaerobic biodegradation, and each operate under different temperature regimes. Mesophilic bacteria are those involved in waste degradation at mid range temperatures of 35 to $40{ }^{\circ} \mathrm{C}$ (Lefebvre et al. 2000 ; Yesiller et al. 2005, 2015), $35^{\circ} \mathrm{C}$ (Lee, 1996), 20 to $44{ }^{\circ} \mathrm{C}$ (Farquhar \& Rovers, 1973). Thermophilic bacteria are those involved in waste degradation at higher temperatures of 50 to $60{ }^{\circ} \mathrm{C}$ (Lefebvre et al., 2000; Yesiller et al., 2005, 2015), 55 to $60{ }^{\circ} \mathrm{C}$ (Lee, 1996), $44{ }^{\circ} \mathrm{C}$ and greater (Farquhar \& Rovers, 1973),

Increasing the temperature from 20 to $40{ }^{\circ} \mathrm{C}$ can increase methane production by up to 100 times (Warith, 2003). In a laboratory study, increasing waste temperature from 22 to $33{ }^{\circ} \mathrm{C}$ increased the rate of gas production by $70 \%$ (Kasali \& Senior, 1989). Temperatures of 34 to $41{ }^{\circ} \mathrm{C}$ were found to be optimal for methane production (Yesiller et al. 2005). Farquhar \& Rovers (1973) state that optimum gas production occurs at $37^{\circ} \mathrm{C}$ in the mesophilic range. Mesophilic temperatures were found to result in high methane production (Lee, 1996). Kasali \& Senior (1989) showed that maintaining mesophilic temperature 
ranges allows methanogensis to proceed at an optimal rate. If temperatures rise too high, it can inhibit the bacterial activity (Lefebvre et al., 2000).

Carbon dioxide, water and heat are the primary by-products of aerobic biodegradation (El-Fadel, 1991). Lanini et al. (2001) modelled the one-dimensional heat and oxygen transfers of MSW and validated the model with an experimental study of a landfill in France. The simulation demonstrated that waste temperatures of up to $70{ }^{\circ} \mathrm{C}$ could be reached due to oxygen diffusion from the top of the landfill resulting in aerobic biodegradation. Rendra et al. (2007) studied the effects of aerobic biodegradation on the stabilization of MSW. Several columns of MSW were studied under aerobic conditions, and peak temperatures of 55 to $59^{\circ} \mathrm{C}$ were observed.

\section{Moisture Content}

Complete stabilization of waste will not occur unless adequate moisture is available in the landfill to support biodegradation (Bolyard \& Reinhart, 2016). Further, moisture also aids in transporting nutrients throughout the landfill (El-fadel et al., 1997; Warith, 2003). The moisture content within the landfill may be influenced by the moisture content of incoming waste, precipitation, groundwater intrusion, leachate collection and recirculation, surface vegetation, and cover and liner materials. A common practice is leachate recirculation, in which leachate is collected and then reinjected back into the landfill. This helps to promote anaerobic biodegradation within the landfill. 
pH

The $\mathrm{pH}$ tolerance of methanogens is approximately 6.6-7.4, and within this range they will grow at the highest rate, leading to optimum methane production (Lee, 1996; Warith, 2003). A pH below 6 or above 8 will severely limit the rate of gas production (Warith, 2003). The type of waste (e.g. industrial waste), alkalinity and groundwater infiltration may all impact the $\mathrm{pH}$ level in the landfill. The $\mathrm{pH}$ may also change during the course of degradation of the waste. Organic acids formed during hydrolysis will lower the $\mathrm{pH}$, but as these acids are converted to methane the $\mathrm{pH}$ will begin to rise again.

\section{Oxygen}

The presence of oxygen in a landfill will promote aerobic biodegradation, which has been found to increase overall rates of biodegradation and thus waste stabilization (El-fadel et al., 2013; Erses et al., 2008). Methanogens are strict anaerobes, meaning their growth is inhibited by the presence of oxygen (Lee, 1996). Therefore, no methane is produced under completely aerobic conditions. Rendra et al. (2007) found that operating a landfill under aerobic conditions increased the amount of settlement achieved, and decreased the concentration of chemical oxygen demand (COD) in the leachate. Erses et al. (2008) conducted an experiment using two laboratory scale reactors. One reactor was operated under aerobic conditions, and the other anaerobic. The aerobic bioreactor settled 37\% and the anaerobic settled 5\%. 


\subsection{Heat Transfer in Landfills}

There are three modes of heat transfer to, from and within a landfill. These are convection, conduction and radiation. These, along with the thermal properties of the waste itself, impact the temperature in the landfill, which impacts biodegradation and overall settlement. Bonany et al. (2013b) and Megalla et al. (2016) developed a conceptual and numerical model for the heat transfer within the Ste. Sophie landfill, summarized by the following equation:

$$
\nabla(k \nabla T)+Q=\rho C_{p} \frac{d T}{d t}
$$

Where $k$ is the thermal conductivity of the waste $(\mathrm{W} / \mathrm{mK}), T$ is the temperature of the waste $(\mathrm{K}), \mathrm{Q}$ is the heat generation in the waste due to biological activity $\left(\mathrm{W} / \mathrm{m}^{3}\right), \rho$ is the density of the waste $\left(\mathrm{kg} / \mathrm{m}^{3}\right), C_{p}$ is the specific heat $(\mathrm{J} / \mathrm{kgK})$ and $t$ is the time (s). The three modes of heat transfer as well as three important thermal properties of waste (thermal conductivity, specific heat and latent heat of phase change) will now be discussed in further detail.

\subsubsection{Conduction}

Heat transfer by conduction occurs due to a temperature gradient. Conduction is an important heat transfer mechanism to consider for landfills because it can occur through solids, liquids and gases. Therefore, heat will be transfered by conduction through the solid waste 
itself, but also through the leachate and LFG. The rate of heat transfer by conduction is defined as follows:

$$
Q=-k A\left(\frac{d T}{d x}\right)
$$

where $Q$ is the heat transfer $\left(\mathrm{W} / \mathrm{m}^{3}\right), k$ is the thermal conductivity $(\mathrm{W} / \mathrm{mK})$ (refer to Chapter 2.3.4 for more information on thermal conductivity), $A$ is the cross sectional area in which the heat transfer is occurring through $\left(\mathrm{m}^{2}\right)$, and $\frac{d T}{d x}$ is the temperature gradient.

\subsubsection{Convection}

Convection refers to a transfer of energy between a surface and a fluid moving over that surface. This type of heat transfer will take place at the surface of the landfill, where air is moving above the surface. Heat transfer by convection is defined as:

$$
Q=h A\left(T_{a}-T_{s}\right)
$$

where $Q$ is the heat transfer $(\mathrm{W}), h$ is the convection coefficient $\left(\mathrm{W} / \mathrm{m}^{2} \mathrm{~K}\right), A$ is the cross sectional area in which the heat transfer is occurring through $\left(\mathrm{m}^{2}\right), T_{a}$ is the ambient temperature $(\mathrm{K})$, and $T_{s}$ is the surface temperature $(\mathrm{K})$. The convection coefficient can be estimated by the following equation, described by Watmuff et al. (1977): 


$$
h=5.7+3.8 v
$$

where $h$ is the convection coefficient $\left(\mathrm{W} / \mathrm{m}^{2} \mathrm{~K}\right)$, and $v$ is the surface wind speed $(\mathrm{m} / \mathrm{s})$.

Convection may occur within the landfill itself if there are differences in total gas pressure. This could result if landfill gas is extracted or if there are changes in atmospheric temperature (Neusinger et al., 2005). Likewise, the movement or advection of leachate within the waste will result in the transfer of heat. Convection via leachate and LFG were not considered in the model presented in this thesis.

\subsubsection{Radiation}

Radiation is the rate at which energy is emitted from a surface. All matter emits radiation due to the oscillations of the electrons which make up the matter (Incropera et al., 2013). These oscillations are driven by the internal energy of the matter, and therefore the temperature of the matter. Unlike convection and conduction, radiation does not require the presence of a medium for the transfer of energy to occur. This is why the sun's energy is able to reach the earth's surface through the vacuum of space.

Incoming solar radiation at the surface of a landfill can be absorbed, reflected or transmitted (Incropera et al., 2013). The Stefan-Boltzmann law describes the incident (incoming) shortwave radiation at the surface:

$$
Q=\epsilon \sigma T_{s}^{4}
$$


where $\sigma$ is the Stefan-Boltzmann constant $\left(5.67 \times 10^{-8} \mathrm{~W} / \mathrm{m}^{2} K^{4}\right), \epsilon$ is the surface emissivity and $T_{s}$ is the surface temperature (K). The emissivity is a radiative property of the surface of the incident material. It provides a measure of how efficiently a surface will emit energy relative to a blackbody and depends on the surface material and finish (Incropera et al., 2013). The emissivity is a value between 0 and 1 .

The net radiation which is released (outgoing) from the landfill surface is defined as follows:

$$
Q=\epsilon \sigma\left(T_{s}^{4}-T_{\text {sur }}{ }^{4}\right)
$$

where $T_{\text {sur }}$ is the temperature of the surroundings $(\mathrm{K})$, which can be estimated using the ambient temperature.

\subsubsection{Thermal Conductivity}

Thermal conductivity is a material property which quantifies its ability to conduct heat. It is the rate at which heat passes through a material, expressed as the amount of heat per unit length per unit temperature (for instance, $\mathrm{W} / \mathrm{mK}$ ). Thermal conductivity is an important parameter for landfills because it will impact the way in which heat is transferred through the waste. A low thermal conductivity means that the material will behave as an insulator, not conducting heat very effectively. Conversely, a high thermal conductivity means that heat will be transferred through a material at a higher rate.

There is a wide range of values cited in the literature for thermal conductivity. Table 2.2 provides a summary table of the thermal conductivity and specific heat values found 
in the literature.

Table 2.2: Summary of thermal conductivities and specific heat capacities cited in literature (N/A used when information was not available).

\begin{tabular}{|c|c|c|}
\hline Source & $\begin{array}{l}\text { Thermal Conductivity } \\
\qquad(\mathrm{W} / \mathrm{mK})\end{array}$ & Specific Heat $(\mathrm{J} / \mathrm{kgK})$ \\
\hline Hanson et al. (2000) & 0.01 to 0.7 & N/A \\
\hline Lefebvre et al. (2000) & 0.1 & 1900 to 3000 \\
\hline Neusinger et al. (2005) & 1.0 & N/A \\
\hline Hanson et al. (2006) & 0.23 & 719 \\
\hline $\begin{array}{c}\text { Gholamifard et al. } \\
2008)\end{array}$ & $\begin{array}{c}0.4 \text { (dry waste) and } 0.6 \text { to } \\
0.8 \text { (waste exposed to } \\
\text { leachate recirculation) }\end{array}$ & $\begin{array}{l}1000 \text { to } 1100 \text { (waste } \\
\text { exposed to leachate } \\
\text { recycle) }\end{array}$ \\
\hline Hanson et al. (2008) & 0.3 to 1.5 & 1000 to 2200 \\
\hline$\frac{\text { Rowe et al. (2010) and }}{\text { Yoshida \& Rowe }}$ & $\begin{array}{c}0.35 \text { (unsaturated) and } \\
0.96 \text { (saturated) }\end{array}$ & $\begin{array}{c}1940 \text { (unsaturated) and } \\
2360 \text { (saturated) }\end{array}$ \\
\hline$\frac{\text { Zambra \& Moraga }}{(2013)}$ & 0.18 & N/A \\
\hline Bonany et al. (2013b) & 0.67 & 1400 \\
\hline Faitli et al. (2014) & 0.24 to 1.15 & 900 to 2100 \\
\hline Megalla (2015) & $\begin{array}{l}0.3 \text { (top one metre of } \\
\text { waste) and } 0.67 \\
\text { (underlying waste) }\end{array}$ & 800 \\
\hline Megalla et al. (2016) & $\begin{array}{l}0.3 \text { (top one metre of } \\
\text { waste) and varied with } \\
\text { time and depth for } \\
\text { underlying waste }\end{array}$ & 2100 \\
\hline
\end{tabular}


Due to the heterogeneous nature of waste, there is great variability in the thermal properties of MSW (Hanson et al., 2000; Yesiller et al., 2015). It is common to have void spaces of air throughout MSW, which significantly lowers the thermal conductivity since air has a lower thermal conductivity than MSW (Faitli et al., 2014). However, as waste settles or is mechanically compacted, the density increases, and the void spaces become smaller which tends to increase the thermal conductivity. Further, as waste becomes saturated, the voids fill with water. Water has a higher thermal conductivity than air $(0.591 \mathrm{~W} / \mathrm{mK}$ and $0.024 \mathrm{~W} / \mathrm{mK}$ for water and air, respectively); therefore, as waste becomes saturated, the thermal conductivity is also increased (Faitli et al., 2014; Neusinger et al., 2005).

Hanson et al. (2000) found the thermal conductivity of MSW to vary from 0.01 to $0.7 \mathrm{~W} / \mathrm{mK}$. Lefebvre et al. (2000) used a thermal shock probe to find that the thermal conductivity of MSW at a landfill in the south of France was $0.1 \mathrm{~W} / \mathrm{mK}$. This is similar to that of sawdust $(0.08 \mathrm{~W} / \mathrm{mK})$, which Rees (1980) used in absence of a value for refuse. Yoshida \& Rowe (2003) and Rowe et al. (2010) estimated the thermal conductivity of unsaturated waste at a Tokyo landfill to be $0.35 \mathrm{~W} / \mathrm{mK}$, and $0.96 \mathrm{~W} / \mathrm{mK}$ for saturated waste. Neusinger et al. (2005) used a value of $1 \mathrm{~W} / \mathrm{mK}$ to model the effects of water content and gas migration on the heat balance of a landfill. Hanson et al. (2006) used a thermal conductivity of $0.23 \mathrm{~W} / \mathrm{mK}$ for a $1 \mathrm{D}$ numerical model investigating placement temperatures and waste lift thicknesses for a MSW landfill in Anchorage, Alaska. For dry wastes, Gholamifard et al. (2008) used a value of $0.4 \mathrm{~W} / \mathrm{mK}$, and for waste exposed to leachate recirculation, a value between 0.6 to $0.8 \mathrm{~W} / \mathrm{mK}$ was used. Using thermal conductivity probes both in the laboratory and in situ, Hanson et al. (2008) determined thermal conductivities for four separate landfills: Michigan (1.0 W/mK), New Mexico 
(0.6 W/mK), Alaska $(0.3 \mathrm{~W} / \mathrm{mK})$ and British Columbia $(1.5 \mathrm{~W} / \mathrm{mK})$. The values varied between sites due to varying soil, weather and placement conditions. However, in general, Hanson et al. (2013) noted that both thermal conductivity and specific heat of the waste increased with increasing unit weight and moisture content. Zambra \& Moraga (2013) used a thermal conductivity of $0.18 \mathrm{~W} / \mathrm{mK}$ for a 2D mathematical model of the self-heating that occurs in the waste pile of a landfill. Bonany et al. (2013b) used a value of $0.67 \mathrm{~W} / \mathrm{mK}$, based on a sensitivity analysis using temperature data collected at the Ste. Sophie landfill in Quebec, Canada. Using laboratory and field probe experiments, Hanson et al. (2013) found the thermal conductivity of a landfill in Michigan, USA to be $1.0 \mathrm{~W} / \mathrm{mK}$.

Megalla (2015) simulated waste temperatures at the Ste. Sophie landfill using a value of $0.3 \mathrm{~W} / \mathrm{mK}$ for waste within the top metre of the surface of the waste lift, and a value of $0.67 \mathrm{~W} / \mathrm{mK}$ for the rest of the waste. This is similar to the previously mentioned approach of Rowe et al. (2010). The top one metre of waste is assumed to be unsaturated, and would therefore have a lower thermal conductivity than the lower layers. The lower layers have a higher thermal conductivity because the waste is more dense due to higher compaction and also more likely to be saturated. As density and moisture content increase, thermal conductivity also increases.

Similarly, Megalla et al. (2016) also assigned a value of $0.3 \mathrm{~W} / \mathrm{mK}$ for the top one metre of waste. However, they varied the thermal conductivity of the underlying waste with depth and time in the model. With time, the waste will settle and become more compact. This will increase density and, as such, thermal conductivity also increases. Further, the landfill is assumed to reach saturation near the bottom of the landfill and increased 
moisture content also increases thermal conductivity. For these reasons, Megalla et al. (2016) increased thermal conductivity with time and at lower depths of the landfill. Figure 2.1 demonstrates this relationship, with periods 1 through 5 representing the addition of 5 waste lifts. The range of thermal conductivities used by Megalla et al. (2016) was based on the range suggested by Faitli et al. (2014).

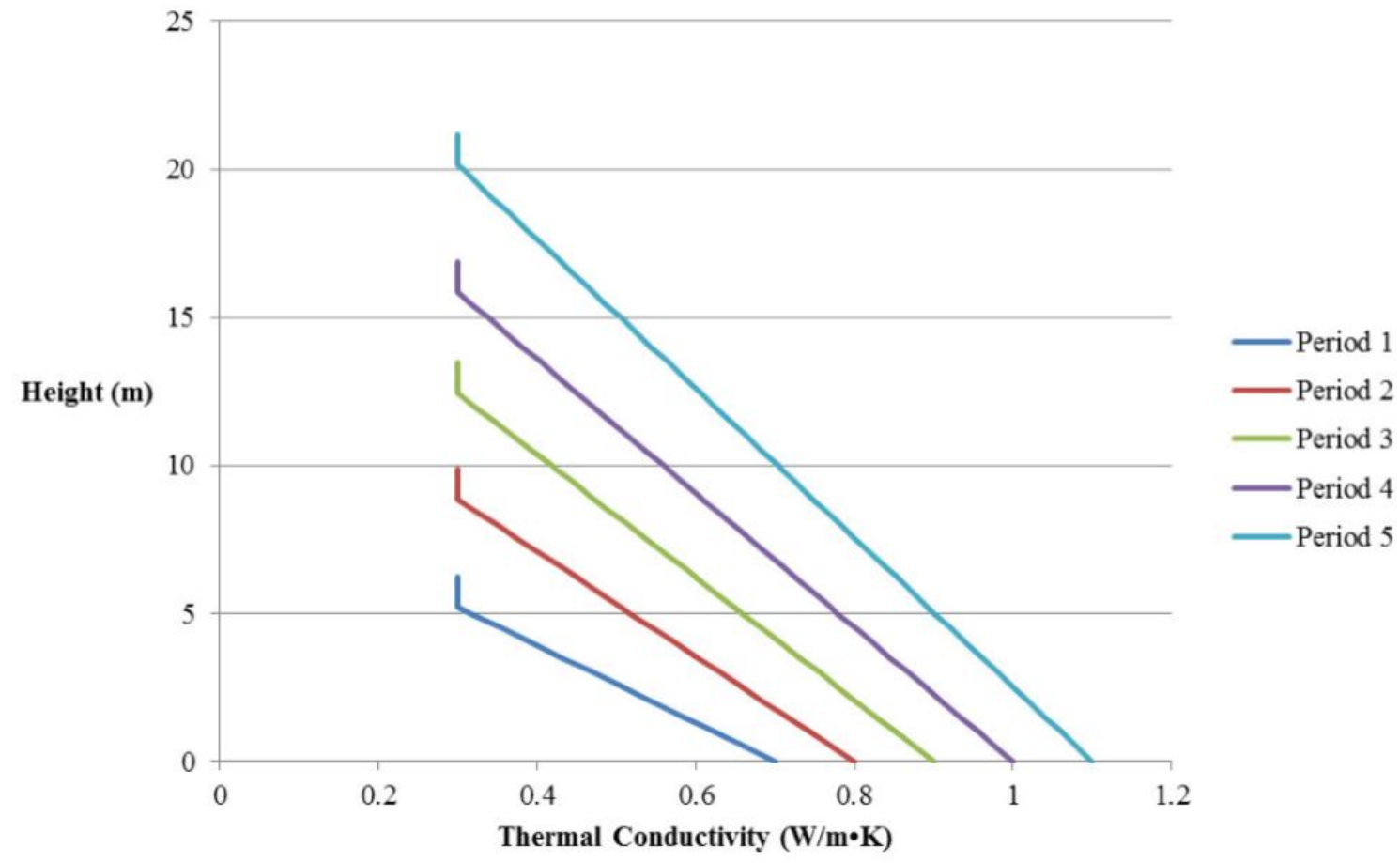

Figure 2.1: Thermal conductivity variance with depth and time used by Megalla et al. (2016).

Faitli et al. (2014) developed a new measuring tool and evaluation method to determine both thermal and physical properties of MSW landfills. Thermal conductivity was found to vary from 0.24 to $1.15 \mathrm{~W} / \mathrm{mK}$ for 17 measurements taken from different locations in a MSW landfill in Hungary. 
This thesis adds to the work of Megalla et al. (2016) by using the optimization module in COMSOL to estimate the thermal conductivity of the Ste. Sophie landfill (see Chapter 4.2.6.

\subsubsection{Specific Heat Capacity}

The specific heat capacity (or simply specific heat) of a material is the amount of energy required to raise the temperature of that material by one degree Celsius or one Kelvin. It is expressed as energy per unit mass per unit temperature (for instance, $\mathrm{J} / \mathrm{kgK}$ ). Specific heat will impact the temperatures in a landfill. For example, if the waste has a high specific heat, it means that a large energy input is required to increase the temperature of the waste, whereas if the waste has a low specific heat, it means that a small energy input is needed to raise the temperature. Similar to thermal conductivity, specific heat is affected by moisture content and density. Since water has a high specific heat ( $4187 \mathrm{~J} / \mathrm{kgK})$, the specific heat of waste will increase with moisture content (Hanson et al., 2000).

Values for specific heat were initially estimated based on those of sawdust (Rees 1980). Lefebvre et al. (2000) sampled waste from a $10 \mathrm{~m}$ deep waste cell and found specific heat of the samples varied from 1900 to $3000 \mathrm{~J} / \mathrm{kgK}$. Hanson et al. (2006) used a specific heat of of $719 \mathrm{~J} / \mathrm{kgK}$ for waste and $1783 \mathrm{~J} / \mathrm{kgK}$ for soil cover layers for a 1D numerical model investigating the impact of placement temperatures and waste lift thicknesses on temperature for a MSW landfill in Anchorage, Alaska. Gholamifard et al. (2008) used values of 1000 to $1100 \mathrm{~J} / \mathrm{kgK}$ to numerically model two landfill sites with leachate 
recycle. By summing the specific heats of individual waste components, Hanson et al. (2008) estimated overall specific heat for four separate landfills: Michigan (2000 J/kgK), New Mexico (1200 J/kgK), Alaska (1000 J/kgK) and British Columbia (2200 J/kgK). The values varied between sites due to varying waste and placement conditions. However, in general, Hanson et al. (2013) noted that both thermal conductivity and specific heat of the waste increased with increasing unit weight and moisture content. Rowe et al. (2010) assumed a value of $1940 \mathrm{~J} / \mathrm{kgK}$ for waste exposed to air and above leachate level (unsaturated), and a value of $2360 \mathrm{~J} / \mathrm{kgK}$ for waste below leachate level (saturated) to simulate the effects of a cooling system design (pipe layout and spacing, and coolant flow rate) on landfill liner temperatures. Faitli et al. (2014) measured specific heats varying from 900 to $2100 \mathrm{~J} / \mathrm{kgK}$.

Bonany et al. (2013b) used a value of $1400 \mathrm{~J} / \mathrm{kgK}$, based on a model sensitivity analysis using temperature data collected at the Ste. Sophie landfill in Quebec, Canada. Megalla (2015) used a value of $800 \mathrm{~J} / \mathrm{kgK}$ as it provided better agreement between simulated and actual temperatures at the Ste. Sophie landfill. Megalla et al. (2016) used a value of $2100 \mathrm{~J} / \mathrm{kgK}$ to model temperature at the Ste. Sophie landfill. The higher value used by Megalla et al. (2016) in comparison to Bonany et al. (2013b) and Megalla (2015) could be attributed to the thermal conductivity vs. depth and time relationship that Megalla et al. (2016) implemented in the model (see Chapter 2.3.4).

This thesis adds to the work of Megalla et al.(2016) by optimizing the specific heat and allowing it to vary with time and depth similar to the thermal conductivity (see Chapter 4.2.7). 


\subsubsection{Latent Heat of Phase Change}

The latent heat of phase change (or simply latent heat) is the amount of energy which must be provided in order to transition to a new phase per unit mass of material. Of importance when looking at waste stabilization in landfills in northern climates is the latent heat required to thaw the frozen liquid fraction of the waste. A large latent heat means that a large amount of energy is required to thaw the waste, whereas a small latent heat means less energy is required and so the transition will occur more easily. The latent heat of fusion refers to a material transitioning from a solid to a liquid, for example, ice thawing into water. The latent heat of fusion of water is $334 \mathrm{~kJ} / \mathrm{kg}$. This is a significant amount of energy considering literature values for specific heat of MSW range from approximately 1 to $3 \mathrm{~kJ} / \mathrm{kg}$ (Table 2.2). Therefore, latent heat is a significant component for landfills in northern climates (Bonany et al., 2013b).

Few studies have been completed concerning the latent heat of MSW. Hanson et al. (2010) noted that latent heat played an important role in the heat gain of a landfill in Alaska, and for a numerical heat budget model, Hanson et al. (2006) used a value of 32.7 $\mathrm{kJ} / \mathrm{kg}$ for waste and $1.7 \mathrm{~kJ} / \mathrm{kg}$ for daily cover soil. Bonany et al. (2013b) used Eq. 2.8 from Andersland \& Anderson (1978) to determine a range of latent heat values for the MSW at Ste. Sophie landfill:

$$
L_{S}=L_{W} w \gamma_{d}\left(1-W_{u}\right)
$$


Where $L_{S}$ is the volumetric latent heat of fusion of soil $\left(\mathrm{kJ} / \mathrm{m}^{3}\right), L_{W}$ is the latent heat of fusion of water ( $\mathrm{kJ} / \mathrm{kg}), w$ is the water content of soil (decimal fraction by mass), $\gamma_{d}$ is the dry density of soil $\left(\mathrm{kg} / \mathrm{m}^{3}\right)$, and $W_{u}$ is the ratio of unfrozen water to total water content (decimal fraction). Using a compacted waste density of $1000 \mathrm{~kg} / \mathrm{m}^{3}$ and a moisture content upon placement of $15-20 \%$ by volume, Bonany et al. (2013b) determined the latent heat of fusion for waste at the Ste. Sophie landfill is approximately 10 to $20 \%$ of that of water. Ultimately, for their models of the Ste. Sophie landfill, Bonany et al. (2013b) used a value of $41.75 \mathrm{~kJ} / \mathrm{kg}$ (12.5\% of water), Megalla (2015) used a value of $38 \mathrm{~kJ} / \mathrm{kg}$ (11\% of that of water), and Megalla et al. (2016) used a similar value of $37.2 \mathrm{~kJ} / \mathrm{kg}$. Bonany et al.(2013a), Megalla (2015) and Megalla et al. (2016) all used the following formulation for when the latent heat of phase change is used:

$$
C_{p}=\left\{\begin{array}{cc}
C_{s} & T<271.55 K \\
\frac{L}{\Delta T} & 271.55 K<T<272.55 K \\
C_{l} & 272.55 K<T
\end{array}\right\}
$$

where $C_{s}$ is the specific heat for frozen waste, and $C_{l}$ is the specific heat for non-frozen waste. From $271.55 \mathrm{~K}$ to $272.55 \mathrm{~K}, C_{p}$ is dependent on the latent heat $(L)$ required to change the state of the liquid fraction from solid (frozen) to liquid or liquid to solid. 


\subsubsection{Heat Generation}

Heat (as well as leachate and landfill gas) is a primary by-product of MSW landfills and is generated as a result of biological activity within the landfill (El-Fadel et al., 1996a; Hanson et al., 2013; Yesiller et al., 2005, 2015). Heat gain within a landfill can be directly related to gas generation (El-Fadel et al., 1997a).

El-Fadel et al. (1996a, 1996b, 1997a) developed a numerical model based on the microbiological, chemical and physical processes associated with anaerobic gas generation which accounts for the generation and transport of gas and heat in landfills. El-Fadel et al. (1996a) used the net enthalpy of reaction associated with anaerobic decomposition (Chapter 2.2.1) to estimate a heat generation rate of $61 \mathrm{kcal} / \mathrm{mol}$ of methane produced, which equates to approximately $255 \mathrm{~kJ} / \mathrm{mol}-\mathrm{CH}_{4}$. An alternative method of determining heat generation is to sum the individual enthalpies for each stepwise reaction for anaerobic decomposition. Calculating the heat generation in this manner results in $26 \mathrm{kcal} / \mathrm{mol}$ of methane produced, or approximately $109 \mathrm{~kJ} / \mathrm{mol}^{-\mathrm{CH}_{4}}$ (El-Fadel et al., 1996a).

Aerobic heats of reaction are approximately twenty times greater than anaerobic heats of reaction (Finger et al., 1976; Lefebvre et al., 2000). Yoshida \& Rowe (2003) used a heat generation value of $460 \mathrm{~kJ} / \mathrm{mol}^{-} \mathrm{O}_{2}$ for aerobic decomposition, and $43.5 \mathrm{~kJ} / \mathrm{mol}^{-\mathrm{CH}_{4}}$ for anaerobic decomposition to model the temperature at the base of a Tokyo landfill in order to study the effect of temperature on landfill liners. Upon placement of each new waste lift, the top one metre was assumed to be under aerobic conditions, and the remainder of the waste lift was assumed to be under anaerobic conditions. Lefebvre et al. (2000) and 
Lanini et al. (2001) also used an aerobic heat generation of $460 \mathrm{~kJ} / \mathrm{mol}^{-} \mathrm{O}_{2}$. Neusinger et al. (2005) used a heat source of $1 \mathrm{~W} / \mathrm{m}^{3}$ to model the heat balance of a landfill. From methane and hydrolysis production rates, Gholamifard et al. (2008) determined the heat production to be $80 \mathrm{~kJ} / \mathrm{mol}^{-\mathrm{CH}_{4}}$, and used this value to simulate the behaviour of bioreactor landfills in the anaerobic methanogenic phase.

Hanson et al. (2006) used finite element analysis to study the effect of waste filling practices on waste decomposition and heat generation at a landfill in Alaska. For temperatures equal to or below $0{ }^{\circ} \mathrm{C}$, zero heat generation was assumed, and for temperatures above $0{ }^{\circ} \mathrm{C}$, the heat generation was defined as a function of time. For the first 120 days after waste placement, a heat generation rate of $2.5 \mathrm{~W} / \mathrm{m}^{3}$ was assumed, and for times greater than 120 days, a heat generation rate of $0.08 \mathrm{~W} / \mathrm{m}^{3}$ was assumed. The initial 120 day simulation time was assumed to be operating under aerobic conditions, whereas for times greater than 120 days, the landfill was assumed to be under anaerobic conditions. This assumption was based on gas concentration data at the landfill. It was found that the frost depths of the waste were less than that for native soils because of waste thermal properties and heat generation in the waste. Hanson et al. (2008) modified the heat generation function of Hanson et al. (2006) so that for temperatures equal to or below $0{ }^{\circ} \mathrm{C}$ or greater than $80^{\circ} \mathrm{C}$, zero heat generation was assumed. Hanson et al. (2008) again used 2.5 and $0.08 \mathrm{~W} / \mathrm{m}^{3}$ for aerobic and anaerobic biodegradation at the Alaska landfill, and also simulated temperatures at a landfill in Michigan using values of 11.3 and $0.38 \mathrm{~W} / \mathrm{m}^{3}$ for aerobic and anaerobic biodegradation, respectively. The heat generation values used by Hanson et al. (2008) were developed by calibrating the model results with measured field temperatures at the respective landfills. Hanson et al. (2008) also proposed an exponential 
growth and decay function for both the Alaska and Michigan landfill sites, as well as sites in New Mexico and British Columbia. They found that the peak heat generation rates for the four sites varied from 0.19 to $2.21 \mathrm{~W} / \mathrm{m}^{3}$. They also defined a total energy expended term to be the area under the heat generation rate vs. time curve, and they found the total expended energy of waste varied from 15 to $191 \mathrm{MJ} / \mathrm{m}^{3}$ for the four sites.

Hanson et al. (2013) built upon Hanson et al. (2008) by proposing a temperaturedependent heat generation term, as follows:

$$
H=A\left(\frac{t}{B_{t}+t}\right)\left(\frac{C_{t}}{C_{t}+t}\right) e^{-\sqrt{\left(\frac{t}{D}\right)}}
$$

where $H$ is the heat generation rate $\left(\mathrm{W} / \mathrm{m}^{3}\right), t$ is the time (day), $A$ is the peak heat generation rate factor $\left(\mathrm{W} / \mathrm{m}^{3}\right), B_{t}$ and $C_{t}$ are shape factors (day) and $D$ is the decay rate factor (day). Hanson et al. (2013) used nonlinear regression in their heat budget model of the landfill to determine these parameters. This was completed for two separate waste cells, Cell D and Cell B.

Hanson et al. (2013) scaled Eq. 2.10 for temperature by generating a family of curves between $0{ }^{\circ} \mathrm{C}$ and $80^{\circ} \mathrm{C}$, based on a dual-ramped scaling function. For waste temperatures below $0{ }^{\circ} \mathrm{C}$ and above $80^{\circ} \mathrm{C}$, the heat generation was zero, as was used in Hanson et al. (2008). Between $30^{\circ} \mathrm{C}$ and $50{ }^{\circ} \mathrm{C}$, the peak heat generation was used, determined from Eq. 2.10. The heat generation rate was assumed to increase linearly between $0{ }^{\circ} \mathrm{C}$ and $30^{\circ} \mathrm{C}$, and to decrease linearly between $50{ }^{\circ} \mathrm{C}$ and $80{ }^{\circ} \mathrm{C}$. The scaling of heat generation with temperature makes it possible to move from one heat generation curve to the next 
as the temperature of the waste changes with time. To track the position on each curve, independent of time, heat generation is plotted as a function of total expended energy. This assumes that waste has a finite amount of energy and the same amount of heat can be extracted from all parts of the landfill.

Bonany et al. (2013b) used a non-linear smooth step function based on the work of Neusinger et al. (2005) to define the bio-heat generated in the landfill, as follows:

$$
Q=\left\{\begin{array}{cc}
0 & T<T_{\text {bio }} \\
Q_{i}\left(-0.000413 T^{2}+0.27143 T-43.677\right) & T_{b i o}<T
\end{array}\right\}
$$

where $T_{b i o}$ is the onset temperature of the bio-heat generation (set at $10{ }^{\circ} \mathrm{C}$ ) and $Q_{i}$ is the scaling multiplier which reflects the peak heat generation rate. Bonany et al. (2013b) used a peak heat generation rate of $18 \mathrm{~W} / \mathrm{m}^{3}$ and Bonany et al. (2013a) used values of 16.5 and $0.3 \mathrm{~W} / \mathrm{m}^{3}$ for aerobic and anaerobic heat generation, respectively.

Megalla (2015) continued the work of Bonany et al. (2013a, 2013b) using the same quadratic relationship presented by Bonany et al. (2013b) in Eq 2.11. However, Megalla (2015) assumed that aerobic decomposition occurred only in the top one metre of waste, and in most cases, used a peak heat generation rate of $5.0 \mathrm{~W} / \mathrm{m}^{3}$. For a waste lift placed under warm summer conditions, an aerobic peak heat generation of $50 \mathrm{~W} / \mathrm{m}^{3}$ was needed to simulate the waste temperatures which rose above $60^{\circ} \mathrm{C}$. This peak heat generation rate 
reflected that which would be found for compost (Zambra et al., 2011). The waste lift placed in summer conditions had higher measured oxygen levels in its top one metre than the other waste lifts did, indicating greater oxygen diffusion or advection in comparison to the other lifts, contributing to the much higher temperatures (Megalla, 2015). Megalla (2015) used the same anaerobic heat generation as Bonany et al. (2013a), a value of 0.3 $\mathrm{W} / \mathrm{m}^{3}$.

Megalla et al. (2016) developed an anaerobic heat generation function for the Ste. Sophie landfill based on the research of Hanson et al. (2013). Megalla et al. (2016) used the heat generation equation (Eq. 2.10) with parameters from waste Cell D of Hanson et al. (2013) as it provided a better fit to the Ste-Sophie data (Table 2.3).

Table 2.3: Parameters used by Megalla et al. (2016) to model heat generation at Ste. Sophie landfill, based on cell D of Hanson et al. (2013).

\begin{tabular}{|c|c|}
\hline Parameter & Value \\
\hline \hline Total expended energy $\left(\mathrm{MJ} / \mathrm{m}^{3}\right)$ & 104 \\
\hline $\mathrm{A}$ & 4.88 \\
\hline $\mathrm{B}_{\mathrm{t}}$ & 50 \\
\hline $\mathrm{C}_{\mathrm{t}}$ & 5000 \\
\hline $\mathrm{D}$ & 180 \\
\hline \hline
\end{tabular}

A quadratic fit was used by Megalla et al. (2016) to describe the dual-ramped heat generation vs. temperature function of Hanson et al. (2013) (Figure 2.2). This quadratic relationship was used in order to simplify the implementation of this concept into COMSOL Multiphysics. 


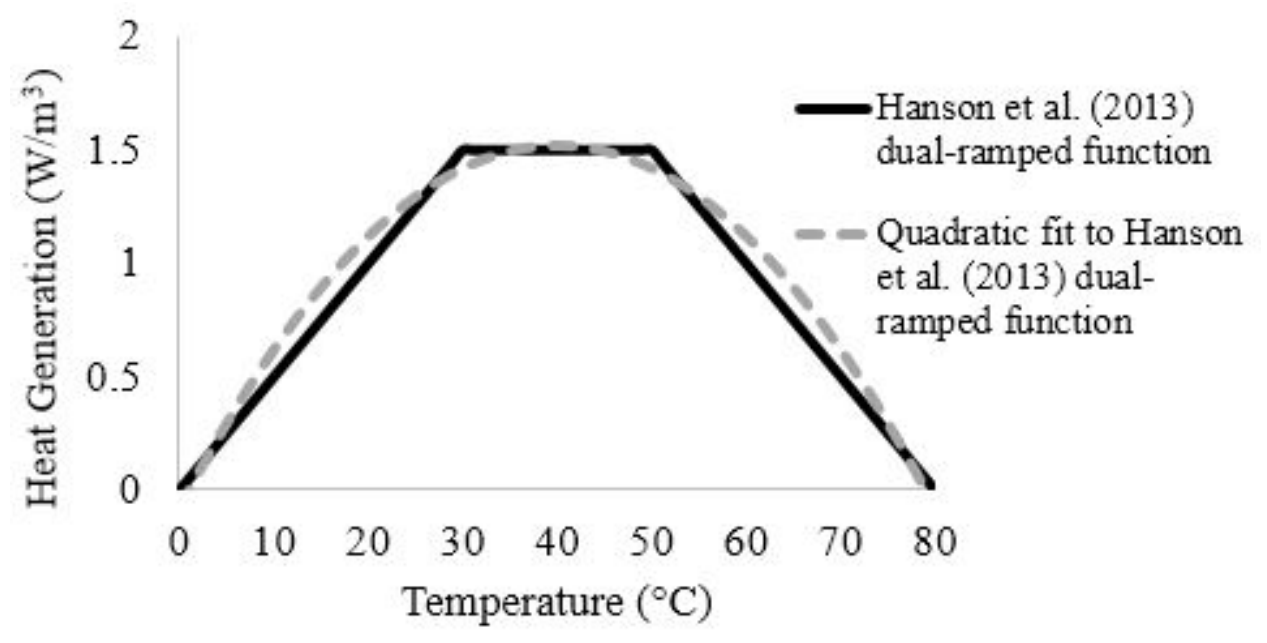

Figure 2.2: Dual-ramped anaerobic heat generation function used by Hanson et al. (2013) and quadratic fit used by Megalla et al. (2016).

Megalla et al. (2016) generated a 3D heat generation plot dependent upon waste age and temperature by multiplying the quadratic dual-ramp heat generation vs. temperature function and the heat generation rate equation (Eq. 2.10). By integrating this $3 \mathrm{D}$ function over time, Megalla et al. (2016) obtained a plot of heat generation, which was dependent on expended energy at peak temperature. Megalla et al. (2016) fit a 6th order polynomial to this heat generation vs. expended energy curve (Figure 2.3) to again simplify the implementation of the concept into COMSOL Multiphysics (Eq. 2.12).. 


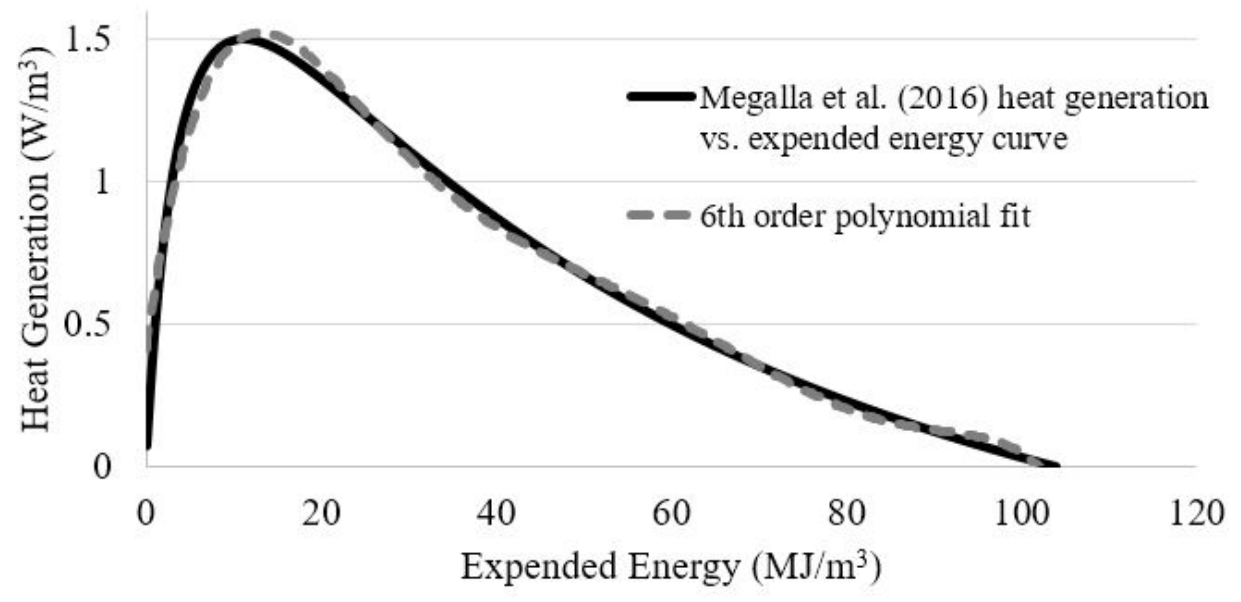

Figure 2.3: Heat generation as a function of expended energy proposed by Hanson et al. (2013) and 6th order polynomial applied by Megalla et al. (2016).

$$
\begin{array}{r}
Q=-1.53 \times 10^{-10} E^{6}+5.549 \times 10^{-8} E^{5}-7.878 \times 10^{-6} E^{4}+5.513 \times 10^{-4} E^{3} \\
-1.948 \times 10^{-2} E^{2}+0.2940 E+0.1
\end{array}
$$

The 6th order polynomial heat generation vs. expended energy function was scaled by the quadratic dual-ramp heat generation vs. temperature function to obtain the final heat generation relationship as a function of expended energy and temperature. Figure 2.4 is the final function used by Megalla et al. (2016) to model the anaerobic heat generation at the Ste. Sophie landfill. 


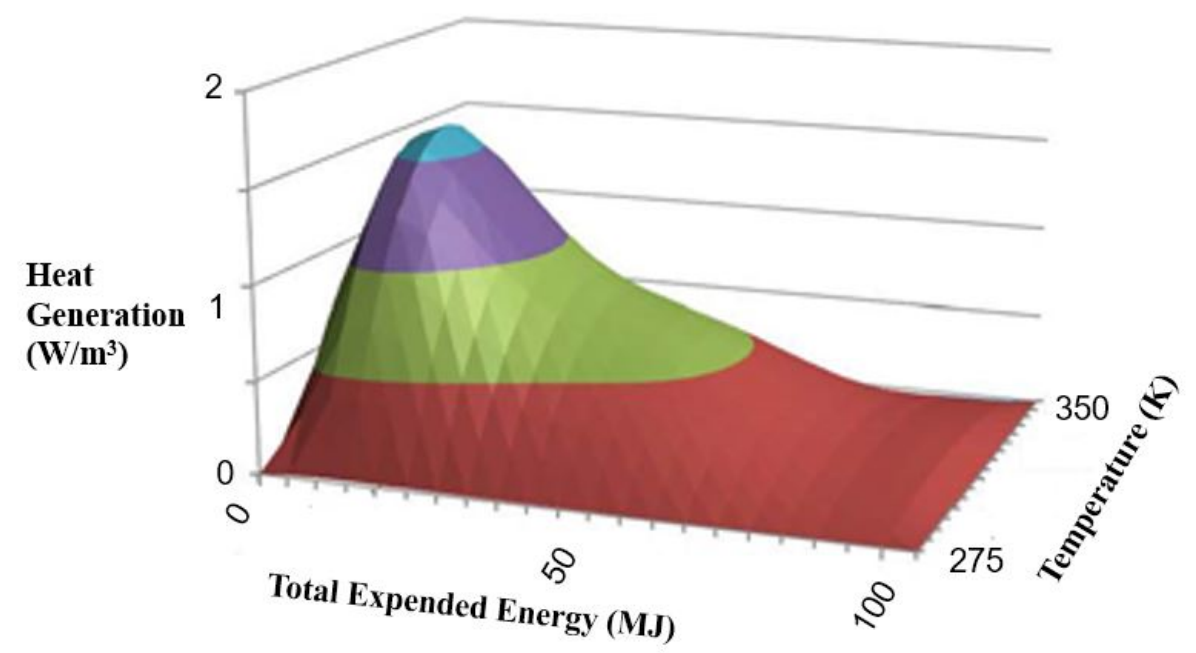

Figure 2.4: 3D function used by Megalla et al. (2016) to model the anaerobic heat generation at the Ste. Sophie landfill.

In terms of aerobic heat generation, Megalla et al. (2016) noted that there was a strong correlation between the oxygen concentration and temperatures in the Ste. Sophie landfill at instrument bundles located near the surface. The increased concentration of oxygen promotes aerobic biodegradation, which in turn results in waste temperature increasing. Megalla et al. (2016) used the following empirical equation to estimate the aerobic heat generation for the top one metre of waste when oxygen concentrations were recorded by sensors in the field:

$$
Q_{a e r}=E_{O_{2}}\left[O_{2}\right]
$$

where $Q_{a e r}$ is the aerobic heat generation rate $\left(\mathrm{W} / \mathrm{m}^{3}\right), E_{\mathrm{O}_{2}}$ is a rate factor, and $\left[\mathrm{O}_{2}\right]$ is 
the concentration of oxygen expressed as a percentage. Megalla et al. (2016) used a trialand-error approach to determining the value of $E_{\mathrm{O}_{2}}$ by best fitting the model temperatures to the actual Ste. Sophie temperatures during times where oxygen is present. The peak aerobic heat generation rate was $44 \mathrm{~W} / \mathrm{m}^{3}$.

\subsection{Landfill Settlement}

Settlement is an important landfill design consideration. Increased settlement pre-closure will provide more airspace in the landfill, which allows more waste to be placed within the landfill without exceeding the approved maximum landfill elevation restriction. Postclosure, waste settlement will affect the integrity of the final cover system, the landfill gas collection system, and the leachate collection and recirculation systems. Re-development options at a closed landfill site are also limited by the long term settlement at the site. Waste composition, moisture content and landfill operating practices impact the rate and magnitude of settlement (El-fadel et al., 1999). The settlement of MSW is due to mechanical, chemical and biological processes (Babu et al. 2010, El-fadel \& Khoury, 2000).

Landfill settlement models generally fall into one or more of the following categories (El-fadel \& Khoury, 2000):

- Soil-mechanics based models

- Rheological

- Empirical 
- Biodegradation-induced settlement

Many models have been developed based on the above categories. These will now be discussed in more detail.

Sowers (1973) predicted settlement of MSW using a soil-mechanics approach based on primary compression and secondary mechanical creep. The following equation was used to predict the settlement:

$$
\Delta H=H_{0} C_{C}^{\prime} \log \left(\frac{\Delta \sigma+\sigma_{0}}{\sigma_{0}}\right)+H_{0} C_{\alpha} \log \left(\frac{t_{2}}{t_{1}}\right)
$$

where $\Delta H$ is the change in height or the overall settlement, $H_{0}$ is the initial height of the waste lift, $C_{C}^{\prime}$ is the coefficient of primary compression (ranging from 0.163 to 0.205 ), $\Delta \sigma$ is the incremental overburden pressure due to an overlying waste lift, $\sigma_{0}$ is the average initial overburden pressure at the centre of the waste lift, $C_{\alpha}$ is the coefficient of secondary mechanical creep (ranging from 0.015 to 0.350 ) and $t$ is the time. Sowers (1973) also noted that the waste values for $C_{\alpha}$ are similar to those displayed by peat and organic soils.

Edil et al. (1990) used the Gibson \& Lo (1961) model and the power creep law to model the settlement in four landfills in northern United States. Both the Gibson \& Lo (1961) model and the power creep law use compressive stress to predict time-dependent settlement. The Gibson \& Lo (1961) model is a rheological model while the power creep law is empirical (Babu et al., 2010). Edil et al. (1990) concluded that primary compression was greater during the filling stages of the landfill, and sedondary compression was greater 
once filling had ceased.

Wall \& Zeiss (1995) and El-fadel et al. (1999) divided landfill settlement into three phases: initial, primary and secondary compression. Initial compression refers to the instantaneous load applied in order to compact the waste upon placement in the landfill. Primary compression refers to gas and porewater being squeezed from the void spaces of the waste, and often occurs simultaneously with initial compression. Finally, secondary compression refers to both creep and settlement due to the biodegradation of the biological waste fractions.

Park \& Lee (2002) state that the decomposition of organics is the most significant cause of the long term settlement of MSW. They used first order kinetics to describe the decomposition.

Marques et al. (2003) developed a three-part model for the one-dimensional compression of MSW. The model includes instantaneous primary strain due to an applied load $\left(\epsilon_{P}\right)$, secondary time-dependent strain due to mechanical creep $\left(\epsilon_{C}\right)$ and time-dependent settlement due to biological decomposition $\left(\epsilon_{B}\right)$ :

$$
\begin{gathered}
\epsilon=\epsilon_{P}+\epsilon_{C}+\epsilon_{B} \\
\epsilon_{P}=C_{C}^{\prime} \log \left(\frac{\Delta \sigma+\sigma_{0}}{\sigma_{0}}\right) \\
\epsilon_{C}=b \Delta \sigma\left(1-e^{-c t^{\prime}}\right) \\
\epsilon_{B}=E_{D G}\left(1-e^{-d t^{\prime \prime}}\right)
\end{gathered}
$$


Where $C_{C}^{\prime}$ is the compression ratio; $\sigma_{0}$ is the initial vertical stress; $\Delta \sigma$ is the change in vertical stress; $b$ is the coefficient of mechanical creep; $c$ is the rate constant for mechanical creep; $t^{\prime}$ is the time since load was applied; $E_{D G}$ is the total amount of strain or settlement that can occur due to biological decomposition; $d$ is the rate constant for biological decomposition; and $t^{\prime \prime}$ is the time since the waste was placed in the landfill. Marques et al. (2003) tested the model using parameters from the Bandeirantes Landfill in Sao Paulo, Brazil, with good agreement.

Durmusoglu et al. (2005) developed a model to account for the fact that a landfill is a multi-phase environment, with solids, liquids and gases interacting and affecting the landfill settlement parameters.

Babu et al. (2010) used a three-part model similar to Marques et al. (2003). The initial instantaneous compression is based on elastoplastic soil behaviour; the secondary compression is modelled using the concept of mechanical creep as an exponential function of time; and biological decomposition is modelled using the same time-dependent degradation term as Park \& Lee (2002).

Van Geel \& Murray (2015) simulated the settlement at the Ste. Sophie landfill using the Marques et al. (2003) equations for primary/instantaneous compression, secondary settlement or mechanical creep, and time-dependent biodegradation-induced settlement. The Marques et al. (2003) parameters were determined using linear least squared regression. The biodegradation-induced settlement term was left out for the first three waste lifts because waste temperatures were not initially warm enough for anaerobic biodegradation to occur. Later waste lifts were placed under warm conditions, and therefore the 
biodegradation-induced settlement term from the Marques et al. (2003) equation was included for these layers. The Marques et al. (2003) model was able to simulate the measured settlement at the Ste. Sophie landfill (Van Geel \& Murray, 2015). Megalla et al. (2016) implemented the Marques et al. (2003) equations and the parameters from Van Geel \& Murray (2015) into their heat budget model to simulate settlement within the model. This allowed for the proper tracking of the instrument bundles within the waste as the waste compressed. This was important as it better reflects the thermal gradients between instrument bundles and provided for a better comparison between simulated and field data.

\subsection{MSW Temperature Modelling}

Modelling is a useful tool to help understand the many interconnected processes occurring within a MSW landfill. Many researchers have conducted simulations of the various landfill processes, such as the transport and generation of heat and gas, biological activity, and waste stabilization and settlement. Temperature is an important consideration because it impacts the stabilization process, but it also has an impact on the engineered components of the landfill system. For example, high temperatures may impact plastic drain pipes, geomembranes, and clay liners (Hanson et al., 2010; Neusinger et al., 2005; Yesiller et al., 2005: Yoshida \& Rowe, 2003). Hanson et al. (2006) found that waste remained frozen 2 years after placement due to the insulating effects of the waste and found that gas generation was delayed 1 to 2 years because of dry, cool conditions. This emphasizes the challenge for solid waste management in northern climates. 
El-Fadel et al. (1996a), El-Fadel et al. (1996b) and El-Fadel et al. (1997a) developed a coupled numerical model which incorporated heat and gas generation and the transport thereof within a sanitary landfill. The model was used to simulate field gas generation and temperature data from the Mountain View Controlled Landfill Project (MVCLP) in California, USA. The Monod model for microbial growth formed the basis of the gas generation module, and a heat balance approach was used to model the heat generation and transport. It was concluded that moisture content, cellulose structure and lignin content should be considered along with temperature when modelling the anaerobic decomposition and gas generation.

Lefebvre et al. (2000) and Lanini et al. (2001) developed a model which considered the heat and oxygen transfers in order to study the initial temperature rises observed in MSW. Aerobic heat production was only considered as it was assumed that heat generated by anaerobic bideogradation was negligible in the short term. Good agreement was found between the model and both a lab scale and full scale MSW landfill in the south of France. It was concluded that although the initial aerobic phase is short lived compared to the entire landfill life, the heat which is generated during this phase is significant. Temperatures may surpass $70{ }^{\circ} \mathrm{C}$ due to aerobic waste decomposition (Lanini et al., 2001). Lefebvre et al. (2000) showed that $97 \%$ of the heat generated in a landfill comes from aerobic reactions.

Neusinger et al. (2005) developed a 3D heat balance model considering the effects of moisture content and gas migration. It was found that maximum temperatures depend upon the thickness of the landfill, and can range from $60{ }^{\circ} \mathrm{C}$ to $80{ }^{\circ} \mathrm{C}$. The maximum temperature simulations were carried out using an anaerobic heat source of $1 \mathrm{~W} / \mathrm{m}^{3}$. 
The aerobic stage of degradation sets up the initial conditions for anaerobic activity, such as temperature and substrate content (Pommier et al., 2008). Therefore, Pommier et al. (2008) argues that it is important to consider the aerobic phase in the overall modelling of MSW.

Gholamifard et al. (2008) developed a 3D numerical two-phase (gas and leachate) flow model coupled with a biological model of heat and gas generation. The model considered the effect of temperature on biomass. Gholamifard et al. (2008) concluded that the parameters impacting temperatures the most throughout the waste are thermal conductivity and specific heat, as well as initial biological concentrations (such as volatile fatty acids) and biomass growth and decay rates.

Hanson et al. (2008) developed a 1D model using finite element analysis. The bottom boundary condition for the model was set as the mean annual earth temperature at $75 \mathrm{~m}$ below the landfill liner. Using measured temperatures at individual landfill sites, a sinusoidal function was developed and applied as the surface boundary condition. Initial waste placement temperatures were set to the ambient temperatures at the time of placement. Heat generation parameters are described in Chapter 2.3.7 and the model can be used in various climatic conditions. In fact, the model was validated using landfill data from New Mexico, Michigan, British Columbia and Alaska. Hanson et al. (2013) continued this work by presenting a more complex heat generation term (Eq. 2.10), and by developing an energy expended-based heat generation function (rather than a time-dependent function), which can more efficiently simulate cold temperature MSW heat generation. The energy expended model assumes that a given waste has a finite amount of energy to be expended, 
and, over time, the same amount of energy can be extracted from all parts of the landfill. The newly developed model was validated using data from two separate waste cells (one cell contained relatively young or new waste, the other relatively older waste). Greater variability in temperatures was noted for the newer wastes.

Bonany et al. (2013b) was the first to develop a heat budget model for the Ste. Sophie landfill, in Quebec, Canada. The simulation confirmed that waste acts as an insulator, with relatively low thermal conductivities. It was observed that the waste remained frozen for 1.5 years, and a latent heat term was used to account for the loss of heat due to phase change. Megalla (2015) continued the work of Bonany et al. (2013b), incorporating an aerobic heat generation term for the top metre of waste. Megalla (2015) found that aerobic heat generation accounted for $56 \%$ of the total heat generated in the domain, with the remaining 44\% attributed to anaerobic heat generation. Megalla et al.(2016) furthered the model by implementing a relationship for waste thermal conductivity with time and depth. Expended energy was incorporated into the model in order to better account for the delayed onset of anaerobic biodegradation which was observed. Megalla et al. (2016) also incorporated settlement into the model. Megalla et al. (2016) found that $64 \%$ of the total heat was generated by aerobic biodegradation, compared with $36 \%$ by anaerobic biodegradation. In order to thaw the waste, it was found that $22 \%$ of the total heat generation was needed to thaw the frozen waste, and $55 \%$ was stored as sensible heat and was responsible for increasing waste temperatures. The remaining heat was lost to the environment. 


\section{Chapter 3}

\section{Field Setup and Data Acquisition}

Few studies have been conducted to monitor waste stabilization processes by placing instruments within full-scale landfills. Efforts have been undertaken in California (El-Fadel, 1991), Florida (Reinhart et al., 2002; Townsend et al., 2008), Michigan (Hanson et al., 2006) and Calgary (Hunte et al., 2012). The challenge associated with the instrumentation of full-scale landfills stems from the high failure rate of instruments due to the harsh nature of the waste. This chapter presents the field setup and data acquisition for a landfill located in Ste. Sophie, Quebec. Temperature, oxygen and settlement data have been collected from the Ste. Sophie landfill for over 7 years, providing valuable insights into the relative importance of the processes and parameters that impact heat generation and transfer at landfills operated in northern climates. The lack of comprehensive field data such as that presented herein highlights the novelty of this research.

The Ste. Sophie landfill, owned and operated by Waste Management Canada (WM), is located approximately $50 \mathrm{~km}$ north-west of Montreal, Quebec, near the village of Ste. Sophie. The landfill is permitted to take in 1.0 million tonnes of waste per year. It takes in municipal solid waste, as well as industrial, commercial \& institutional waste, construction \& demolition waste, and contaminated soils. Approximately 70 million tonnes of 
landfill gas (LFG) is collected annually, and approximately half is piped $13 \mathrm{~km}$ away to the Cascades Inc. pulp and paper mill in Ste. Jerome, Quebec, via Gaz Metro. The piped gas provides enough energy to power the entire pulp and paper mill. The remaining LFG collected from the landfill is flared.

\subsection{Instrument Bundles}

WM began filling the south-east corner of Zone 4 with MSW in late 2009 (Figure 3.1). Twelve instrument bundles were placed in two vertical columns within the waste as it was placed. Waste lift 1 was placed in January, 2010, and contains bundles 1 through 6 . Waste lift 2 was placed in December 2010, and contains no bundles. Waste lift 3 was placed in January 2011, and contains bundles 7 and 8. Waste lift 4 was placed in August 2011, and contains bundles 9 and 10. Waste lift 5 was placed in March 2012, and contains bundles 11 and 12. The vertical bundle arrangements and initial waste lift heights are summarized in Figure 3.2. The blue coloured lifts correspond to those placed under cold ambient conditions, and the red coloured lifts correspond to those placed under warm ambient conditions. The lift waste heights have since decreased from those noted in Figure 3.2 due to settlement over time. 


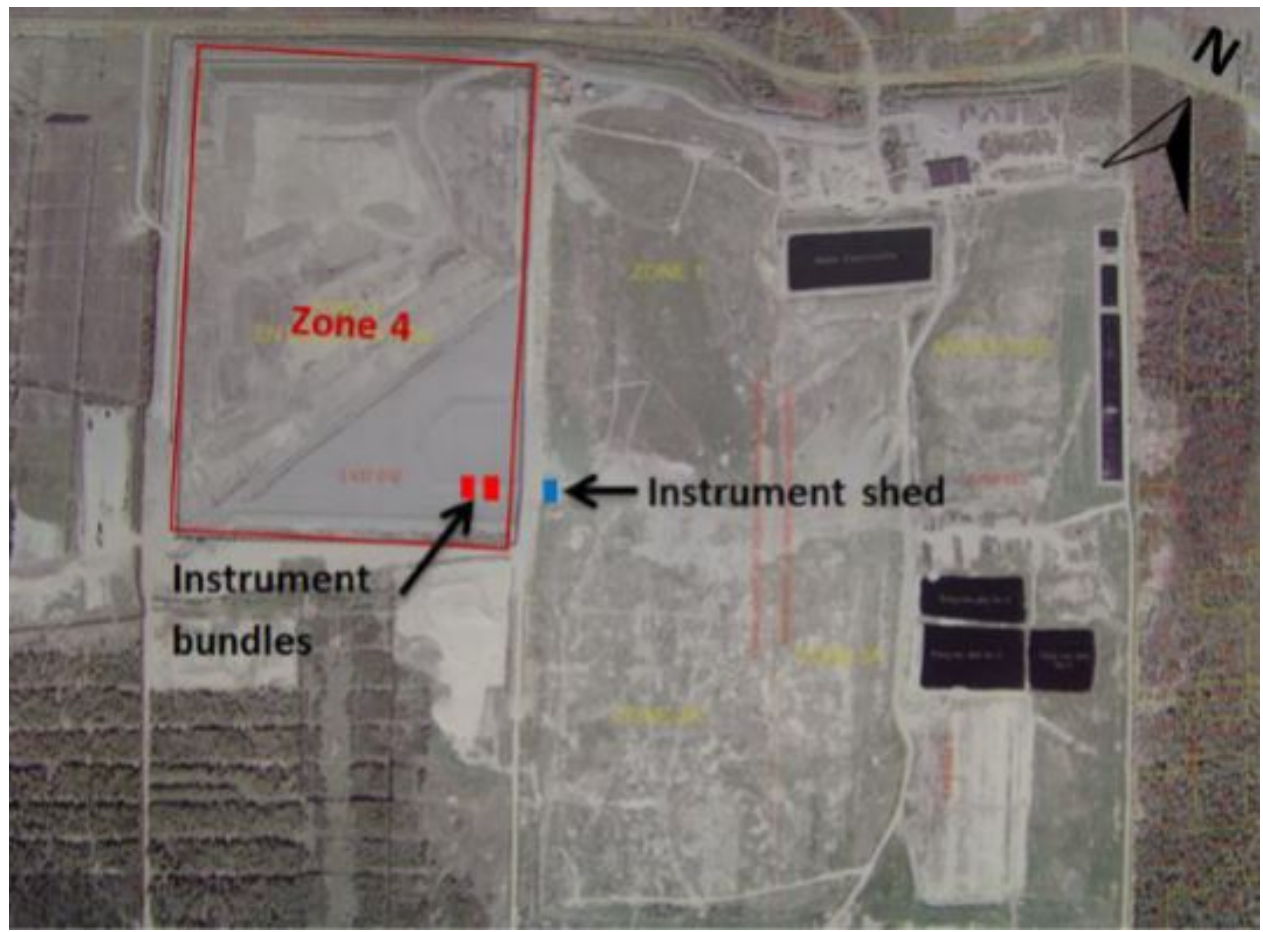

Figure 3.1: Aerial view of Zone 4 where the instrument bundles and instrument shed are located. 

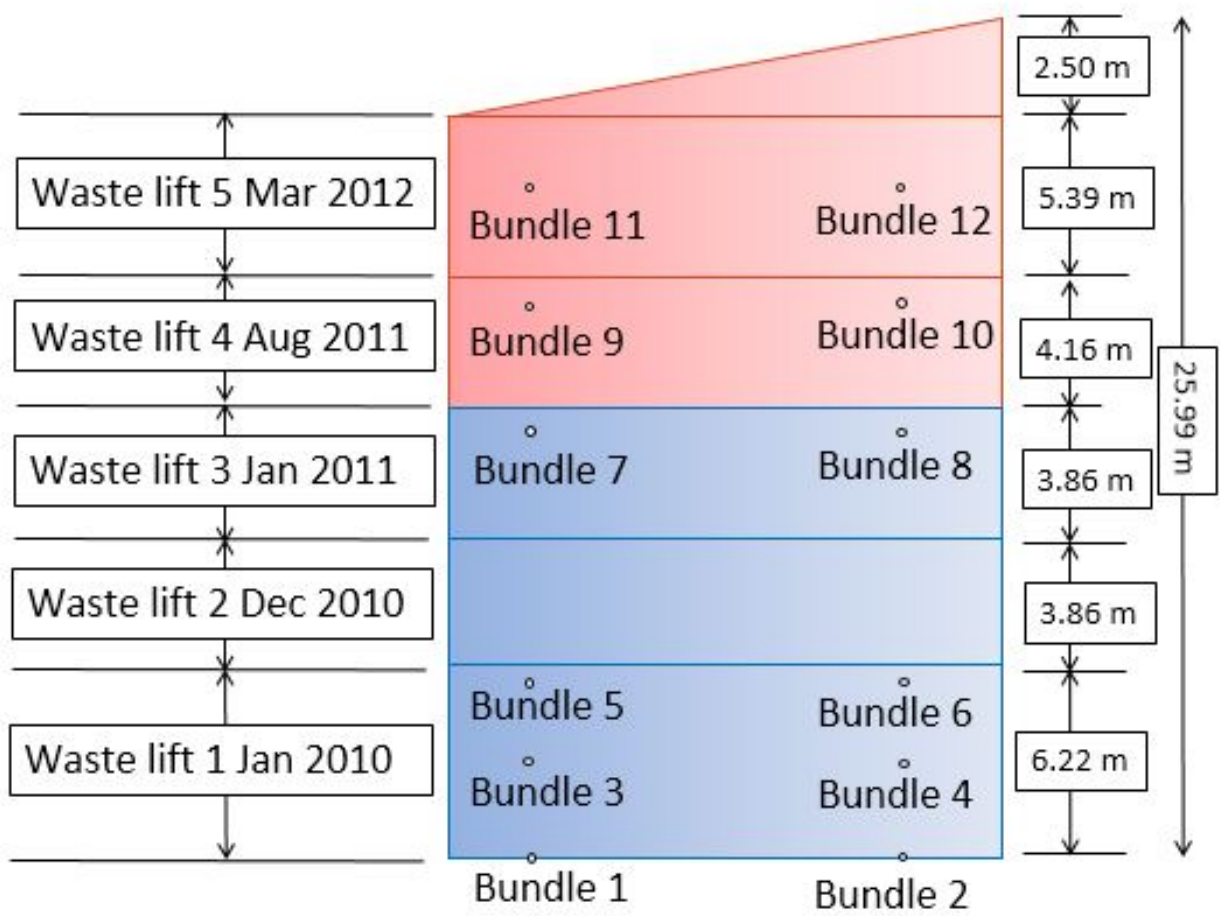

Figure 3.2: Lift placement dates and heights.

Each instrument bundle is equipped with an oxygen sensor (percent by volume), a moisture and electrical conductivity sensor, a total earth pressure cell, a vibrating wire piezometer to measure leachate head and a liquid settlement system. Each of the instruments is mounted on a $60 \mathrm{~cm}$ by $60 \mathrm{~cm}$ steel plate. Two hollow plastic lines run from each instrument bundle to the nearby instrument shed which allow leachate or landfill gas samples to be obtained, or for injection of air to the bundles. An image of an instrument bundle used at the Ste. Sophie landfill is provided in Figure 3.3, and Table 3.1 provides a summary of each of the instruments. 


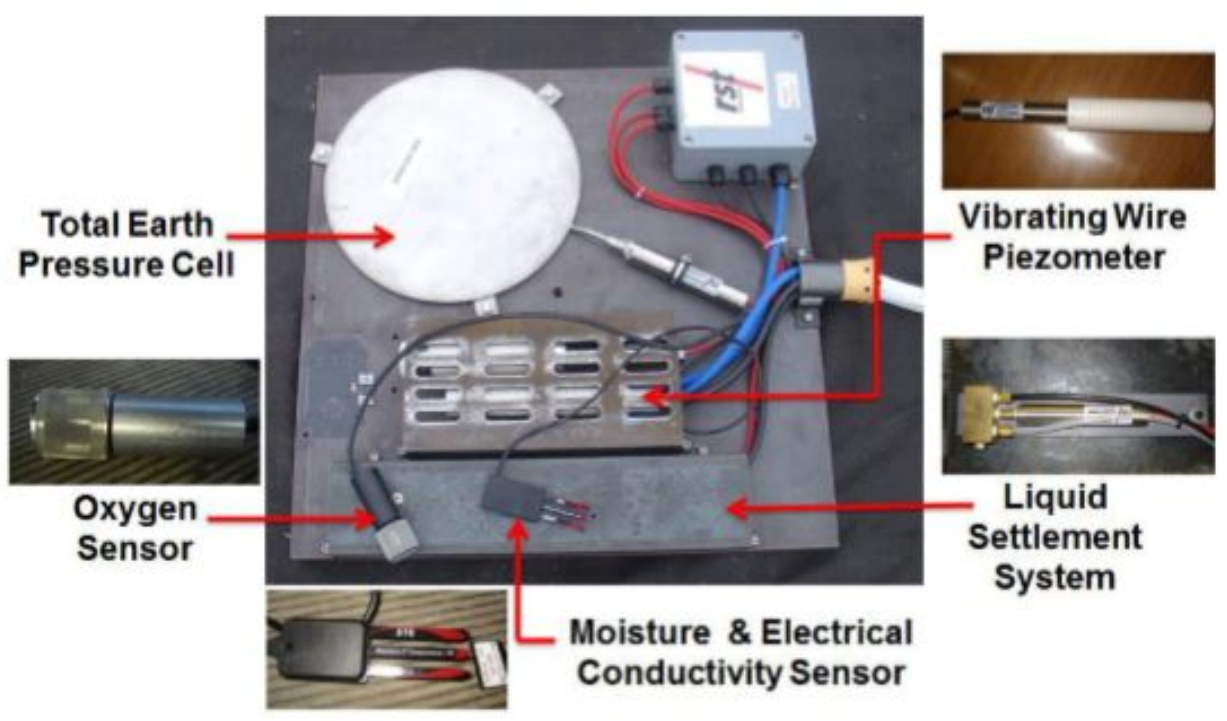

Figure 3.3: Instrument bundle used for data collection at the Ste. Sophie landfill.

Each of the instrument bundles are connected by cables to a Campbell Scientific CR1000 FlexDAQ Datalogger that is housed in an instrument shed outside the landfill footprint. Instrument data are continuously recorded at 30 minute intervals, and can be downloaded either by direct connection in the instrument shed, or through remote wireless connection. The dates in which data collection began for each of the bundles is provided in Table 3.2 
Table 3.1: Instruments used to collect data at the Ste. Sophie landfill.

\begin{tabular}{|l|l|}
\hline Sensor & Description \\
\hline \hline Oxygen & - Measures concentration of oxygen as percent by volume \\
- Installed in sand and placed above instrument bundle \\
- Also measures temperature
\end{tabular}


Table 3.2: Date in which data collection began for each bundle.

\begin{tabular}{|c|c|}
\hline Bundle Number & $\begin{array}{c}\text { Date of Data Collection } \\
\text { Commencement }\end{array}$ \\
\hline \hline 1 and 2 & November 9, 2009 \\
\hline 3 and 4 & January 16th, 2010 \\
\hline 5 and 6 & June 23, 2010 \\
\hline 7 and 8 & January 29, 2011 \\
\hline 9 and 10 & August 25, 2011 \\
\hline 11 and 12 & March 17, 2012 \\
\hline
\end{tabular}

Figure 3.4 provides a detailed summary of the locations and elevations of bundles at the time of placement. Bundles 1 and 2 were placed at the base of the landfill, above the LCS, in November 2009. The filling of waste lift 1 began in January 2010, and bundles 3 and 4 were placed approximately $3 \mathrm{~m}$ from the base of the landfill, in the centre of the first waste lift as it was placed. Bundles 5 and 6 were also placed near the top waste lift 1, approximately $5 \mathrm{~m}$ from the base of the landfill. Data collection for bundles 3 and 4, and 5 and 6 began January 16, 2010, and June 23, 2010, respectively. The placement of waste lift 2 began in December 2010, and contains no bundles. The placement of waste lift 3 began in January 2011. Bundles 7 and 8 were placed approximately $0.75 \mathrm{~m}$ below the surface of lift 3. The data collection for bundles 7 and 8 began January 28, 2011. Waste lift 4 was placed in August 2011, and was the first lift that was placed during warm ambient conditions. Bundles 9 and 10 are located $1 \mathrm{~m}$ below the surface of lift 4 , and data collection commenced August 23, 2011. Waste lift 5 was also placed under warm ambient 
conditions in March 2012. Bundles 11 and 12 were placed in the top portion of waste lift 5 and data collection began March 14, 2012. It was noted in survey data that regrading occurred, and that material was placed above the bundles in November 2013. Again, more material was noted to have been added around October 2014. Waste lifts 6 and 7 are used to represent the addition of the material above the bundles.

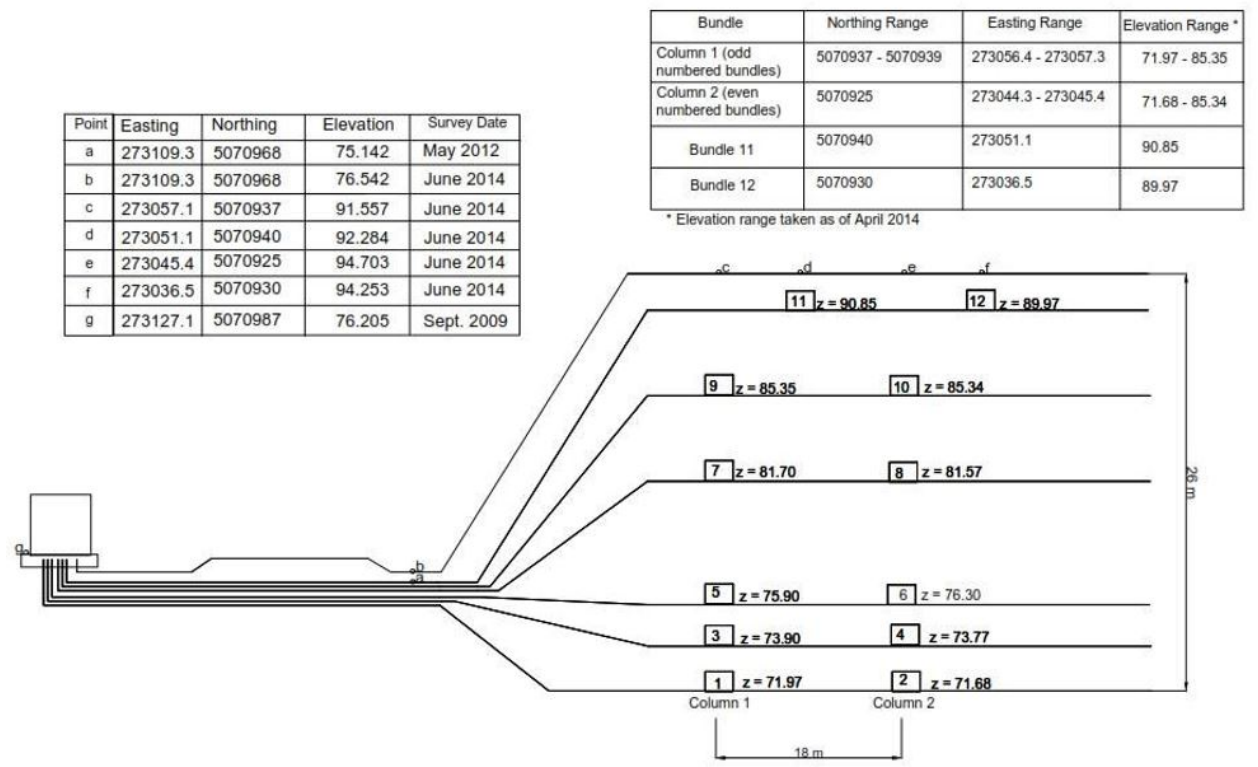

Figure 3.4: Bundle placement locations and elevations. 


\subsection{Field Data Analysis}

\subsubsection{Temperature Data}

Temperature data from initial installation in December 2009 through to December 2016 are presented in Figure 3.5. Black vertical lines are used to define the beginning of lift placements 1 through 7 . The ambient temperature is plotted in grey.

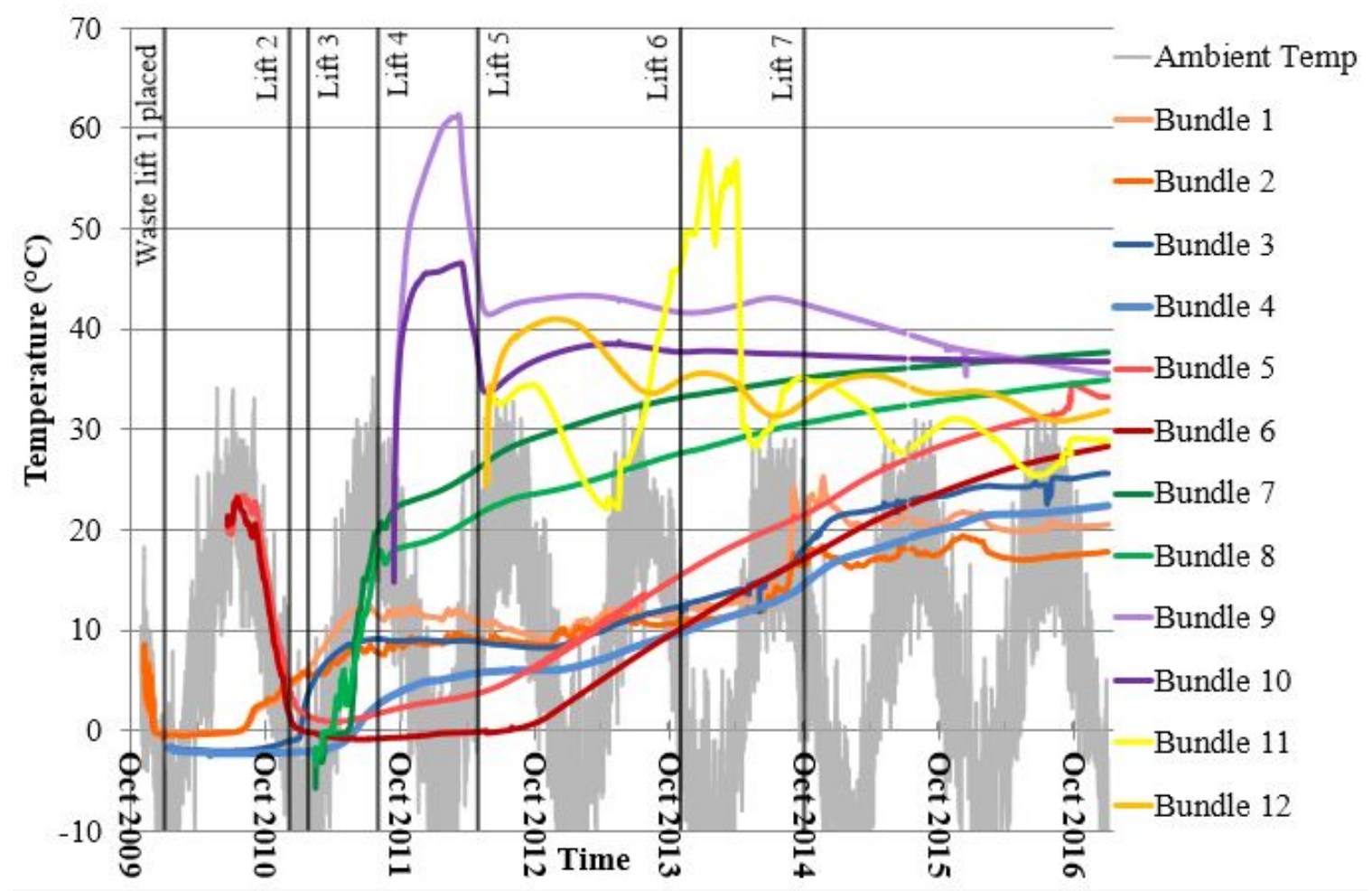

Figure 3.5: Temperature variations with time at bundles 1 through 12 .

Referring to Figure 3.5, the bundle temperatures will be now discussed in more detail. The temperature data were modelled and are presented in Chapter 4 


\section{Bundles 1 and 2}

Bundles 1 and 2 were placed at the base of the landfill, and their temperatures followed ambient conditions until waste lift 1 was placed above them. The bundles remained insulated by the waste placed above them at approximately $0{ }^{\circ} \mathrm{C}$ until August 2010. The bundles then began to increase steadily before reaching a plateau at approximately $10{ }^{\circ} \mathrm{C}$ for nearly 2 years. Around October 2013, temperatures began climbing again. Bundles 1 and 2 remained at averages of approximately 21 and $18{ }^{\circ} \mathrm{C}$, respectively, for the remainder of the study period.

\section{Bundles 3 and 4}

Bundles 3 and 4 were placed approximately $3 \mathrm{~m}$ from the base of the landfill in January 2010. They were placed within frozen waste, and remained below $0{ }^{\circ} \mathrm{C}$ for approximately one year, despite ambient temperatures rising to approximately $30{ }^{\circ} \mathrm{C}$ during the summer. There was approximately $3 \mathrm{~m}$ of waste placed above these bundles, which insulated them at the frozen temperatures. In January 2011 the temperature at bundle 3 increased sharply and then remained constant around $9{ }^{\circ} \mathrm{C}$ until October 2012. It is anticipated that prior to January 2011, any heat added to the waste was used as latent heat for phase change. In May 2011, bundle 4 also started increasing, although not as sharply or to the same magnitude as bundle 3. Bundle 3 leveled out at around $6{ }^{\circ} \mathrm{C}$ until October 2012. After October 2012, both bundles rose steadily, reaching temperatures of approximately 25 and $22{ }^{\circ} \mathrm{C}$ for bundles 3 and 4 , respectively. 


\section{Bundles 5 and 6}

Bundles 5 and 6 were placed relatively close to the surface of lift 1 . Therefore, they followed the ambient temperatures with a slight time lag until lift 2 was placed above them. After the placement of lift 2, they too became insulated. Bundle 5 remained just above 0 ${ }^{\circ} \mathrm{C}$, while bundle 6 remained below $0{ }^{\circ} \mathrm{C}$ for 1.5 years. By October 2012 , both bundles rose in temperature until the end of the study period. Bundle 5 rose to approximately 34 ${ }^{\circ} \mathrm{C}$, and bundle 6 rose to approximately $28{ }^{\circ} \mathrm{C}$.

\section{Bundles 7 and 8}

Bundles 7 and 8 were placed near the top of lift 3 in frozen waste. They followed ambient conditions with a slight time lag until the placement of lift 4 . Lift 4 was placed during warm conditions, thus bundles 7 and 8 became insulated at approximately $20{ }^{\circ} \mathrm{C}$. They rose to temperatures of approximately 37 and $24{ }^{\circ} \mathrm{C}$ by the end of the study period for bundle 7 and 8 , respectively.

\section{Bundles 9 and 10}

Bundles 9 and 10 were placed near the top of lift 4 during warm conditions. It can be seen that temperatures rose significantly above ambient temperatures, to approximately $60{ }^{\circ} \mathrm{C}$ and $45{ }^{\circ} \mathrm{C}$ for bundle 9 and 10 , respectively. This rise in temperature is attributed to the presence of oxygen in the waste, which stimulates aerobic biodegradation (see Chapter 
3.2.2). Since aerobic biodegradation is an exothermic process, it resulted in a temperature rise at the bundles. The placement of lift 5 occured in March 2012, and resulted in a decrease in temperature at bundles 9 and 10. Referring to Figure 3.6, it is noted that this point in time corresponds to a decrease in oxygen. Therefore, as the concentration of oxygen was decreased, aerobic biodegradation ceased to occur, and temperatures fell. The bundles became insulated by waste lifts 5, 6 and 7 and remained at fairly constant temperatures for the remainder of the study period.

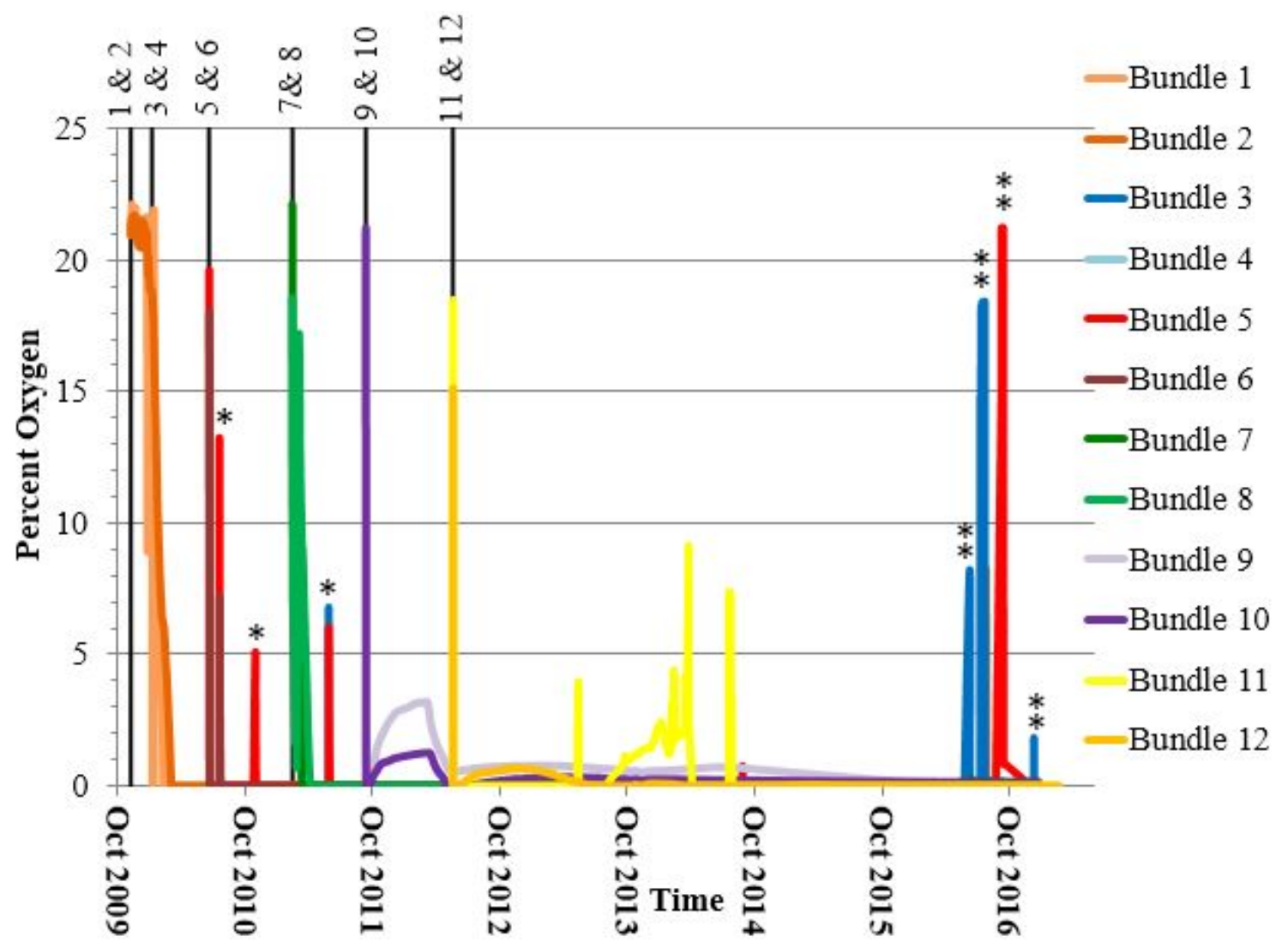

Figure 3.6: Percent oxygen with time at bundles 1 through 12 . 


\section{Bundles 11 and 12}

Bundles 11 and 12 were placed near the top of lift 5 during warm conditions. Initially, the bundles follow ambient temperatures. However, bundle 11 had a significant rise in temperature starting around the summer of 2013. This is the same point in time in which regrading took place at the landfill surface above the odd numbered instrument bundles (just before placement of waste lift 6). From Figure 3.6, it can be seen that this also corresponds to an increase in oxygen measured at bundle 11. Therefore, aerobic biodegradation was taking place at the bundle, which resulted in an increase in temperature. The sharp decrease in temperature corresponds to the point in which oxygen is no longer present at the bundle (Figure 3.6). After the placement of waste lift 7, the temperatures still follow ambient temperature, but are muted and delayed somewhat due to the added $2 \mathrm{~m}$ of soil placed above the bundles due to lifts 6 and 7 . Bundles 11 and 12 are no longer as close to the surface and are therefore more insulated from ambient conditions.

\subsubsection{Oxygen Data}

Figure 3.6 shows the oxygen data collected from all of the bundles. The black vertical bars show the time in which each bundle was placed and began collecting data. At the time of placement of each bundle, readings indicate that air is present with approximately $21 \%$ oxygen present, which declines sharply to zero as aerobic decomposition consumes the oxygen.

Early in the study period, oxygen tests were conducted in the field. A small pump was 
used to force air out to the bundles to see that the oxygen sensors were working. These tests are highlighted in Figure 3.6 by a single asterisk $(*)$ placed above the spikes in oxygen concentration. Further field experiments were conducted by the author of this thesis from June to December 2016. These experiments are highlighted by double asterisks above the oxygen spikes. The purpose of these experiments was to observe if the temperature would rise due to the presence of oxygen at the bundle. This experiment was not continued by the author of this thesis. However, continuation of these experiments could provide valuable information regarding aerobic heat generation, and could help calibrate the heat budget model presented in Chapter 4

The placement of bundles 9 and 10 around October 2011 show oxygen present for a prolongued period of time. Similarly, from May to August 2013, increases and decreases in percent oxygen can also be noted at bundle 11. The increased percent oxygen at bundle 11 is due to regrading activities which took place at the surface of the landfill. The regrading allowed air to reach the bundle and therefore corresponding rises in oxygen were recorded. Increased temperatures were noted at the bundles at the same time as increased percent oxygen readings due to increased aerobic activity.

\subsubsection{Settlement Data}

Figure 3.7 shows the settlement data collected from all of the bundles. The black vertical bars show the time in which each waste lift was placed. Significant settlement occurs over 
time. Instantaneous compression results in the increased settlement at the time of placement of each waste lift. Continued settlement occurs in the long term due to secondary settlement or mechanical creep, and biodegradation-induced settlement. Bundles 1 and 2 are placed at the very base of the landfill, and they undergo settlement as a result of the waste layers placed above and the reconsolidation and consolidation of the clay layer below the landfill. The settlement was incorporated into the model and the results are presented in Chapter 5

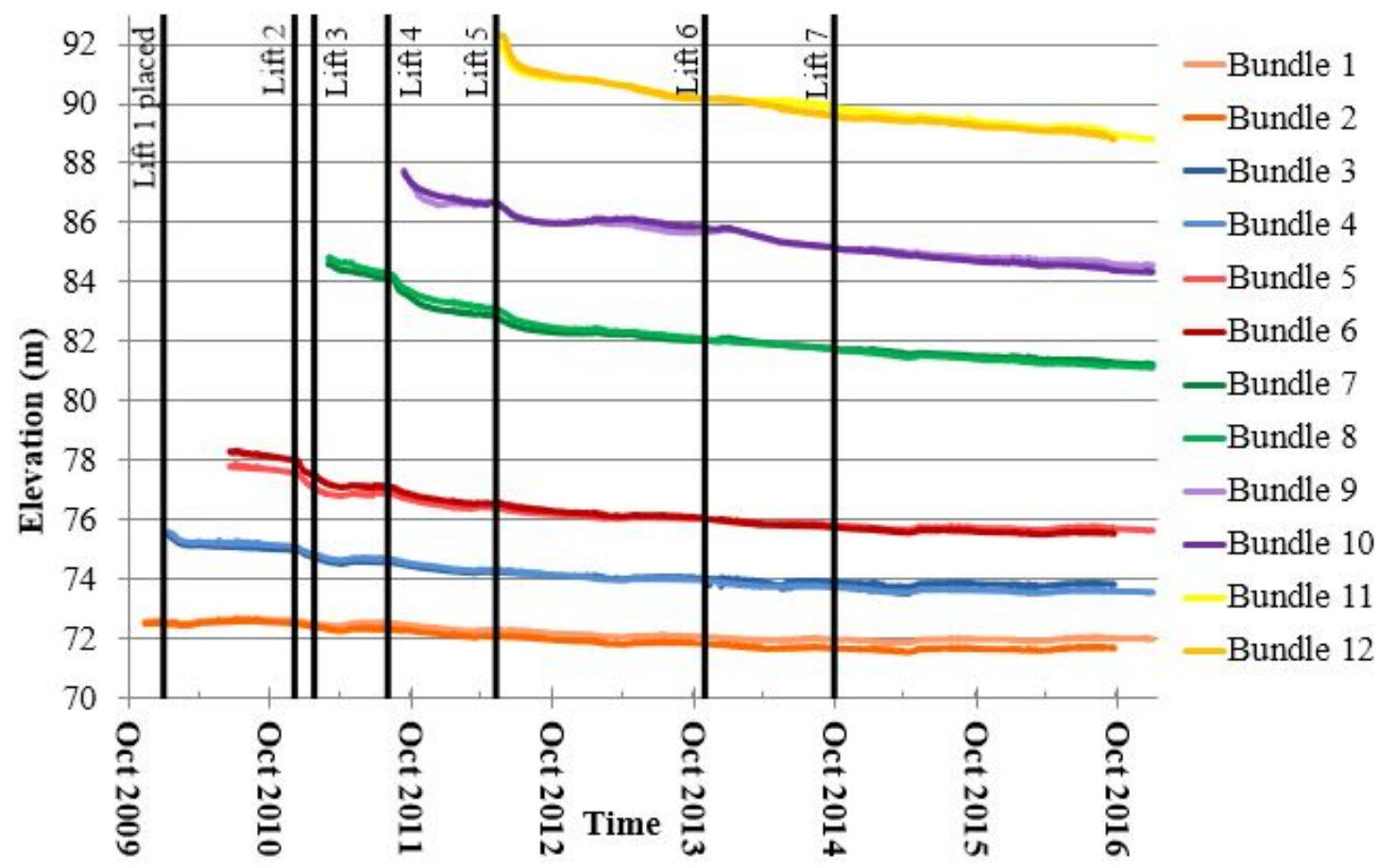

Figure 3.7: Settlement with time at bundles 1 through 12 . 


\section{Chapter 4}

\section{Ste. Sophie Heat Budget Model}

\subsection{Model Development and Overview}

COMSOL Multiphysics version 5.2a, a finite element software package, was used to model the overall heat transfer processes occurring in the Ste. Sophie landfill. A 1D vertical model was set up to represent the height of the landfill. A mesh size of $0.01 \mathrm{~m}$ was used based on the comprehensive mesh element study conducted by Megalla et al. (2016). The bottom boundary condition was defined as a prescribed temperature, based on the measured waste temperatures at bundle 1, which is located at the base of the landfill just above the LCS. The top boundary condition was defined as a heat flux boundary, with the inward heat flux calculated based on incoming shortwave solar radiation, outgoing longwave radiation, and convection at the surface (Chapter 4.2.2). The side boundaries were defined as zero heat flux boundaries.

The model was run as 7 separate simulation periods, with each one representing the addition of a new waste lift. For example, period 1 simulates the placement of waste lift 1 just until the placement of waste lift 2. Period 2 proceeds with the placement of waste lift 2 on top of waste lift 1 and simulates just until the placement of waste lift 3 (and so on for the 
remaining waste lifts). The length of each simulated period and the cumulative waste lift heights are outlined in Table 4.1. Within the waste lifts, odd numbered bundles 3 through 11 were represented using probes in COMSOL, which track temperature, settlement, heat generation and expended energy at the instrument bundle locations with time. The model begins with the placement of bundle 3 in January 2010, and finishes December 2016. Time steps of 7200 s were used to simulate the data.

Table 4.1: Modelled simulation times and cumulative waste lift heights.

\begin{tabular}{|c|c|c|}
\hline Period & Length of study (days) & Cumulative waste lift height (m) \\
\hline \hline 1 & 331 & 6.22 \\
2 & 45 & 10.08 \\
3 & 207 & 13.94 \\
4 & 204 & 18.1 \\
5 & 594 & 23.49 \\
6 & 334 & 24.49 \\
7 & 827 & 25.49 \\
\hline \hline
\end{tabular}

The heat budget model presented in this thesis is based upon the works of Bonany et al. (2013b), and Megalla et al. (2016). The author improved the fit of the model to the measured Ste. Sophie data by making the following changes:

- Two $1 \mathrm{~m}$ lifts were added after period 5, representing periods 6 and 7. These were added after noting some regrading had occurred over the bundles. Lidar data confirmed that soil material had also been placed over the location of the bundles during 
the regrading.

- New relationships for thermal conductivity and specific heat as a function of depth and time were developed using the COMSOL Multiphysics Optimization software package. The thermal conductivity and specific heat were varied with time and depth within the domain and are presented in Chapters 4.4.2 and 4.4.3, respectively.

- A new value for the latent heat of phase change for frozen to unfrozen waste was determined by using a trial and error approach to minimize the sum of squared differences (SSD) between the simulated temperatures and measured temperatures at the Ste. Sophie landfill (Chapter 4.4.1).

- The maximum anaerobic heat generation rate was adjusted using trial and error to minimize the SSD (Chapter 4.4.1).

- The concept of expended energy was used to simulate the biodegradation-induced settlement (Chapter 5). This concept changed the biodegradation induced settlement from a time domain to a temperature domain.

Within COMSOL, several processes and parameters were used to model the overall heat transfer throughout the landfill. The following sections provide details on the development of the heat budget model for the Ste. Sophie landfill. Table 4.2 outlines the information which was specified, either as a scalar value or as a function, in order to run the model. The sections following Table 4.2 will outline the development of the model. Some parameters were adopted from previous studies by Bonany et al. (2013b) and Megalla et 
al. (2016) (conduction from underlying soil, surface heat flux, and aerobic heat generation) and several parameters were modified in order to improve the fit of the model to the Ste. Sophie temperature data (anaerobic heat generation coefficient, latent heat of phase change, thermal conductivity and specific heat).

Table 4.2: Conditions specified when using COMSOL Multiphysics.

\begin{tabular}{|c|c|}
\hline Heat Transfer Condition & How Condition is Defined \\
\hline \hline Thermal conductivity & Function varying with time and depth* \\
\hline Density & $930 \mathrm{~kg} / \mathrm{m}^{3}$ \\
\hline Volumetric heat capacity & Function varying with time and depth* \\
\hline Latent heat of phase change & $10000 \mathrm{~kJ} / \mathrm{kg}$ \\
\hline Initial temperature of domain & $\begin{array}{c}\text { Scalar value, different for each } \\
\text { simulation period }\end{array}$ \\
\hline $\begin{array}{c}\text { General inward heat flux (incoming } \\
\text { radiation) }\end{array}$ & $\begin{array}{c}\text { Function varying with time } \\
\text { Heat transfer coefficient (convection) }\end{array}$ \\
\hline Ambient temperature & Function of wind velocity \\
\hline Initial temperature of landfill bottom & Function varying with time \\
\hline $\begin{array}{c}\text { Surface-to-ambient radiation (outgoing } \\
\text { longwave radiation) }\end{array}$ & $\begin{array}{c}\text { Scalar value, different for each } \\
\text { simulation period }\end{array}$ \\
\hline Anaerobic heat generation & Function of temperature and expended \\
\hline Aerobic heat generation & Function of oxygen concentration \\
\hline
\end{tabular}

* varying from one simulation period to the next but constant during each simulation period. 


\subsection{Initial Model Parameters}

\subsubsection{Conduction from Underlying Soil}

At the base of the landfill, heat may be transferred from the underlying soil to the landfill, or from the landfill to the underlying soil. Bundle 1 is located at the very base of the landfill, just above the LCS. The temperature data collected from this bundle were used to prescribe a bottom boundary condition for the heat budget model.

\subsubsection{Surface Heat Flux}

The net heat flux at the surface of the landfill is a function of incoming solar radiation, convection at the surface, and net longwave radiation, as follows:

$$
\begin{gathered}
\Delta(k \nabla T)=q_{\text {solar radiation }}+q_{\text {convection }}+q_{\text {longwave radiation }} \\
q_{\text {solar radiation }}=\epsilon Q_{0} \\
q_{\text {convection }}=h\left(T_{a m b}-T_{s}\right) \\
q_{\text {longwaveradiation }}=\epsilon \sigma\left(T_{a m b}^{4}-T_{s}^{4}\right)
\end{gathered}
$$

where $\epsilon$ is the surface emissivity, $Q_{0}$ is the net shortwave solar radiation $\left(\mathrm{W} / \mathrm{m}^{2}\right), h$ is the convection coefficient $\left(\mathrm{W} / \mathrm{m}^{2}\right), T_{a m b}$ is the ambient temperature $(\mathrm{K}), T_{s}$ is the surface 
temperature $(\mathrm{K})$, and $\sigma$ is the Stefan-Boltzmann constant for blackbody radiation (5.67 $\times$ $\left.10^{-8} \mathrm{~W} / \mathrm{m}^{2} K^{4}\right)$.

Surface emissivity describes the amount of thermal radiation emitted from an object. It varies between 0 and 1 , with 0 being a perfect reflector of radiation and 1 being a perfect emitter of radiation. The emissivity of an object depends on both the type of material and the nature of the surface. A value of 0.9 was assigned as the surface emissivity of the waste in the model.

Temperature, solar radiation and wind velocity data were obtained from the Mirabel Airport weather station, which is located less than $20 \mathrm{~km}$ south-west of the Ste. Sophie landfill. A sinusoidal function was fit to the Ste. Sophie temperature data in order to estimate ambient temperature in the model. A function was fit to the solar radiation data in order to estimate net shortwave solar radiation in the model. The convection coefficient was estimated using the wind velocity and the equation proposed by Watmuff et al. (1977) (Eq. 2.5.

\subsubsection{Aerobic Heat Generation}

The aerobic heat generation rate is the same as that used by Megalla et al. (2016). Megalla et al. (2016) noted that there was a correlation between oxygen concentration and temperature. This relationship was especially notable in bundles 9 and 11, and an empirical relationship between oxygen concentration and aerobic heat generation was used to simulate the rise in temperatures noted at these bundles (Eq. 2.13). 


\subsubsection{Latent Heat of Phase Change}

There is a lack of research considering the latent heat of phase change of frozen waste. However, this is an important term to consider for landfills operated in northern climates because it helps explain why the waste may remain frozen for such a long time. Bonany et al. (2013b) and Megalla et al. (2016) used values of $41.75 \mathrm{~kJ} / \mathrm{kg}$ and $37.2 \mathrm{~kJ} / \mathrm{kg}$, respectively, for their models of the Ste. Sophie landfill (Chapter 2.3.6). A trial and error approach of minimizing the sum of squared differences (SSD) between modelled and measured temperatures was used here to determine the latent heat of the waste (Chapter 4.4.1).

\subsubsection{Anaerobic Heat Generation Coefficient}

Megalla et al. (2016) used Eq. 2.12 to define the anaerobic heat generated in the model as a function of expended energy (Chapter 2.3.7). It was noted that the original modelled temperatures were being overpredicted at later times, suggesting that too much heat was being generated by the model. To improve the fit at later times, an anaerobic heat generation coefficient, $\mathrm{H}(0<\mathrm{H} \leq 1)$ was added to lower the rate of anaerobic heat generation (Eq. 4.5). A trial and error approach of minimizing the SSD between modelled and measured temperatures was used to determine the value of the anaerobic heat generation coefficient (Chapter 4.4.1). 


\subsubsection{Thermal Conductivity}

Thermal conductivity increases with increasing moisture content and density. There is much research concerning the thermal conductivity of MSW (Chapter 2.3.4). The difficulty in estimating the thermal conducitivity of waste stems from the heterogeneous nature of MSW. Megalla et al. (2016) implemented a relationship for thermal conductivity such that it increased with time and depth (Chapter 2.1). COMSOL Multiphysics' optimization module was utilized in order to estimate a relationship for the thermal conductivity as a function of depth and time (Chapter 4.4.2).

\subsubsection{Specific Heat}

Megalla (2015) used a specific heat value of $800 \mathrm{~J} / \mathrm{kgK}$, and Megalla et al. (2016) used a value of $2100 \mathrm{~J} / \mathrm{kgK}$. However, similar to thermal conductivity, specific heat will increase with increasing moisture content and density. Therefore, assuming one specific heat value accross the entire simulation is not realistic to conditions in the field. COMSOL Multiphysics' optimization module was utilized in order to estimate a relationship for the specific heat as a function of depth and time (4.4.3). 


\subsection{Methodology}

The COMSOL parameters for conduction from the underlying soil, surface heat flux, and aerobic heat generation were all implemented in the model based on the previous works of Bonany et al. (2013b) and Megalla et al. (2016). The latent heat, maximum anaerobic heat generation rate, specific heat and thermal conductivity were modified by the author of this thesis.

The first step taken was to use the model developed by Megalla et al. (2016) and to optimize the thermal conductivity. The Sparse Nonlinear Optimizer (SNOPT) was used within COMSOL, which employs a gradient-based optimization technique in order to minimize the squared error between the simulated temperatures and the measured Ste. Sophie landfill temperatures. During the fourth simulation period, the measured temperatures at bundle 9 were not used for optimization, and during the fifth, sixth and seventh periods, bundle 11 was not used for optimization. This is because for those periods, the respective bundles were near the surface of the landfill, and therefore temperatures were more strongly correlated to ambient conditions and the aerobic heat generation term rather than being a function of the waste properties.

The initial optimization was very broad, and did not specify bounds on the thermal conductivity values. It was found that the optimized model led to thermal conductivity increasing with depth and time, as was assumed by Megalla et al. (2016). Next, both thermal conductivity and specific heat were optimized. A similar trend of increasing thermal conductivity and specific heat with depth and time was found. However, by the final two 
simulation periods, the optimized thermal conductivity and specific heat values were surpassing those stated in literature (Table 2.2). As such, optimization bounds were added for thermal conductivity and specific heat for each simulation period based on literature values. Maximum and minimum thermal conductivity and specific heat values were assumed at the top of each waste lift. From these values, an upper and a lower bound with depth were applied for each simulation period by defining two lines with negative slopes. Lower values were assumed at the top of each lift than at the bottom of the landfill because density and moisture content both affect the thermal conductivity and specific heat of the waste. Specifically, as moisture content and density increase, thermal conductivity and specific heat increase. At the bottom of the landfill, the waste is assumed to have a higher density than near the top. Further, waste at the bottom of the landfill is assumed to be at or approaching saturation. Since water has a significantly higher thermal conductivity than air $(0.591 \mathrm{~W} / \mathrm{mK}$ and $0.024 \mathrm{~W} / \mathrm{mK}$ for water and air, respectively), the overall thermal conductivity at the base of the landfill is expected to be higher than at the top.

The optimized thermal conductivity and specific heat solutions for each previous simulation period were used as the lower bound for the next simulation period. The upper bounds were spaced from one simulation period to the next such that the solutions for the final simulation period could not surpass the highest values stated in literature.

Next, it was noted that the model was over predicting temperatures in the final years of the simulation. It was hypothesized that lowering the anaerobic heat generation rate would improve the fit of the model to the Ste. Sophie temperature data as it would decrease the amount of heat being generated. Therefore, a coefficient, $\mathrm{H}(0<\mathrm{H} \leq 1)$, was added 
to the anaerobic heat generation equation, allowing the user to lower the anaerobic heat generation rate (Eq. 4.5). The same amount of energy will still be expended from the waste, however the rate at which this occurs is decreased, and therefore it will take longer for all of the energy to be expended.

$$
\begin{aligned}
Q=H[-1.53 \times & 10^{-10} E^{6}+5.549 \times 10^{-8} E^{5}-7.878 \times 10^{-6} E^{4} \\
& \left.+5.513 \times 10^{-4} E^{3}-1.948 \times 10^{-2} E^{2}+0.2940 E\right]+0.1
\end{aligned}
$$

Finally, it was noted that simulated waste temperatures in the first three lifts were remaining frozen for a longer period of time than the temperature data in the field indicated. To address this, the latent heat of the waste in the frozen months had to be reduced, indicating either less moisture was actually in the waste than originally assumed, or that not all of the moisture within the waste was completely frozen at the time of placement. After the anaerobic heat generation coefficient and latent heat were modified, the thermal conductivity and specific heat were re-optimized.

A trial and error approach was used to determine the latent heat of phase change and anaerobic heat generation coefficient by minimizing the sum of squared differences (SSD) (Chapter 4.4). The latent heat and anaerobic heat generation coefficient could not be optimized by the model because of the way the model was set up. The model was set up as seven separate model simulations (one simulation period for the addition of each of the 
seven waste lifts). The output from the previous simulation period served as the initial conditions for the next simulation period. The COMSOL Optimization module could be used for each simulation period but could not be used to optimize parameters across all of the simulation periods. The latent heat and anaerobic heat generation rates were assumed to be constant over all of the simulation periods and hence were varied manually to reduce the model error in comparison to the field data. Conversely, the thermal conductivity and specific heat were assumed to change or increase with time due to settlement and hence were optimized for each simulation period. The resulting latent heat, anaerobic heat generation coefficient, thermal conductivity and specific heat values are now discussed.

\subsection{Results and Discussion}

The anaerobic heat generation coefficient $(\mathrm{H})$ and latent heat $(\mathrm{L})$ values were determined using a trial and error approach to minimize the SSD between modelled and measured temperatures. The SSD values are listed in Table 4.3. As can be observed in Table 4.3. the anaerobic heat generation coefficient and the latent heat were adjusted to reduce the SSD of the Megalla et al. (2016) model. The two simulations listed in Table 4.3 after $\mathrm{H}=0.5$ and $\mathrm{L}=10.0 \mathrm{~kJ} / \mathrm{kgK}$ indicate optimal parameters were reached. Then, a final model simulation was conducted which optimized the thermal conductivity and specific heat parameters with time and depth. Figure 4.1 shows the final optimized temperatures in comparison to the measured temperatures at Ste. Sophie. 
Table 4.3: Increase in SSD in comparison to the Megalla et al. (2016) model (note $\mathrm{H}$ is heat generation coefficient, and L is latent heat capacity of frozen waste).

\begin{tabular}{|c|c|c|c|c|c|c|}
\hline Conditions & $\begin{array}{c}\text { Increase } \\
\text { in B3 } \\
\text { SSD } \\
(\%)\end{array}$ & $\begin{array}{c}\text { Increase } \\
\text { in B5 } \\
\text { SSD } \\
(\%)\end{array}$ & $\begin{array}{c}\text { Increase } \\
\text { in B7 } \\
\text { SSD } \\
(\%)\end{array}$ & $\begin{array}{c}\text { Increase } \\
\text { in B9 } \\
\text { SSD } \\
(\%)\end{array}$ & $\begin{array}{c}\text { Increase } \\
\text { in B } 11 \\
\text { SSD } \\
(\%)\end{array}$ & $\begin{array}{c}\text { Total } \\
\text { increase } \\
\text { in SSD } \\
(\%)\end{array}$ \\
\hline $\begin{array}{c}\mathrm{H}=0.65 \\
\mathrm{~L}=37.2 \mathrm{~kJ} / \mathrm{kgK}\end{array}$ & -17 & 1 & 67 & 12 & -58 & -5 \\
\hline $\begin{array}{c}\mathrm{H}=0.70 \\
\mathrm{~L}=37.2 \mathrm{~kJ} / \mathrm{kgK}\end{array}$ & -29 & -11 & 15 & 0 & -57 & -21 \\
\hline $\begin{array}{c}\mathrm{H}=0.75 \\
\mathrm{~L}=37.2 \mathrm{~kJ} / \mathrm{kgK}\end{array}$ & 0 & 6 & 36 & 2 & -49 & -7 \\
\hline $\begin{array}{c}\mathrm{H}=0.70 \\
\mathrm{~L}=18.6 \mathrm{~kJ} / \mathrm{kgK}\end{array}$ & -46 & -42 & -13 & -10 & -52 & -34 \\
\hline $\begin{array}{c}\mathrm{H}=0.60 \\
\mathrm{~L}=18.6 \mathrm{~kJ} / \mathrm{kgK}\end{array}$ & -37 & -73 & -6 & 9 & -57 & -33 \\
\hline $\begin{array}{c}\mathrm{H}=0.70 \\
\mathrm{~L}=10.0 \mathrm{~kJ} / \mathrm{kgK}\end{array}$ & -21 & -57 & -4 & 22 & -47 & -22 \\
\hline $\begin{array}{c}\mathrm{H}=0.60 \\
\mathrm{~L}=10.0 \mathrm{~kJ} / \mathrm{kgK}\end{array}$ & -43 & -79 & -13 & 11 & -55 & -35 \\
\hline $\begin{array}{r}\mathbf{H}=\mathbf{0 . 5 0} \\
\mathrm{L}=\mathbf{1 0 . 0} \\
\mathrm{kJ} / \mathrm{kgK}\end{array}$ & -50 & -86 & -18 & 18 & -53 & -36 \\
\hline $\begin{array}{c}\mathrm{H}=0.40 \\
\mathrm{~L}=10.0 \mathrm{~kJ} / \mathrm{kgK}\end{array}$ & -63 & -87 & 12 & 47 & -44 & -24 \\
\hline $\begin{array}{c}\mathrm{H}=0.60 \mathrm{~L}=5.0 \\
\mathrm{~kJ} / \mathrm{kgK}\end{array}$ & -32 & -64 & -20 & 17 & -51 & -30 \\
\hline $\begin{array}{c}\text { Optimize } K \\
\text { and } C \text { with } \\
\begin{array}{c}\mathrm{H}=\mathbf{0 . 5 0} \text {, and } \\
\mathrm{L}=\mathbf{1 0 . 0} \\
\mathrm{kJ} / \mathrm{kgK}\end{array}\end{array}$ & -72 & -90 & -18 & 7 & -55 & -43 \\
\hline
\end{tabular}




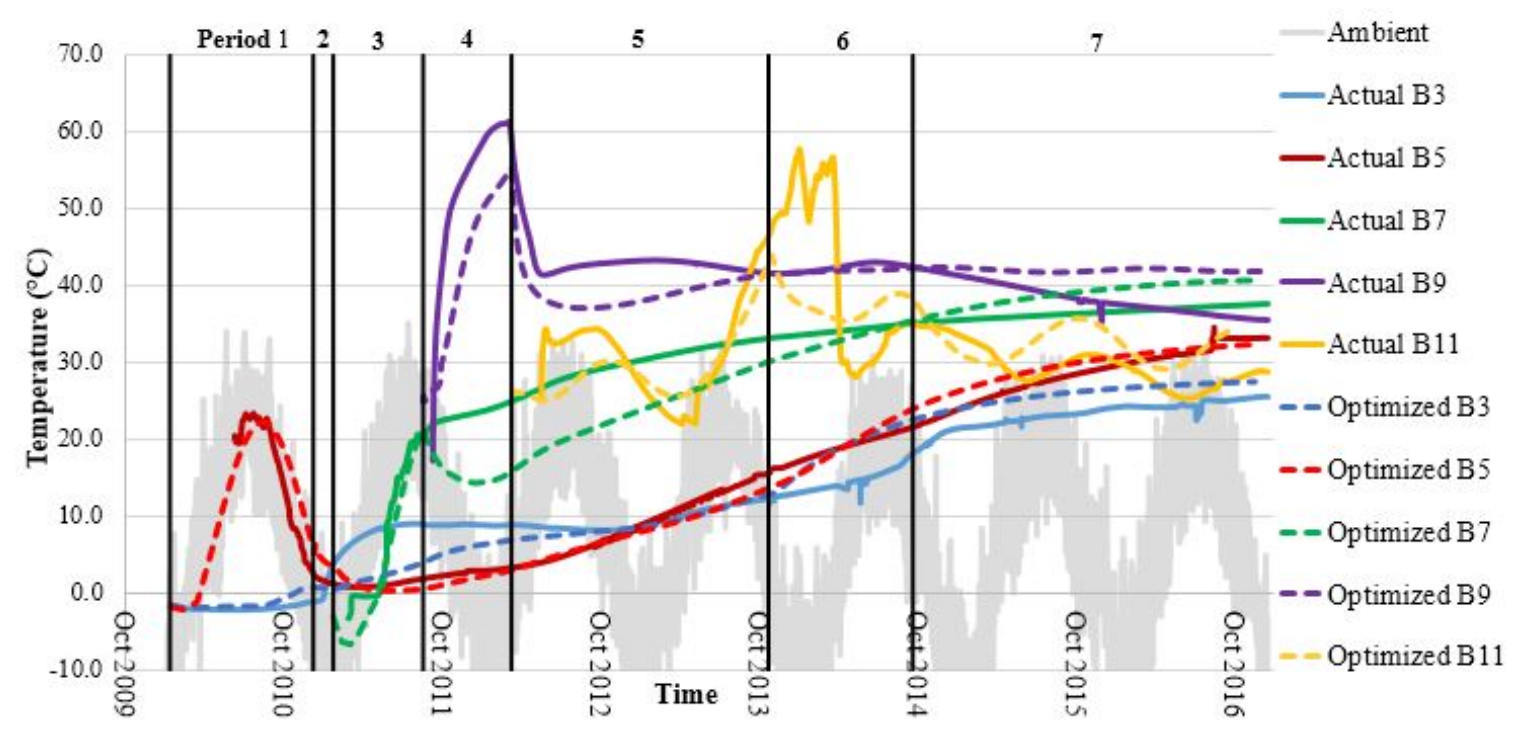

Figure 4.1: Optimized modelled temperature results.

\subsubsection{Anaerobic Heat Generation Coefficient and Latent Heat}

A heat generation coefficient of 0.5 and a latent heat of $10.0 \mathrm{~kJ} / \mathrm{kgK}$ were found to decrease the SSD by the greatest amount (36\%) in comparison to the Megalla et al. (2016) model which used a heat generation coefficient of 1 and a latent heat value of $37.2 \mathrm{~kJ} / \mathrm{kgK}$. Therefore, these values were used to optimize the thermal conductivity and specific heat relationships with depth (Chapter 4.4.2 and 4.4.3, respectively).

The anaerobic heat generation coefficient effectively allows the user to lower the maximum anaerobic heat generation rate. The same amount of energy will still be expended from the waste (assumed to be $104 \mathrm{MJ} / \mathrm{m}^{2}$ ), however the rate at which this occurs is decreased, and therefore it will take longer for all of the energy to be expended. Higher 
thermal conductivity and specific heat values could also help address the higher temperatures, however, the optimized thermal conductivity and specific heat values were already reflecting the maximum values found in the literature.

As explained in Section 2.3.7, the anaerobic heat generation term for the Ste. Sophie heat budget model was developed based on the work of Hanson et al. (2013). Hanson et al. (2013) developed the dual-ramped heat generation function using best fit nonlinear regression of temperature field data obtained from two waste cells (cell D and cell B) at a landfill in Michigan. Waste cell D contained predominantly curbside waste and did not use leachate recirculation while cell $\mathrm{B}$ contained a higher proportion of construction and demolition waste, and did recirculate leachate throughout the waste cell. Megalla et al. (2016) used waste cell D parameters to develop the maximum anaerobic heat generation for their Ste. Sophie heat budget model as it provided a better fit to the Ste. Sophie field data in comparison to waste cell B. However, it was found that temperatures were being overpredicted at the end of the 7 year simulation period in comparison to the temperatures measured in the field. This suggested that too much heat was being generated by the model. The temperatures of waste cell $\mathrm{D}$ at the end of the 5 year study period ranged from 24 to $50{ }^{\circ} \mathrm{C}$, with the reading of $50{ }^{\circ} \mathrm{C}$ being at a depth of approximately half the total waste height (Hanson et al., 2013). At the Ste. Sophie landfill, at the end of the 7 year study period, temperatures ranged from 26 to $38{ }^{\circ} \mathrm{C}$, with a temperature of $36{ }^{\circ} \mathrm{C}$ at approximately half the total waste height. A higher anaerobic heat generation rate was needed for waste cell D at the Hanson et al. (2013) Michigan site in order to account for the higher temperature readings. Similarly, a lower rate of anaerobic heat generation was needed to simulate the lower temperatures at the Ste. Sophie landfill. 
Reducing the anaerobic heat generation rate resulted in the waste in lifts one through three remaining frozen for a longer period of time (longer than the temperature data in the field indicated). To address this, the latent heat of the waste placed in the winter months had to be reduced, indicating either less moisture in the waste or not all of the moisture within the waste was frozen at the time of placement.

\subsubsection{Thermal Conductivity}

Figure 4.2 shows the thermal conductivity solutions for each of the 7 simulation periods, with each period representing the addition of a new waste lift. Figures 4.2 (a) through (h) show the bounds applied for each simulation period. Optimizing the thermal conductivity and specific heat decreased the SSD an additional 7\%, to a total of $43 \%$ lower than the original model. 


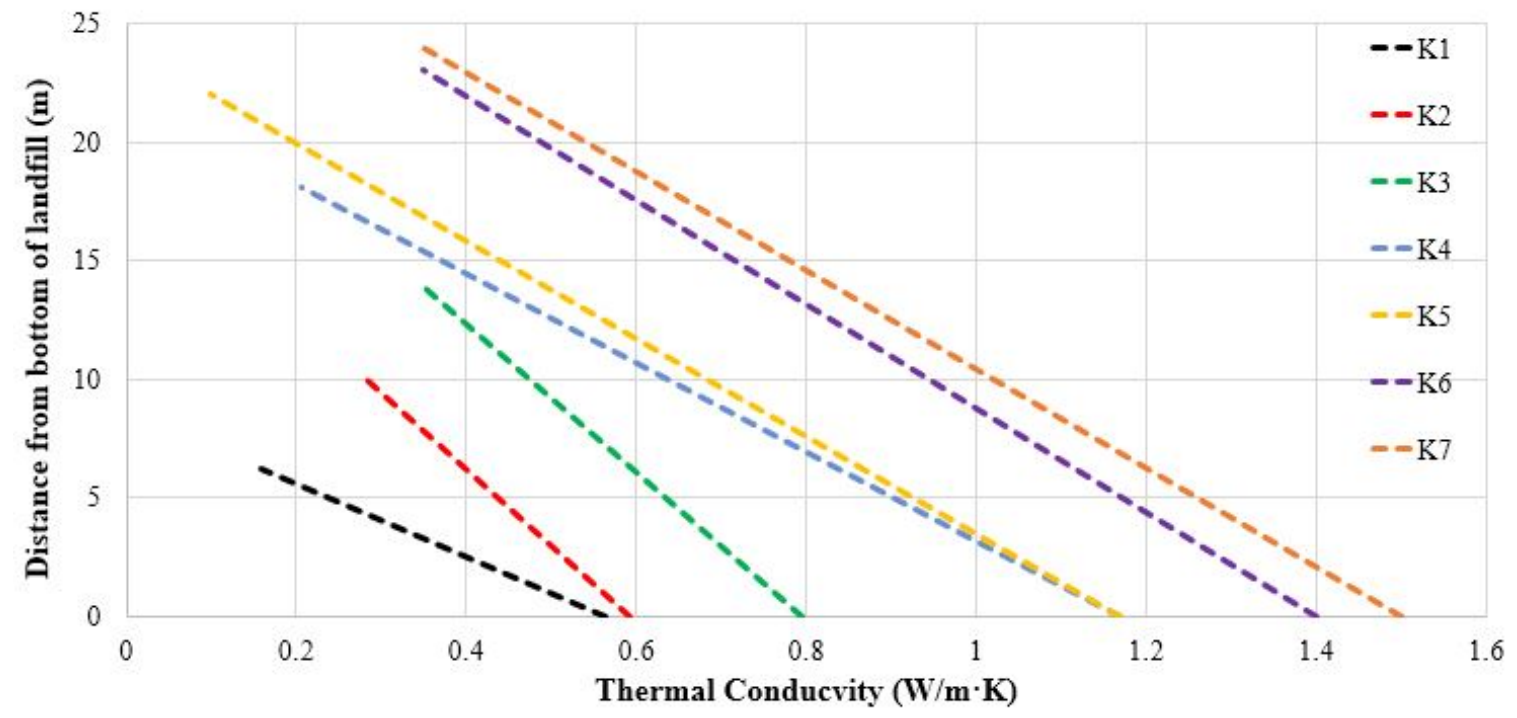

Figure 4.2: Optimized thermal conductivity $(\mathrm{K})$ results for each simulation period (for example, $\mathrm{K} 1$ represents the thermal conductivity solution for simulation period 1). 


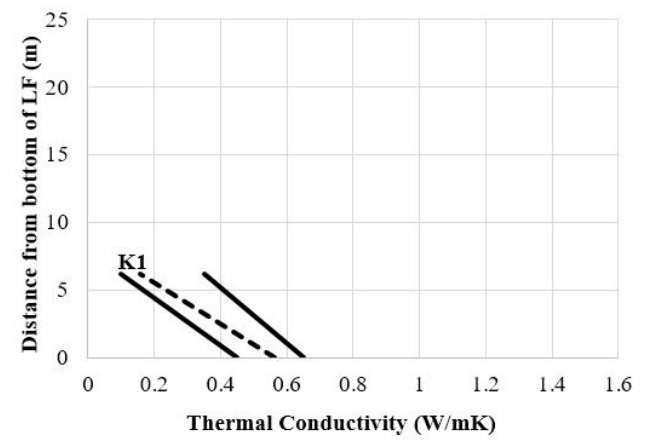

(a) Bounds enforced for period 1 .

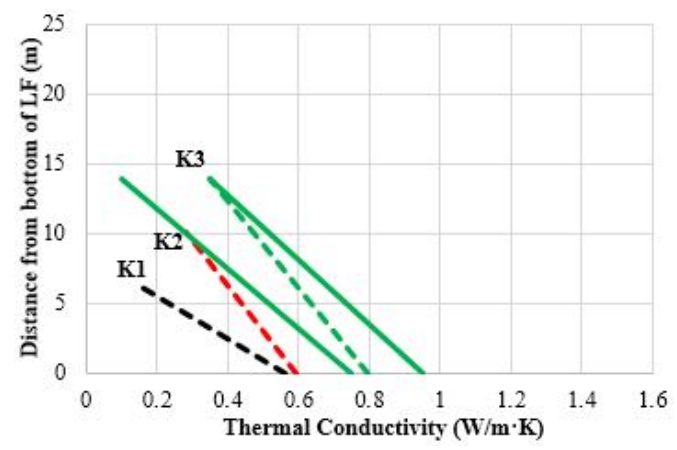

(c) Bounds enforced for period 3.

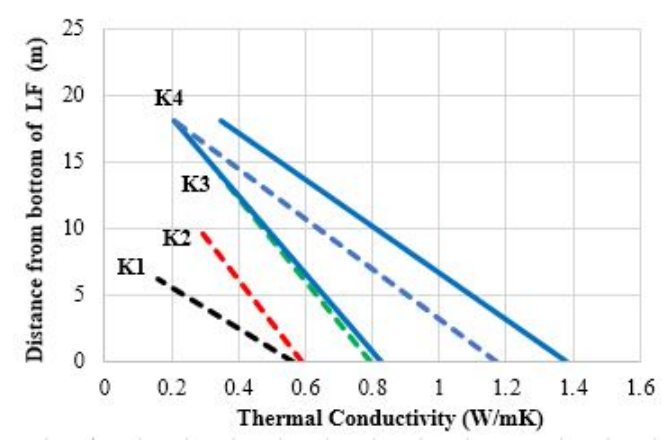

(e) Modified bounds enforced for period 4.

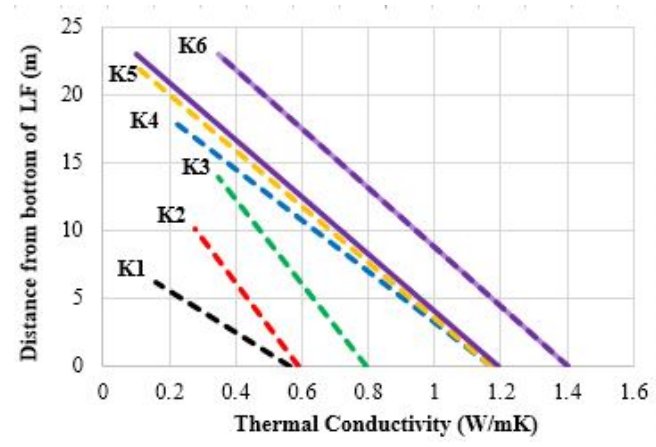

(g) Bounds enforced for period 6.

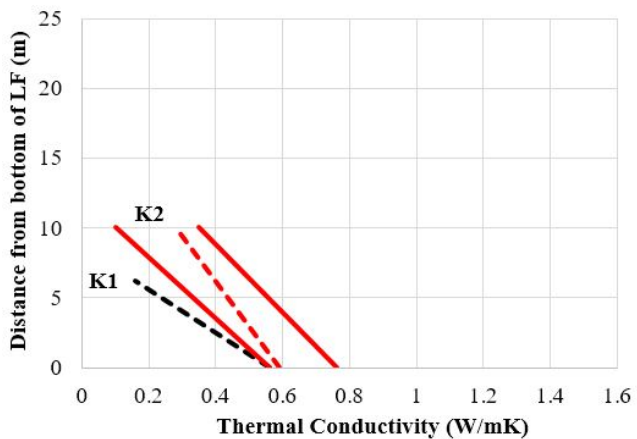

(b) Bounds enforced for period 2.

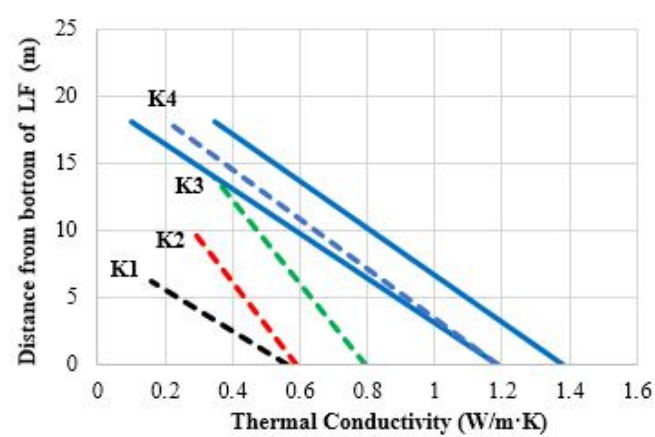

(d) Initial bounds enforced for period 4.

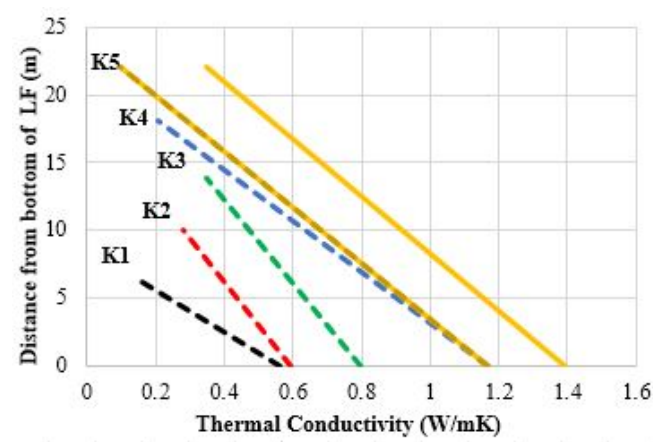

(f) Bounds enforced for period 5.

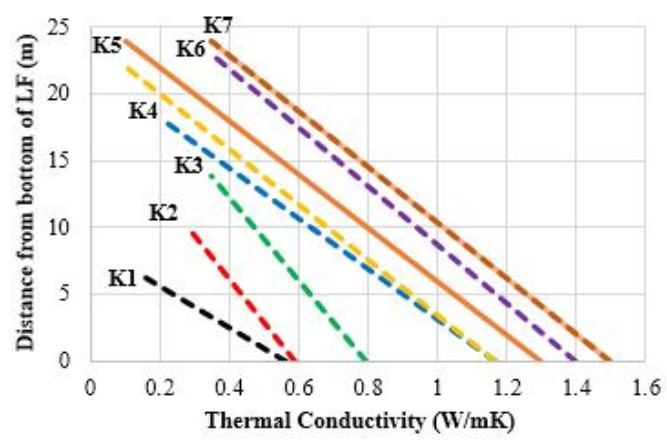

(h) Bounds enforced for period 7.

Figure 4.3: Upper and lower bounds specified during optimization of thermal conductivity (bounds displayed using solid lines, solutions displayed as dashed lines). 
Megalla et al. (2016) used a thermal conductivity of $0.3 \mathrm{~W} / \mathrm{mK}$ for the top one metre of each waste lift. The optimization solutions resulted in thermal conductivities varying from 0.1 to $0.35 \mathrm{~W} / \mathrm{mK}$ at the top of each lift (the specified range at the top of each lift was also 0.1 to $0.35 \mathrm{~W} / \mathrm{mK}$ ). While waste would likely have similar densities upon placement in the landfill, the moisture content could vary significantly based on waste composition and climatic conditions at the time of placement.

The optimization solutions for periods 1 and 2 both fall within the specified bounds, without touching the upper or lower boundaries (Figures 4.3 (a) and (b)). At the top of the landfill during period 3 (near bundle 7), the thermal conductivity is touching the upper boundary, suggesting a higher thermal conductivity may have provided a better fit (Figure 4.3 (c)). At the base of the landfill during period 4 (near bundle 3), the thermal conductivity solution is touching the lower boundary, suggesting a lower thermal conductivity may have provided a better fit (Figure 4.3 (d)). This period was optimized a second time by maintaining the thermal conductivity solution at the top of the lift and widening the lower boundary at the base of the landfill (Figure 4.3 (e)). Optimizing a second time resulted in a solution falling within the specified bounds rather than touching the lower boundary as the initial solution did. The solution to period 5 lies directly on the lower boundary, suggesting lower thermal conductivities throughout the waste would improve the fit (Figure 4.3 (f)). Referring to the simulated temperatures in Figure 4.1, it can be noted that the temperatures at bundles 7 and 9 are being underpredicted. A lower thermal conductivity would allow the waste to retain heat, thus increasing the simulated temperatures at bundles 7 and 9 .

The solutions to period 6 and 7 lie directly on the upper boundaries (Figures 4.3 (g) 
and (h)). The optimization solver wants these periods to have higher thermal conductivities. In period 6, bundle 3 temperature is overpredicted, and in period 7 all bundles are overpredicted. Higher thermal conductivities would allow heat to dissipate more easily and thus simulated temperatures would be lower, providing a better fit to the measured temperatures. However, the upper boundary of thermal conductivity at the base of the landfill corresponds to the maximum value found in the literature. This could mean that the assumption of lower thermal conductivity at the surface or the assumption of a linear increase in thermal conductivity with depth is incorrect. A non-linear relationship with depth or a two-layer model that allows for a greater thermal conductivity for a bulk of the waste may improve the results.

\subsubsection{Specific Heat}

Figure 4.4 shows the specific heat solutions for each of the 7 simulation periods, with each period representing the addition of a new waste lift. Figures 4.5 (a) through (f) show the specific heat optimization bounds applied for simulation periods 1 through 3 , and Figures 4.6 (a) through (d) show the optimization bounds applied for periods 4 through 7. 


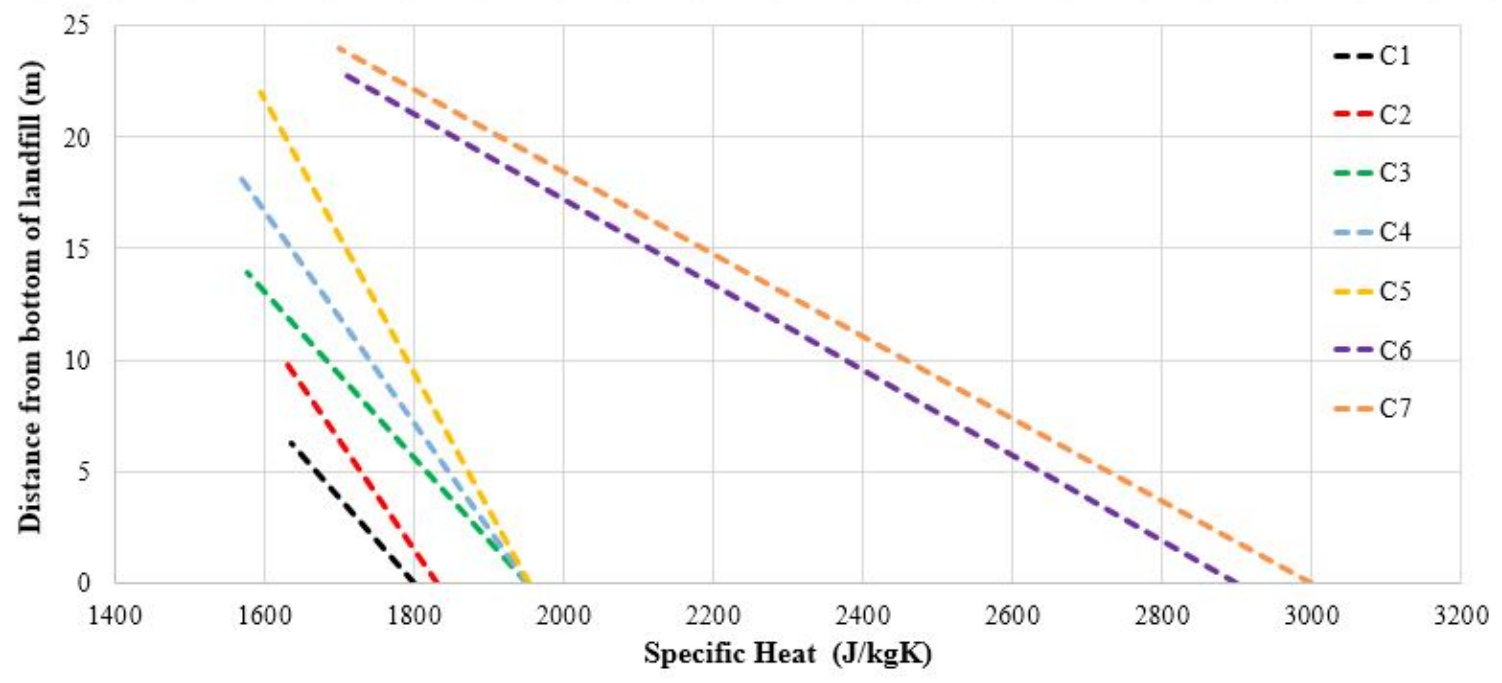

Figure 4.4: Optimized heat capacity (C) results for each simulation period (for example, $\mathrm{C} 1$ represents the specific heat solution for simulation period 1). 


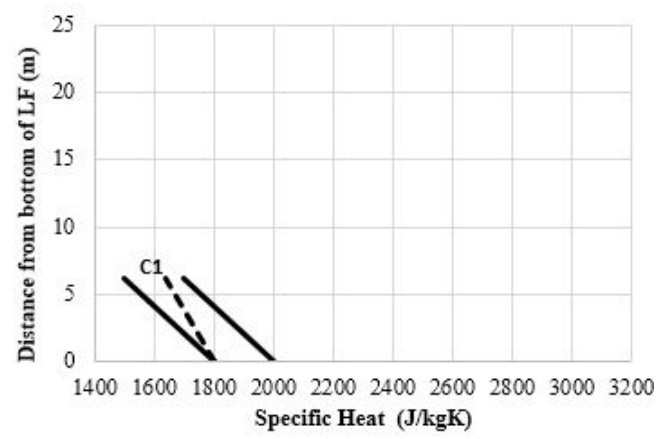

(a) Initial bounds enforced for period 1 .

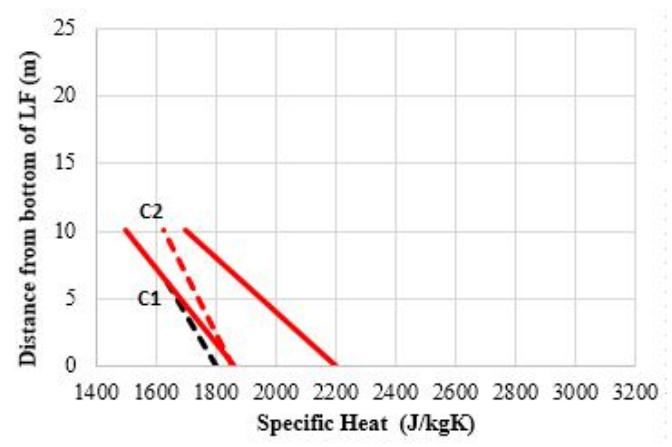

(c) Initial bounds enforced for period 2.

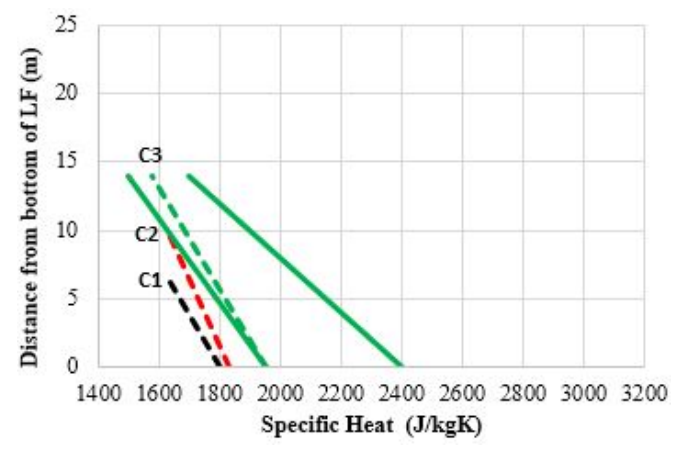

(e) Initial bounds enforced for period 3.

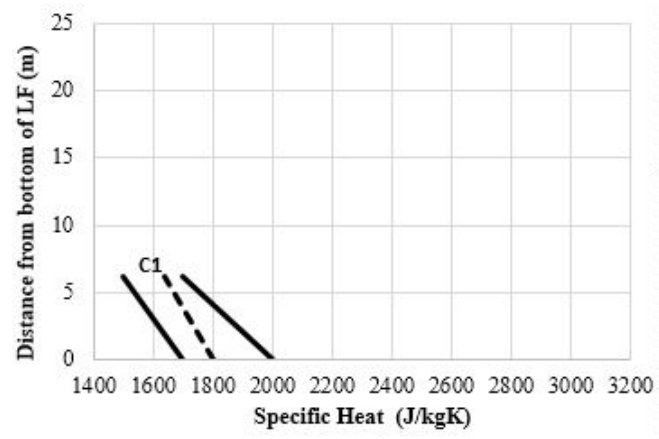

(b) Modified bounds enforced for period 1.

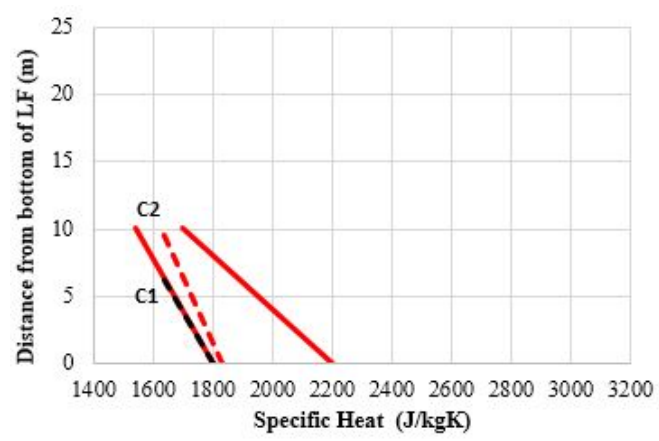

(d) Modified bounds enforced for period 2.

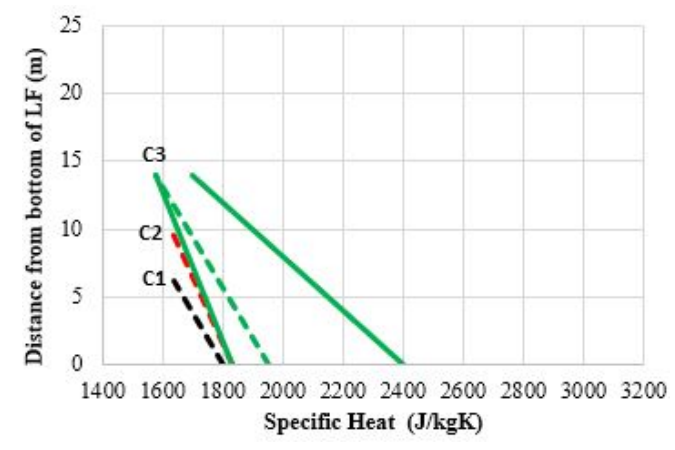

(f) Modified bounds enforced for period 3.

Figure 4.5: Upper and lower bounds specified during optimization of heat capacity for periods 1 through 3 (bounds displayed using solid lines, solutions displayed as dashed lines). 


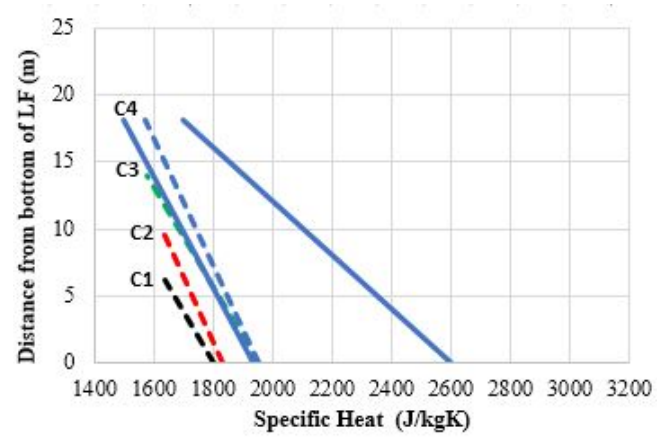

(a) Bounds enforced for period 4.

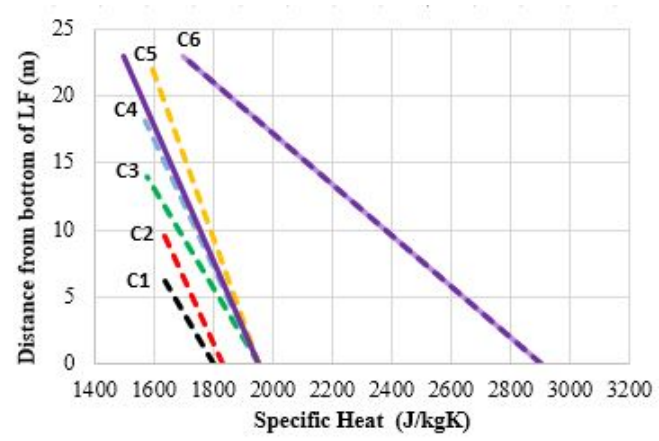

(c) Bounds enforced for period 6.

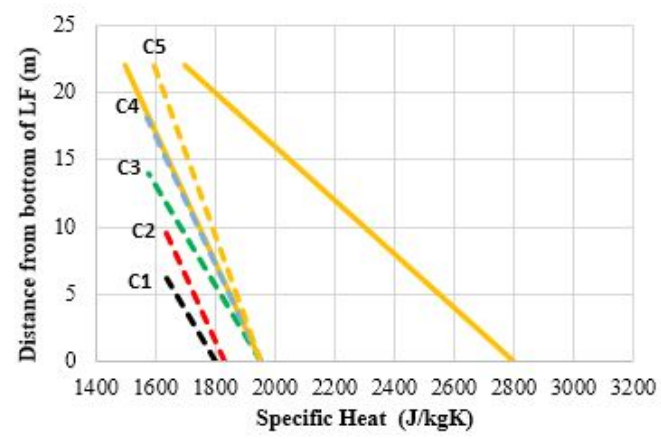

(b) Bounds enforced for period 5.

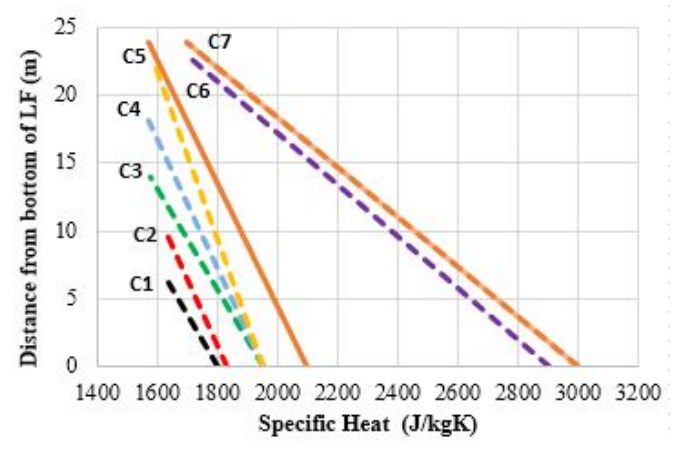

(d) Bounds enforced for period 7.

Figure 4.6: Upper and lower bounds specified during optimization of heat capacity for periods 4 through 7 (bounds displayed using solid lines, solutions displayed as dashed lines).

Megalla et al.(2016) used a specific heat value of $2100 \mathrm{~J} / \mathrm{kgK}$ for all simulation periods and did not vary the specific heat with depth. The same trends as thermal conductivity were assumed here, where specific heat increases with time and depth in the model.

For periods 1 through 5, the specific heat at the top of each waste lift varied between 1570 and $1637 \mathrm{~J} / \mathrm{kgK}$. For periods 1 through 3, the solutions touched the lower bound at the bottom of the landfill (Figures 4.5 (a), (c) and (e)). These periods were each optimized 
a second time by widening the lower boundary at the base of the landfill (Figures 4.5 (b), (d) and (f)). Optimizing a second time resulted in the solutions falling within the specified bounds rather than touching the lower boundary as the initial solution did.

For periods 4 and 5, the optimized specific heats tend towards the minimum value possible at the base of the landfill (Figures 4.6 (a) and (b)). This indicates the model was trying to simulate higher temperatures at bundle 3 . A lower specific heat value would increase the temperatures at bundle 3 .

The solutions to period 6 and 7 lie directly on the upper boundaries (Figures 4.6 (c) and (d)). The solver wants these periods to have higher specific heats. In period 6, the temperature at bundle 3 is overpredicted, and in period 7 all bundles are overpredicted. Higher specific heats would decrease the simulated temperatures and would provide better fits which is why the specific heat solutions reach the maximum values. Similar to thermal conductivity, the upper boundary of specific heat at the base of the landfill corresponds to the maximum value found in the literature. A non-linear relationship with depth or a two-layer model that allows for a greater specific heat for a bulk of the waste may improve the results.

\subsection{Heat Budget}

An energy or heat budget model was calculated for the Ste. Sophie landfill during each of the 7 simulation periods. The total energy budget can be described by the following 
equation:

$$
Q_{\text {sensible }}+Q_{\text {latent }}=Q_{\text {conv }}+Q_{\text {shortwave }}+Q_{\text {longwave }}+Q_{\text {cond }}+Q_{\text {aerobic }}+Q_{\text {anaerobic }}
$$

The analysis shows the amount of heat lost, gained or transferred throughout the landfill due to convection at the surface $\left(Q_{\text {conv }}\right)$, shortwave radiation at the surface $\left(Q_{\text {shortwave }}\right)$, longwave radiation at the surface $\left(Q_{\text {longwave }}\right)$, conduction at the base of the landfill $\left(Q_{\text {cond }}\right)$, aerobic biodegration $\left(Q_{\text {aerobic }}\right)$ and anaerobic biodegradation $\left(Q_{\text {anaerobic }}\right)$. The summation of all of these processes is the total heat generation, which is used as either sensible heat $\left(Q_{\text {sensible }}\right)$ to increase the waste temperature or latent heat $\left(Q_{\text {latent }}\right)$ to thaw frozen waste. The heat budget was calculated based on a $1 \mathrm{~m}^{2}$ column of waste, using the landfill volume as the control volume (this changed for each of the 7 simulation periods as waste lifts were added). The results of the analysis are shown in Table 4.4 . 
Table 4.4: Simulated heat budget results (number of simulation days listed in brackets under period number).

\begin{tabular}{|c|c|c|c|c|c|c|c|c|}
\hline $\begin{array}{l}\text { Heat Term } \\
\left(\mathrm{MJ} / \mathrm{m}^{2}\right)\end{array}$ & $\begin{array}{l}\text { Period } 1 \\
(331)\end{array}$ & $\begin{array}{c}\text { Period } 2 \\
\text { (45) }\end{array}$ & $\begin{array}{l}\text { Period } 3 \\
(207)\end{array}$ & $\begin{array}{l}\text { Period } 4 \\
(204)\end{array}$ & $\begin{array}{c}\text { Period } 5 \\
(594)\end{array}$ & $\begin{array}{l}\text { Period } 6 \\
(334)\end{array}$ & $\begin{array}{l}\text { Period } 7 \\
(822)\end{array}$ & $\begin{array}{l}\text { Total } \\
(2537)\end{array}$ \\
\hline $\begin{array}{l}\text { Convection at } \\
\text { surface }\end{array}$ & -2319 & -110 & -1457 & -1174 & -3870 & -2177 & -5079 & -16186 \\
\hline $\begin{array}{l}\text { Shortwave } \\
\text { radiation at } \\
\text { surface }\end{array}$ & 3738 & 153 & 2418 & 1250 & 5414 & 2682 & 6567 & 22222 \\
\hline $\begin{array}{l}\text { Longwave } \\
\text { radiation at } \\
\text { surface }\end{array}$ & -1345 & -52 & -811 & -468 & -1597 & -874 & -2010 & -7157 \\
\hline $\begin{array}{c}\text { Net heat } \\
\text { gained at } \\
\text { surface }\end{array}$ & 74 & -9 & 150 & -392 & -53 & -369 & -522 & -1121 \\
\hline $\begin{array}{l}\text { Conduction } \\
\text { from soil } \\
\text { below }\end{array}$ & 34 & 28 & 60 & 36 & 4 & -23 & -230 & -91 \\
\hline Aerobic & 0 & 0 & 0 & 518 & 203 & 30 & 0 & 751 \\
\hline Anaerobic & 3 & 0 & 0 & 19 & 355 & 605 & 1279 & 2261 \\
\hline $\begin{array}{l}\text { Net heat } \\
\text { gained }\end{array}$ & 3 & $\mathbf{0}$ & $\mathbf{0}$ & 537 & 558 & 635 & 1279 & 3012 \\
\hline Latent & 60 & 23 & 42 & 3 & 2 & 0 & 0 & 130 \\
\hline Sensible & 51 & -4 & 168 & 178 & 507 & 243 & 527 & 1670 \\
\hline Net heat lost & 111 & 19 & 210 & 181 & 509 & 243 & 527 & 1800 \\
\hline
\end{tabular}

At the surface, heat can be lost, gained or transferred due to convection, incoming solar radiation and net longwave radiation. These were calculated by integrating the respective heat fluxes over time. Heat is lost through convection and longwave radiation at the surface for all 7 periods. Conversely, heat is gained through shortwave radiation during all 7 periods. The resultant net heat flux at the surface was calculated for each period by summing 
these three modes of heat transfer. During period 1, heat was gained at the surface due to the incoming shortwave radiation and the cold temperature of the waste. During period 2, heat was lost at the surface due to the relatively low solar radiation. During this period the ambient temperature was lower than the surface waste temperatures as it took place in the winter months from December 2011 to January 2012. Period 3 took place from January 2011 to August 2011, primarily in spring and summer. Therefore, heat was gained at the surface. Conversely, period 4 took place from August 2011 to March 2012, primarily in fall and winter and therefore heat was lost at the surface. Further, during period 4 a significant amount of aerobic heat was generated near the surface of the landfill. Period 5 took place from March 2012 to November 2013. Heat was again lost at the surface as the heat generated within the landfill resulted in surface waste temperatures which were greater than the ambient temperatures. Periods 6 and 7 also resulted in a net loss of heat at the surface for the same reasons. It should be noted that snow cover would also affect the heat gained, lost or transferred at the surface, however this was not accounted for in the model. Snow cover would increase the albedo at the surface of the landfill, and would decrease the solar radiation absorbed at the surface. Further, snow would insulate the surface of the landfill, and would decrease the heat transferred by convection and longwave radiation.

At the base of the landfill, heat gained, lost or transferred due to conduction was calculated by determining the thermal gradient between the base of the landfill and a node located at $0.1 \mathrm{~m}$ from the base. Heat was gained at the base of the landfill during periods 1 through 5 as the base temperature was greater than the waste temperature. However, during periods 6 and 7 the waste temperatures were greater than the base temperature, resulting in a loss of heat. 
Aerobic heat generation was assumed to only occur in the top metre of waste for periods 4, 5 and 6 where field data indicated oxygen was present in the waste. As such, all the heat lost at the surface of the landfill during periods 4,5 and 6 is likely heat generated via aerobic activity. The aerobic heat generation was calculated using an empirical formula (Eq. 2.13). The aerobic heat was tracked in the model and integrated over time to determine the overall aerobic heat generated for each period. Similarly, anaerobic heat generation was tracked and integrated in the model based on the methods of Hanson et al. (2013) (Chapter 2.5). Waste lifts 1, 2 and 3 (corresponding to periods 1, 2 and 3) were all placed under cold winter conditions, where temperatures were not warm enough for aerobic or anaerobic heat generation. Therefore, only limited heat was generated during these periods. During periods 4, 5 and 6, aerobic and anaerobic activity resulted in heat gain throughout the landfill. Aerobic activity was not assumed to occur during period 7 as field data did not indicate the presence of oxygen. Anaerobic activity continued during period 7. Cumulatively, aerobic heat generation resulted in $751 \mathrm{MJ} / \mathrm{m}^{2}(25 \%)$ of heat generated and anaerobic heat generation resulted in $2261 \mathrm{MJ} / \mathrm{m}^{2}(75 \%)$ of heat generated. This ratio is significant as it highlights the major contribution of anaerobic heat generation throughout the life of the landfill. Previous work by Lefebvre et al. (2000) assumed that within the first 160 days of waste placement aerobic reactions accounted for $97 \%$ of the heat generated in a landfill. Similarly, to study the initial temperature rises observed in MSW, Lanini et al. (2001) only considered aerobic heat generation because it was assumed that anaerobic biodegradation was negligible in the short term. However, the results presented herein show that the anaerobic contribution will continue to increase as time progresses, and that anaerobic heat generation plays a significant role in warming the waste. 
Finally, latent and sensible heat were calculated. If the transfer of energy occurring is associated with a phase change (such as changing from solid to liquid), it is referred to as latent heat. Conversely, sensible heat is the transfer of energy without a phase change. Sensible heat was calculated using the following equation:

$$
Q_{\text {sensible }}=m C \Delta T
$$

where $m$ is the mass of waste $(\mathrm{kg}), C$ is the specific heat, and $\Delta T$ is the difference between the average initial temperature and average final temperature for the entire domain for each period. Using the assumption of energy conservation, it was possible to determine the latent heat using the heat budget equation as follows:

$$
Q_{\text {latent }}=Q_{\text {conv }}+Q_{\text {shortwave }}+Q_{\text {longwave }}+Q_{\text {cond }}+Q_{\text {aerobic }}+Q_{\text {anaerobic }}-Q_{\text {sensible }}
$$

To verify the heat budget equation, the latent heat required to thaw the first three waste lifts (all placed under frozen conditions) was calculated, similar to the calculation for sensible heat. The total depth of the first three waste lifts is $13.94 \mathrm{~m}$. Using the latent heat term of $10 \mathrm{~kJ} / \mathrm{kgK}$ (presented in Section 4.4.1), approximately $130 \mathrm{MJ} / \mathrm{m}^{2}$ of heat is required to thaw the frozen waste, confirming Eq. 4.8 does provide a reasonable energy balance. There was a net increase in heat storage during all periods except for period 2 . This is indicated by positive sensible heat values for all periods except for the second. The temperature of the domain decreased during the second period as this was a short simulation period during December 2010 and January 2011. Latent heat was required 
to thaw the frozen waste even into the fifth period, demonstrating that waste can remain frozen for upwards of 3 years . Latent heat accounted for $130 \mathrm{MJ} / \mathrm{m}^{2}$ of heat stored in the waste, and sensible heat accounted for $1670 \mathrm{MJ} / \mathrm{m}^{2}$. The result is a net loss of heat from the landfill over the entire simulation period $\left(1212 \mathrm{MJ} / \mathrm{m}^{2}\right)$ which represents $41 \%$ of the heat generated within the landfill due to biodegradation.

\subsection{Summary}

The modelling presented in this chapter illustrates that the heat or energy budget of a landfill is a complex system to assess. As more field data were collected for the Ste. Sophie landfill, model parameters were further calibrated to improve the simulated fit. With this, the understanding of the relative importance of various parameters and processes is further understood. The specific heat (and latent heat for frozen waste) and thermal conductivity store and transfer heat generated by aerobic and anaerobic biodegradation, which in turn impact the waste temperature and settlement with time. The optimization of the thermal conductivity and specific heat support the assumption that these parameters should increase with depth and time, as assumed by Megalla et al.(2016). In addition, this study also allowed the specific heat to vary with depth in a landfill, which better reflects conditions expected in the field. Extending the simulation of Megalla et al. (2016) and optimizing the thermal conductivity and specific heat still resulted in simulated temperatures higher than those measured in the field during the last 2 to 3 years of simulation. To improve the model fit at later times, the latent heat and anaerobic heat generation rate 
were decreased. A heat budget was calculated for the vertical waste profile simulated, and it was found that after 7 years the aerobic heat generation accounted for $25 \%$ of the total heat generated, compared to $75 \%$ generated by anaerobic biodegradation. Several studies in the literature concluded that the aerobic heat generation was the primary heat source, raising temperatures to optimal conditions for biodegradation and methane generation. However, the aerobic to anaerobic heat generation ratio calculated in this thesis is significant as it highlights the major contribution of anaerobic heat generation throughout the life of the landfill. Of the total heat generated by aerobic and anaerobic biodegradation, $4 \%$ was needed to thaw the frozen waste, $55 \%$ was stored as sensible heat and increased the waste temperatures. The remaining $41 \%$ was lost to the surrounding environment: $38 \%$ lost through longwave radiation and convection at the surface, and 3\% lost through conduction at the base of the landfill. Aerobic heat generation was assumed to only occur in the top metre of waste for periods 4,5 and 6 . As such, all the heat lost at the surface of the landfill during these periods is likely heat generated via aerobic activity. This loss of aerobic heat further highlights the significant contribution of anaerobic heat generation throughout the 7 year simulation period. 


\section{Chapter 5}

\section{Temperature-Dependent}

\section{Biodegradation-Induced Settlement Model}

\subsection{Introduction}

At the Ste. Sophie landfill, waste lifts 1, 2 and 3 were placed under cold winter conditions (below $0{ }^{\circ} \mathrm{C}$ ), whereas waste lifts 4 and 5 were placed under warm conditions. Therefore, Megalla et al. (2016) only considered time-dependent biodegradation-induced settlement for waste lifts 4 and 5. The temperatures of waste lifts 1,2 and 3 were not initially warm enough to support anaerobic biodegradation, and therefore time-dependent biodegradation-induced settlement was not applied to these waste lifts. However, over time waste lifts 1, 2 and 3 do increase to temperatures favourable for anaerobic biodegradation to take place. Therefore, not including biodegradation-induced settlement for these waste lifts does not provide an accurate representation of the overall settlement occurring. Instead of the time-dependent biodegradation-induced settlement term proposed by Marques et al. (2003) and used by Megalla et al. (2016) in waste lifts 4 and 5, a temperaturedependent biodegradation-induced settlement term was proposed and developed by the author of this thesis and applied to all waste lifts, regardless of initial conditions. 


\subsection{Methodology}

Van Geel \& Murray (2015) developed a settlement model for the Ste. Sophie landfill based on the model proposed by Marques et al. (2003). As explained in Chapter 2.4, Marques et al. (2003) presented a settlement model based on three components: an instantaneous or primary settlement component due to an applied load $\left(\epsilon_{P}\right)$, a secondary settlement component due to mechanical creep $\left(\epsilon_{C}\right)$, and a biological decomposition settlement component $\left(\epsilon_{B}\right)$ (Eqs. 2.16, 2.17) and 2.18, respectively). Van Geel \& Murray (2015) determined the parameters for these settlement equations using regression analysis, so that it was possible to use this model to simulate the settlement at Ste. Sophie. The regressed parameters are shown in Table 5.1 for the odd numbered bundles. The first waste lift uses regressed parameters termed 'fluff' parameters. In the first waste lift, waste was placed on top of the leachate collection system as a single 1- $1.5 \mathrm{~m}$ thick uncompacted layer. Subsequent waste layers were placed in approximately 0.3-0.4 m layers. Each of these subsequent layers were compacted using a sheepsfoot roller, until the first lift was complete. Van Geel \& Murray (2015) assumed that this compaction series would impact the settlement of the first waste lift, and therefore different values of $b$ and $c$ were assigned, termed $b_{f u f f}$ and $c_{\text {fluff }}$. 
Table 5.1: Best fit Marques et al. (2003) parameters determined by Van Geel \& Murray (2015).

\begin{tabular}{|c|c|}
\hline Parameter & Regressed Value \\
\hline \hline$b_{\text {fluff }}\left(\mathrm{kPa}^{-1}\right)$ & 0.00432 \\
$c_{\text {fluff }}\left(\mathrm{day}^{-1}\right)$ & 0.0142 \\
$C^{\prime}{ }_{C}$ & 0.0376 \\
$b\left(\mathrm{kPa}^{-1}\right)$ & 0.00119 \\
$c\left(\mathrm{day}^{-1}\right)$ & 0.0208 \\
$E_{D G}$ & 0.112 \\
$d\left(\mathrm{day}^{-1}\right)$ & 0.00406 \\
$\sum s^{2}$ & 2.08 \\
$R^{2}$ & 0.990 \\
\hline \hline
\end{tabular}

To improve the simulation of the temperature data in the field, Megalla et al. (2016) implemented the settlement model used in Van Geel \& Murray (2015) into the COMSOL heat budget model. This allowed for a better comparison between simulated and field data because the model could account for settlement and the fact that the instrument bundles are getting closer together over time, which impacts the thermal gradients and corresponding heat flux. The model could also track the location of the instrument bundle and compare the value simulated at this location to the value measured in the field. This was difficult to do without properly accounting for settlement.

To implement settlement in COMSOL Multiphysics, a Moving Mesh interface was employed. At the start of each simulation period, an initial displacement is used to represent the instantaneous settlement due to an applied load, according to the following equation: 


$$
\epsilon_{P}=C_{C}^{\prime} \log \left(\frac{\Delta \sigma+\sigma_{0}}{\sigma_{0}}\right)
$$

Where $C_{C}^{\prime}$ is the compression ratio, $\sigma_{0}$ is the initial vertical stress, $\Delta \sigma$ is the change in vertical stress.

The time-dependent settlement terms in the Marques et al. (2003) model (settlement due to mechanical creep and biological decomposition) were implemented using prescribed mesh velocities. Nodes were assigned to the top of each waste lift, and the mesh was deformed according to the derivative of the mechanical creep and biological settlement equations. The derivative represents the velocity at which each of the waste lifts decrease in height. Therefore, the rate of settlement due to mechanical creep and biological decomposition were represented by the following equations by Megalla et al. (2016):

$$
v_{\epsilon_{\mathrm{C}+\mathrm{B}}}=\frac{d}{d t} H_{0} b \Delta \sigma\left(1-e^{-c t^{\prime}}\right)+\frac{d}{d t} H_{0} E_{D G}\left(1-e^{-d t^{\prime \prime}}\right)
$$

Where $b$ is the coefficient of mechanical creep, $c$ is the rate constant for mechanical creep, $t^{\prime}$ is the time since load was applied, $E_{D G}$ is the total amount of strain or settlement that can occur due to biological decomposition, $d$ is the rate constant for biological decomposition, and $t^{\prime \prime}$ is the time since the waste was placed in the landfill.

Megalla et al. (2016) only considered time-dependent biodegradation-induced settlement for the fourth and fifth waste lifts of the Ste. Sophie landfill because the temperatures of the first, second, and third waste lifts were not initially warm enough for anaerobic biodegradation to occur. However, over time waste lifts one through three do increase 
to temperatures favourable for anaerobic biodegradation to take place. Therefore, not including biodegradation-induced settlement for waste lifts one, two and three at later times does not provide an accurate representation of the overall settlement occurring. Instead of the time-dependent biodegradation-induced settlement term proposed by Marques et al. (2003) and used by Megalla et al. (2016) in the fourth and fifth waste lifts, a temperaturedependent biodegradation-induced settlement term was proposed and developed.

It is widely recognized that biodegradation rates are temperature-dependent, as are corresponding heat and gas generation rates. Hanson et al. (2013) proposed temperaturedependent heat generation rates, which were incorporated into the modelling efforts of Megalla et al. (2016). It was proposed herein that the temperature-dependent biodegradation-induced settlement could be linked to the heat generation model. The model proposed by Hanson et al. (2013) and incorporated by Megalla et al. (2016) tracked the expended energy with time and assumed a fixed amount of total expended energy for the given waste. Here it was assumed that the total biodegradation-induced settlement $\left(\mathrm{E}_{\mathrm{DG}}\right)$ is achieved when the total expended energy is exhausted and biodegradation is complete. Likewise, it was assumed that if 50\% of the expended energy was exhausted or released, then $50 \%$ of the biodegradation-induced settlement should have occurred.

The temperature-dependent heat generation term proposed by Hanson et al. (2013) reflects a typical landfill gas generation curve. As the temperature in the waste increases, the heat generation rate increases (Figure 5.1 a). By integrating the heat generation vs. time plot, the heat generation becomes a function of expended energy rather than time (refer to Chapter 2.3.7 for more detail). Hanson et al. (2013) then developed a family of curves for 
temperatures between 0 and $80^{\circ} \mathrm{C}$, expressed as a function of expended energy (Figure 5.1p). It then becomes possible to track the position on each curve as the temperature of the waste is changing. This effectively allows the simulation of waste degradation as the temperature changes. It also makes it possible to estimate the amount of biodegradationinduced settlement that occurs as the temperature of the waste is changing.

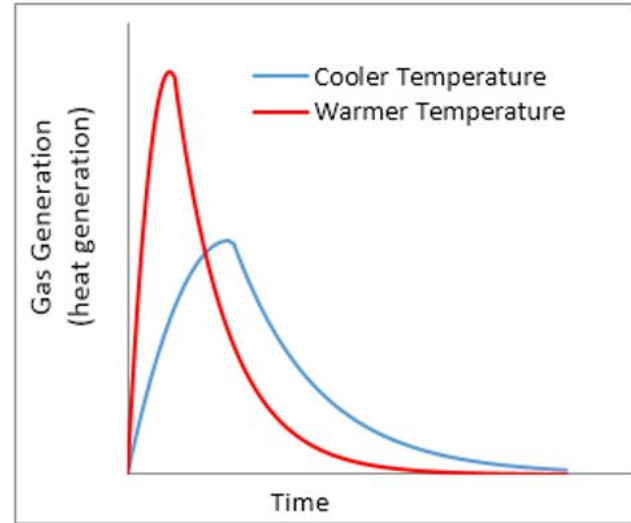

(a) Time-dependent heat generation curve.

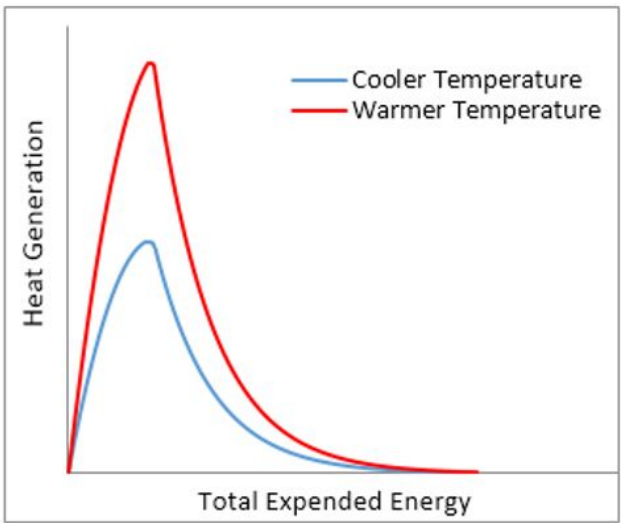

(b) Normalized heat generation curves.

Figure 5.1: Conceptual plots to demonstrate temperature-dependent heat generation model proposed by Hanson et al. (2013).

As explained in Chapter 2.3.7, Megalla et al. (2016) applied the temperature-dependent heat generation relationship into the model in order to simulate the anaerobic heat generation occurring within the Ste. Sophie landfill. The 3D relationship between heat generated, temperature and expended energy applied by Megalla et al. (2016) (Figure 2.4) can also be used to predict the amount of biodegradation-induced settlement occurring. The ratio of expended energy to total expended energy was directly applied to the settlement model by changing the Marques et al. (2003) time-dependent biodegradation-induced settlement 
term into a temperature-dependent biodegradation-induced settlement term, as follows:

$$
\epsilon_{B}=E_{D G}\left(\frac{\text { ExpendedEnergy }}{\text { TotalExpendedEnergy }}\right)
$$

Total energy expended is a fixed value based on waste composition. Hanson et al. (2013) determined the heat generation parameters, including the total expended energy, for two waste cells at a landfill in Michigan, USA, by nonlinear regression analysis when fitting their model to field data. Megalla et al. (2016) and this thesis used the values from Hanson et al. (2013) that resulted in the best fit to the Ste. Sophie temperature data (Cell D; Table 2.3. The total energy expended for Cell D was $104 \mathrm{MJ} / \mathrm{m}^{3}$. Figure 5.2 shows the modelled expended energies at each of the bundles over time for the optimized simulation presented in Chapter 4

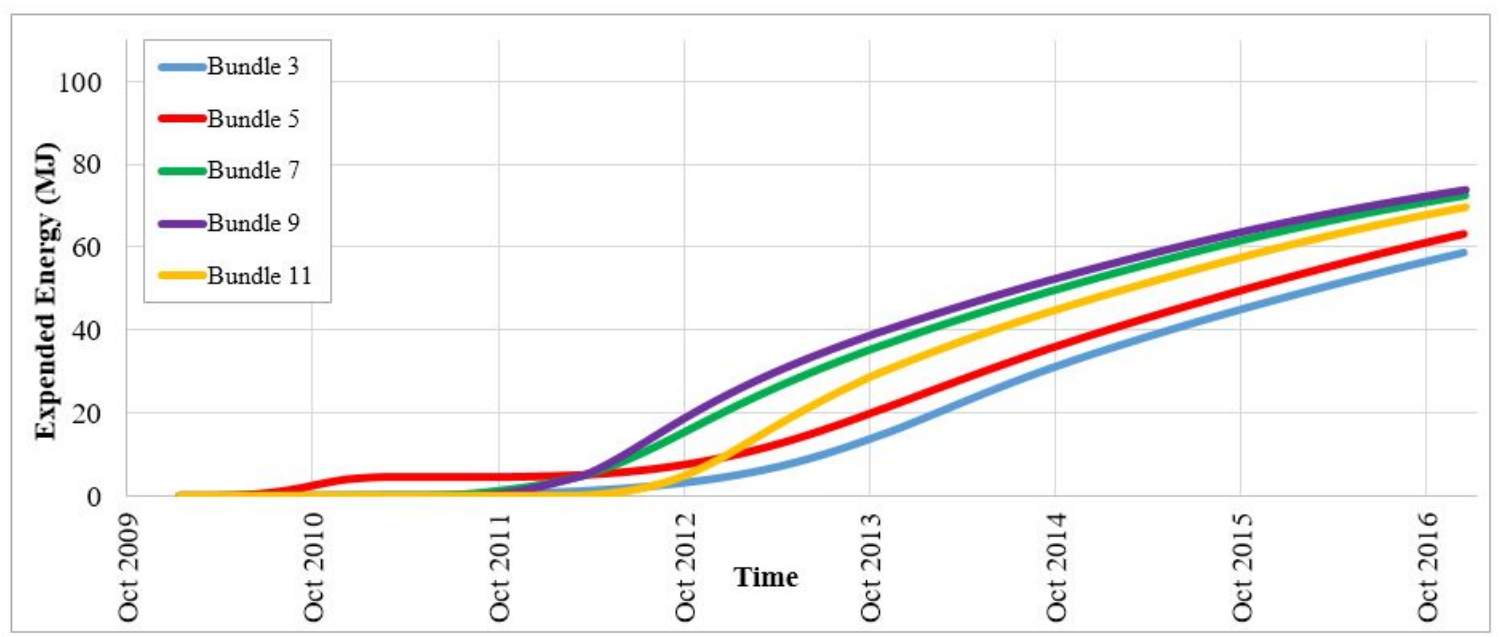

Figure 5.2: Simulated expended energy as a function of time for all bundles.

The temperature-dependent biodegradation-induced settlement term (Eq. 5.3) was 
added as a prescribed mesh velocity at the top of each lift similar to the implementation of the mechanical creep term. By taking the derivative of the expended energy with time, it is possible to track the settlement due to biological decomposition (Eq 5.3).

$$
v_{H_{\mathrm{B}}}=H_{0} E_{D G}\left(\frac{\frac{d(\text { ExpendedEnergy })}{d t}}{\text { TotalExpendedEnergy }}\right)
$$

The modified Marques et al. (2003) predicted settlement model, which uses the new temperature-dependent biodegradation-induced settlement term, will be referred to as the TDBI settlement model (as opposed to the time-dependent biodegradation-induced settlement term presented by Marques et al. (2003) and used by Megalla et al. (2016) to model the settlement of the fourth and fifth waste lifts of the Ste. Sophie landfill). The inclusion of this model should improve the predicted biodegradation-induced settlement that will occur as the temperature of the waste lifts increases. This is especially true for waste lifts 1 through 3.

\subsection{Results and Discussion}

Settlement at the Ste. Sophie landfill was modelled for each of the odd numbered bundles using both the time-dependent biodegradation-induced settlement used by Megalla et al. (2016) which assumes zero biodegradation-induced settlement in lifts 1 through 3 , and the TDBI model. Figures 5.3 through 5.7 present the field data in comparison to the Megalla et al. (2016) model and the TDBI model. Timing of the 7 waste lift placements are shown 
by vertical grey bars on each of the plots. The segments of time between each waste lift placement are referred to as periods 1 through 7. It is important to note that Van Geel $\&$ Murray (2015) used field data only up to November 2013 to determine the regressed Marques et al. (2003) parameters. While the parameters from Van Geel \& Murray (2015) are used here, the settlement is calculated through to December 2016. Recalibration of the Marques et al. (2003) parameters for the longer period of time may have provided a better fit. However, the model still would not be able to account for the impact of changing temperatures on biodegradation-induced settlement.

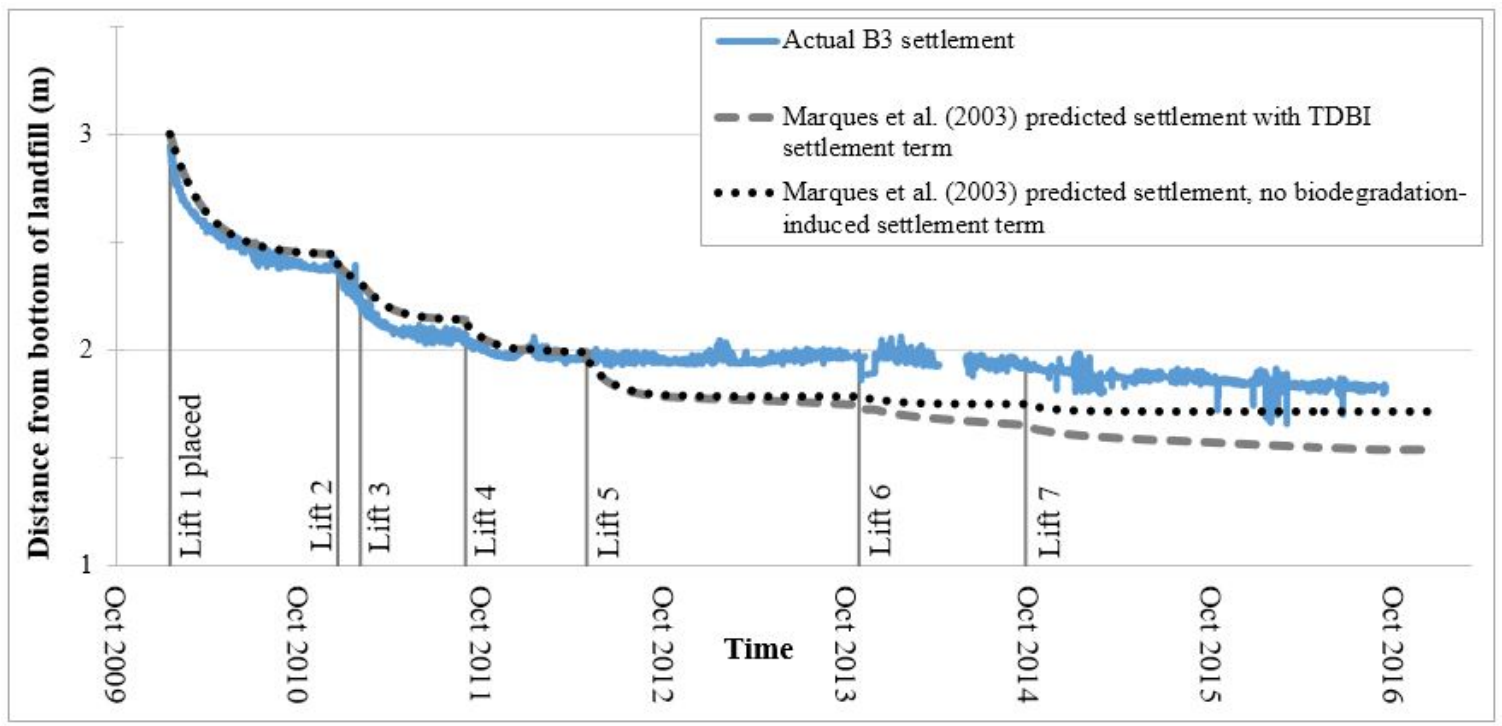

Figure 5.3: Simulated temperature-dependent biodegradation-induced settlement at bundle 3 . 


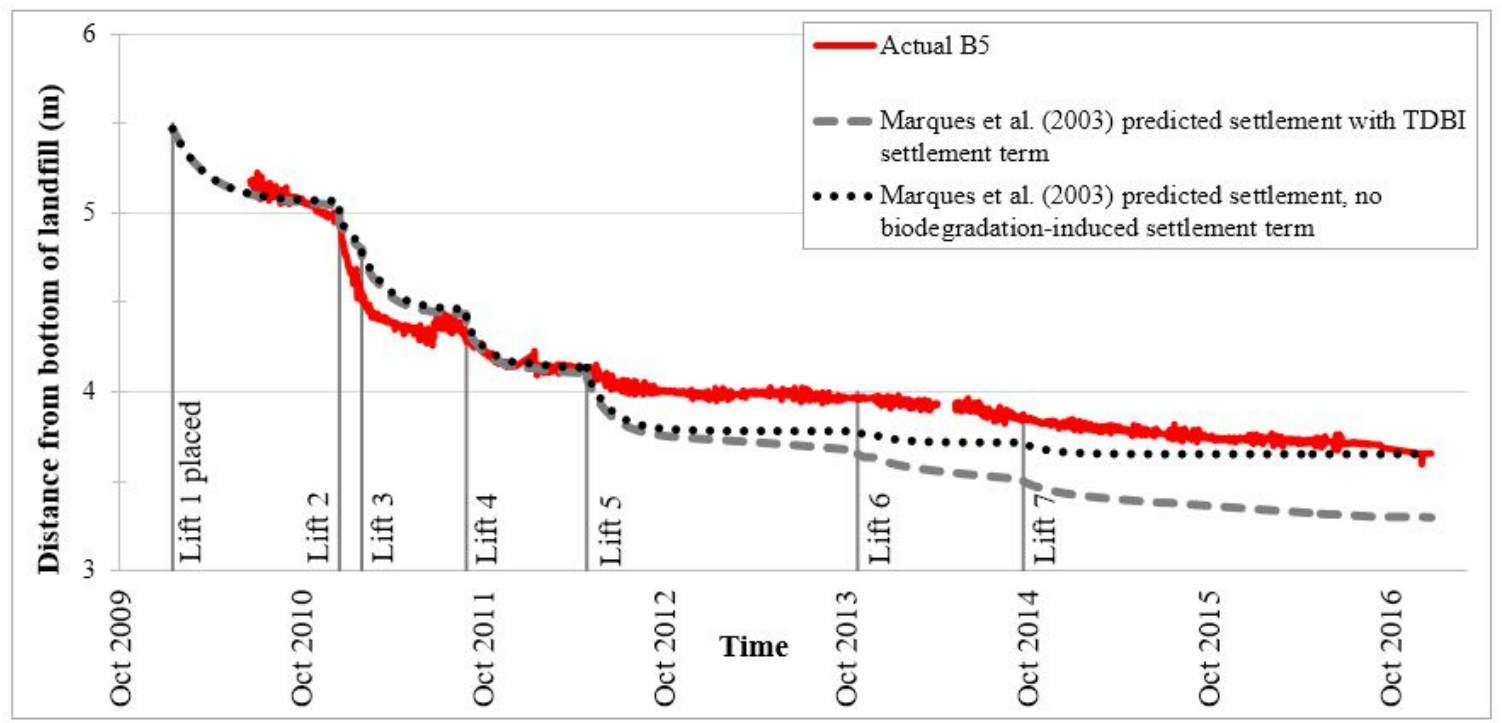

Figure 5.4: Simulated temperature-dependent biodegradation-induced settlement at bundle 5 .

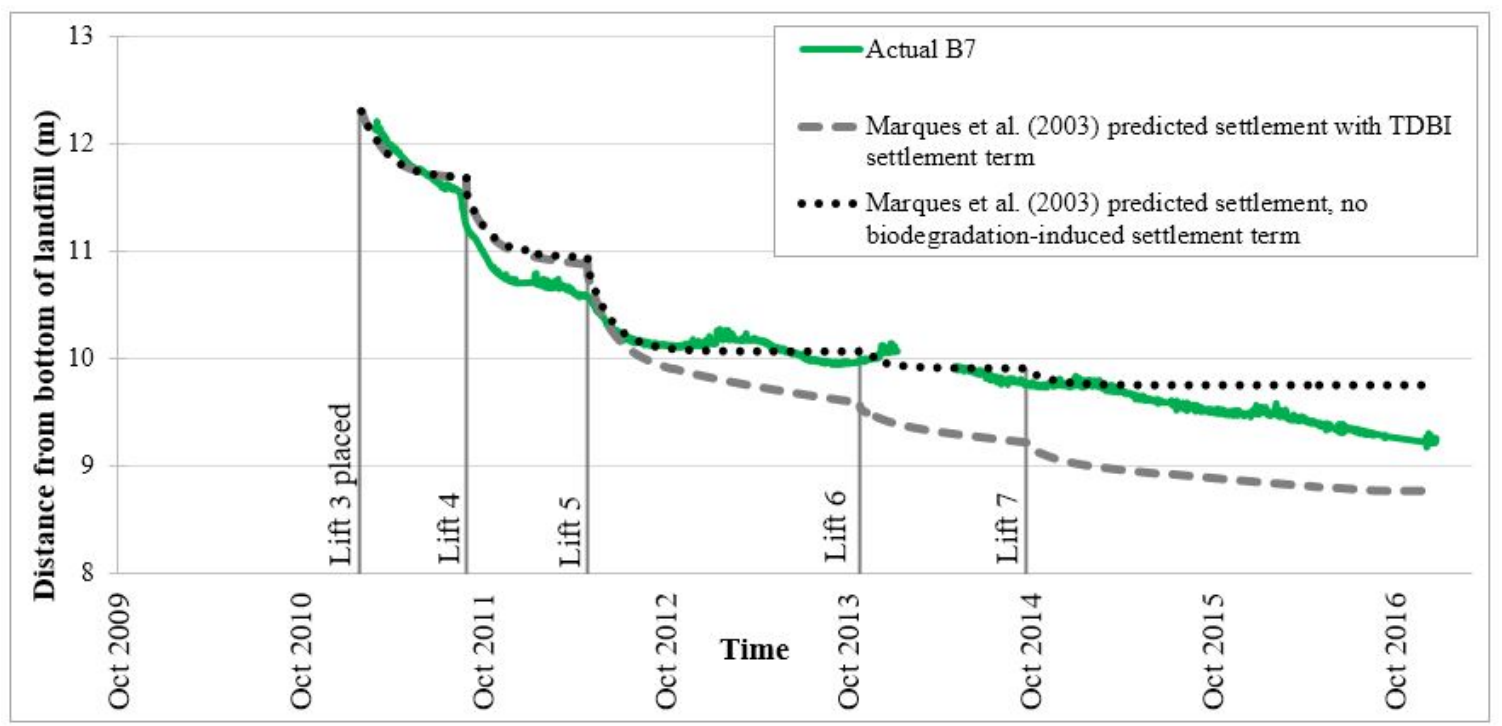

Figure 5.5: Simulated temperature-dependent biodegradation-induced settlement at bundle 7 . 


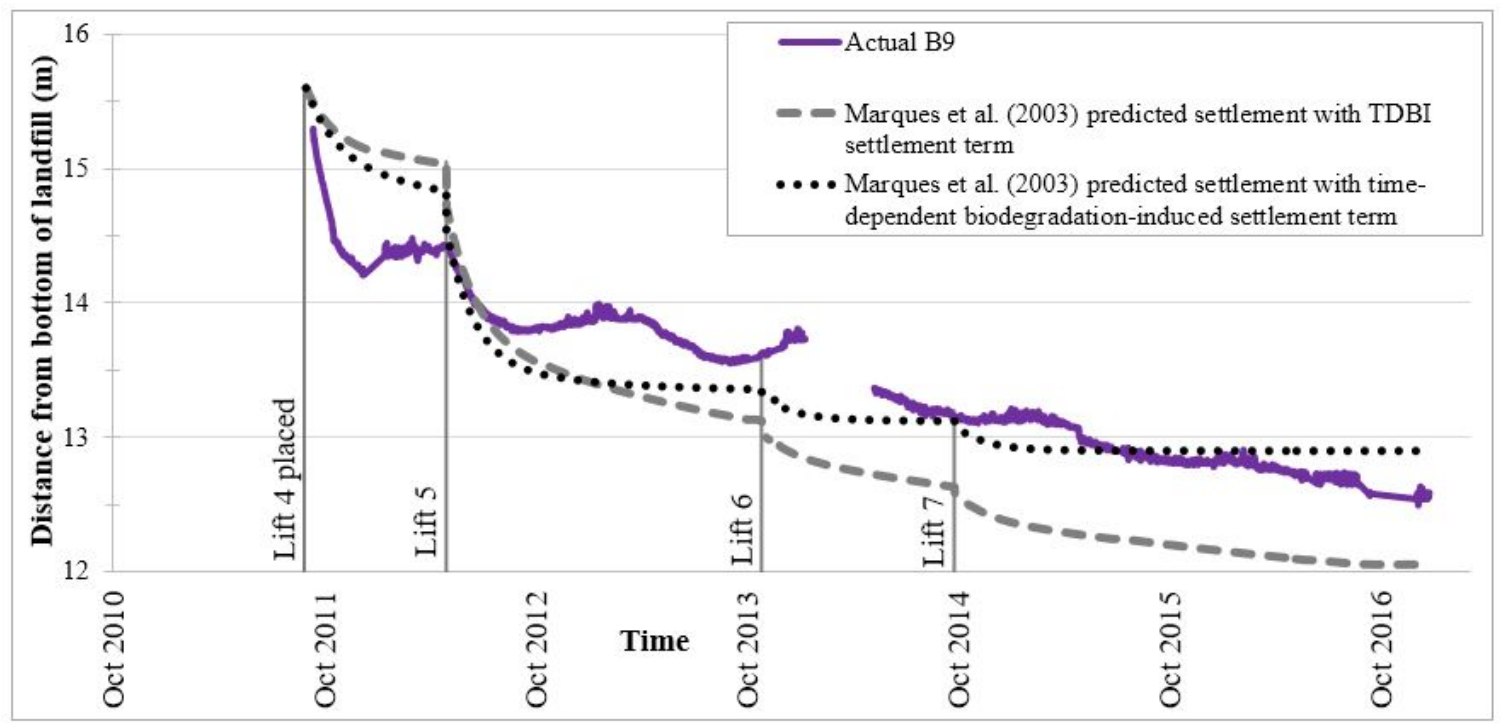

Figure 5.6: Simulated temperature-dependent biodegradation-induced settlement at bundle 9 .

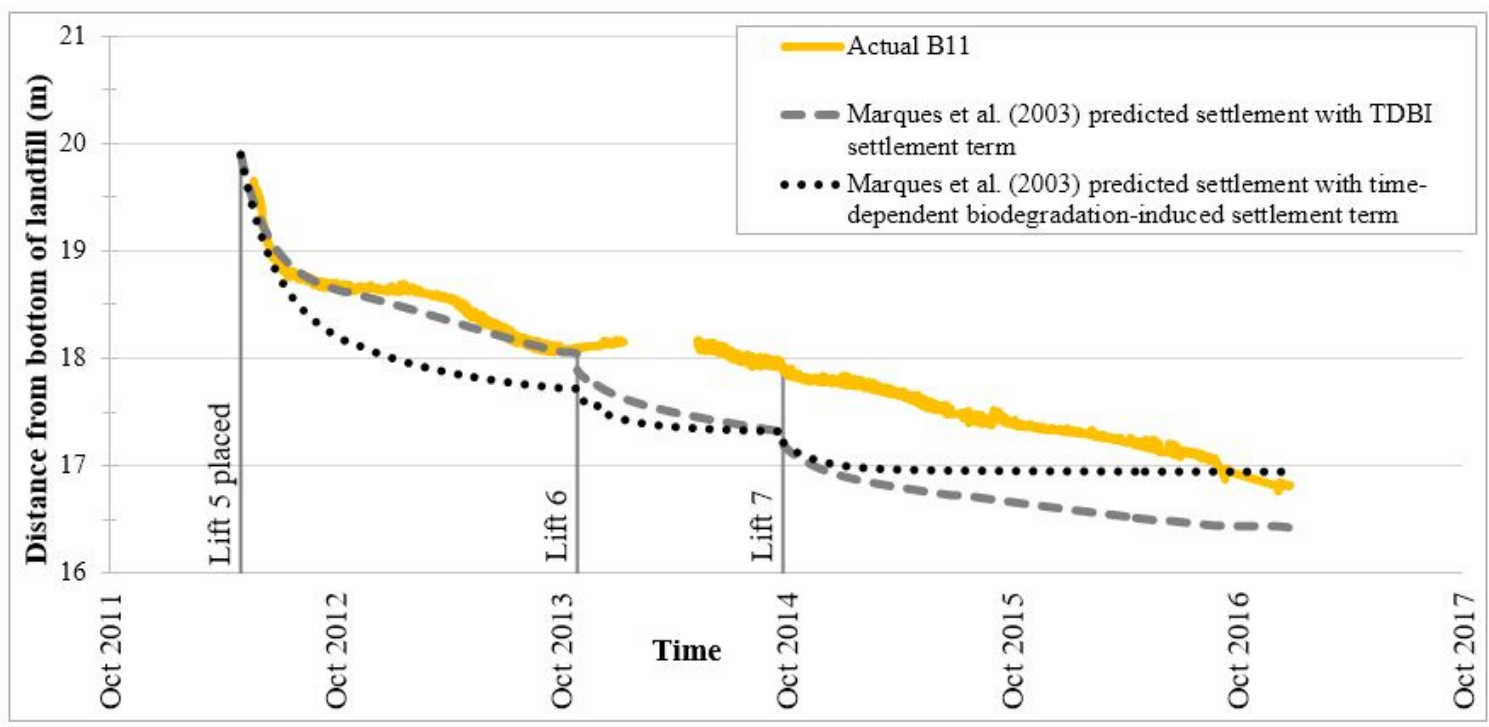

Figure 5.7: Simulated temperature-dependent biodegradation-induced settlement at bundle 11 . 
Figures 5.3, 5.4 and 5.5 compare the predicted TDBI settlement with the Marques et al. (2003) model without biodegradation-induced settlement for bundles 3, 5 and 7, respectively. Bundles 3 and 5 are located in waste lift 1 , and bundle 7 is located in waste lift 3. Recall that for Megalla et al. (2016), waste lifts 1, 2 and 3 did not include the timedependent biodegradation-induced settlement term from the Marques et al. (2003) model because temperatures were not initially warm enough to have anaerobic biodegradation occurring. Therefore, bundles 3, 5 and 7 are not modelled using the Marques et al. (2003) time-dependent biodegradation-induced settlement term.

For bundle 3 (Figure 5.3), both models predict similar settlements for periods 1 through 4 as these were the periods used by Van Geel \& Murray (2015) to estimate the Marques et al. (2003) parameters. Just before the placement of waste lift 6, around October 2013, the TDBI model begins to predict more settlement than the Marques et al. (2003) model without time-dependent biodegradation-induced settlement. Referring back to the optimized modelled temperature results (Figure 4.1), it can be noted that the temperatures start to exceed $10{ }^{\circ} \mathrm{C}$ around that time. As the temperatures rise at bundle 3 , the rate of anaerobic biodegradation is increasing, and therefore TDBI settlement also starts to occur, which is why the two models begin to differ in their predictions at this point in time. Between October 2013 and October 2016, the field data indicate an increase in the rate of settlement. The Marques et al. (2003) model results without time-dependent biodegradation-induced settlement do not indicate this increase in settlement rate. However, the TDBI model is able to simulate this rate of increase. A similar trend is noted for bundle 5 (Figure 5.4) and bundle 7 (Figure 5.5). 
Bundles 3, 5 and 7 all overpredict settlement in the fifth, sixth and seventh periods because Van Geel \& Murray (2015) only used data up to October 2013 to determine the regressed Marques et al. (2003) parameters. A recalibration of the model using all of the data through to December 2016 would yield a better fit; however, it would not properly account for the increasing biodegradation-induced settlement rates that occur with increasing temperature. What is important to note is that the TDBI settlement model picks up the trend better than the Marques et al. (2003) model without time-dependent biodegradationinduced settlement. Over time, the settlement at each of these bundles slowly continues. The Marques et al. (2003) model without time-dependent biodegradation-induced settlement levels out or plateaus over time and does not pick up this trend. The TDBI settlement model accounts for the delayed temperature-dependent biodegradation-induced settlement which is occurring at these bundles.

Figures 5.6 and 5.7 compare the predicted TDBI settlement with the Marques et al. (2003) model, including the time-dependent biodegradation-induced settlement, for bundles 9 (located in waste lift 4) and 11 (located in waste lift 5), respectively. Waste lifts 4 and 5 were placed under conditions warm enough for anaerobic biodegradation to occur, therefore the Marques et al. (2003) predicted settlement does include the time-dependent biodegradation-induced settlement term.

At early times at both bundles 9 and 11, the Marques et al. (2003) model with timedependent biodegradation-induced settlement predicts more settlement than the TDBI settlement model. However, similar to bundles 3, 5 and 7, the TDBI model simulates the trend of the actual data in the long term. It is important to note that Van Geel \& Murray (2015) 
included the time-dependent biodegradation-induced settlement to improve the model fit to the data up to October 2013, which is a relatively short time for bundles 9 and 11 . The time-dependent biodegradation-induced settlement term is an exponential function and it is clear from the plots that when the timeframe is extended to December 2016, the regressed exponential function parameters of Van Geel \& Murray (2015) predict a more rapid biodegradation-induced settlement. This is evidenced by the rapid initial settlement which quickly plateaus, indicating that the biodegradation-induced settlement occurs over a shorter period of time. However, the field data indicate that the biodegradation-induced settlement is occurring over a longer period of time, and the TDBI settlement is simulating this trend.

Finally, it should be noted that the settlement is overpredicted at all 5 bundles once lift 5 has been placed. There are two reasons for this. First, the Marques et al. (2003) model parameters were fit to the settlement data early in the settlement history of the waste (up to October 2013). The model fit could be improved by recalibrating the model using all data up to December 2016. Second, the instantaneous primary settlement term of Marques et al. (2003) (Eq. 5.1) does not account for the stress history of the waste. As such, a second lift of $30 \mathrm{kPa}$, for example, generates the same instantaneous compression as a fifth lift of $30 \mathrm{kPa}$ placed two years later.

\subsection{Summary}

Megalla et al. (2016) initially incorporated settlement into their Ste. Sophie heat budget 
model using the equations proposed by Marques et al. (2003) and the regressed parameters presented in Van Geel \& Murray (2015). However, the Marques et al. (2003) model cannot simulate a temperature-dependent biodegradation-induced settlement process as it does not address the change in temperature, and hence biodegradation rate, over time. A TDBI settlement model was proposed, and was found to be an effective way to incorporate temperature-dependent biodegradation-induced settlement provided waste temperature is either simulated or measured with time. The TDBI settlement model was able to simulate the trends in temperature data observed in the field. This is the only proposed landfill settlement model which links biodegradation-induced settlement to waste temperatures and the corresponding heat generation rate, which reflects the gas generation and biodegradation rates. The TDBI settlement model allows a better simulation of the biodegradationinduced settlement as the waste transitions from low temperatures, at which degradation is negligible, to warm temperatures approaching optimal conditions for anaerobic biodegradation. 


\section{Chapter 6}

\section{Simulation of Strategic Waste Lift Placement}

At the Ste. Sophie landfill, waste remained frozen for two years as a result of waste placement temperatures. Waste lifts 1, 2 and 3 were all placed under cold, winter conditions. Waste acts as an insulator, due to its low thermal conductivity and high latent heat of fusion. As such, each successive cold waste layer makes it more difficult for heat to be transferred throughout the landfill. Frozen waste upon placement means biodegradation is delayed until the waste thaws and temperatures rise to those favorable for anaerobic biodegradation, and therefore biodegradation-induced settlement is also delayed, and waste stabilization takes longer to achieve. In order to study the effects of optimally placing waste lifts throughout the year to maximize airspace utilization, a simulation was completed whereby waste lift 2 was placed in July 2010, rather than in December 2010. The implementation of expended energy and the TDBI settlement model allowed this comparison to be made. Figure 6.1 presents the two modelled temperature results: the actual waste lift sequence model, and the warm lift 2 sequence model. Placing waste lift 2 during the summer instead of the winter resulted in increased temperatures across the entire domain. 


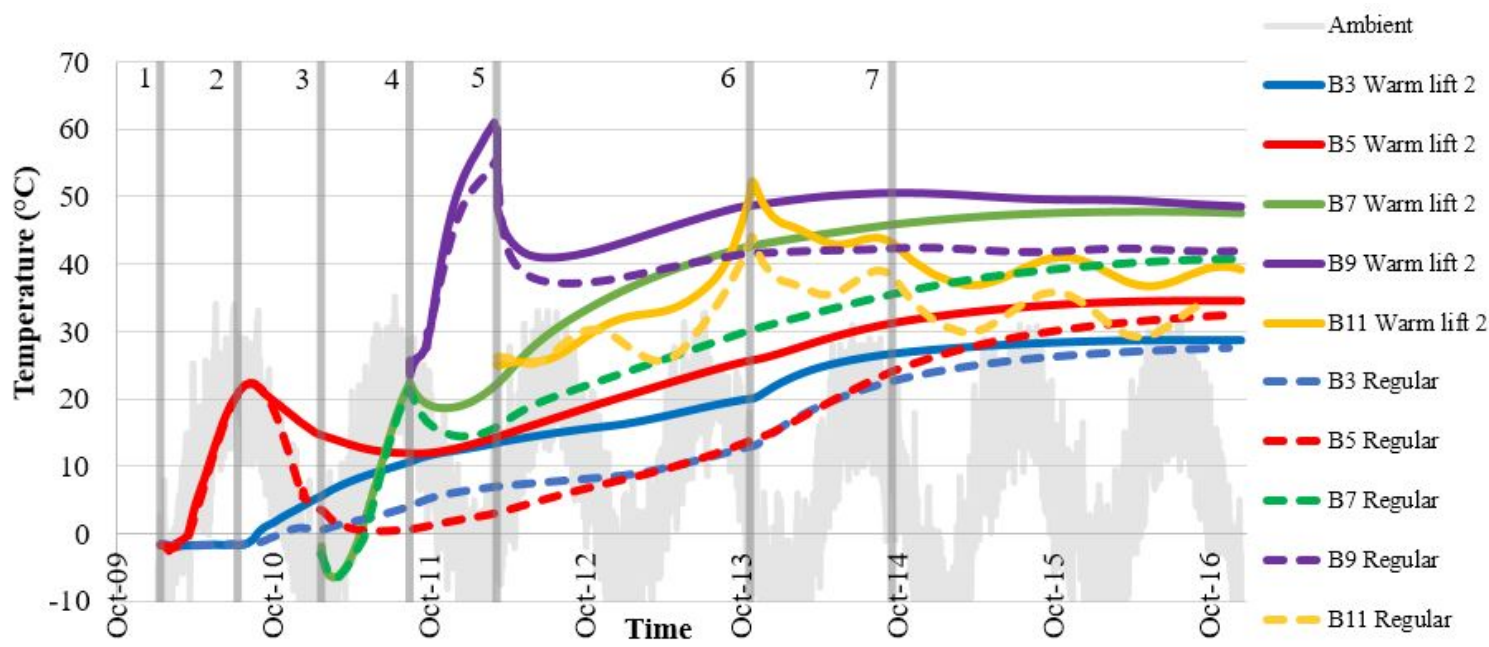

Figure 6.1: Comparison of modelled temperatures from regular (actual) waste lift sequence and warm lift 2 waste lift sequence (vertical bars showing placement times for waste lifts 1 through 7).

Figures 6.2 and 6.3 present the two modelled expended energy results: the actual waste lift sequence model, and the warm lift 2 sequence model, respectively. The warm lift 2 model increased the simulated expended energies at early times at bundles 3,5 and 7 . Figure 6.4 compares the expended energies at each of the individual bundles for the actual waste lift sequence and the warm lift 2 sequence. 


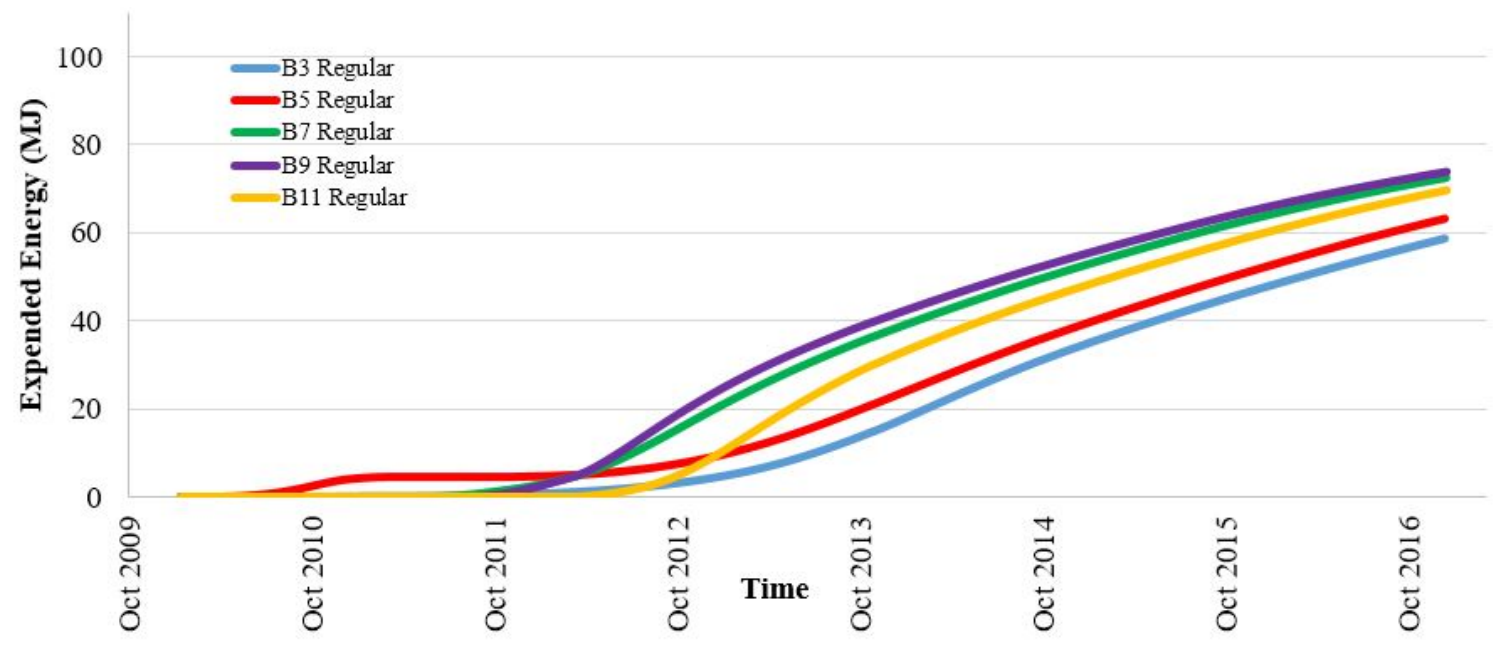

Figure 6.2: Regular waste lift sequence modelled expended energies.

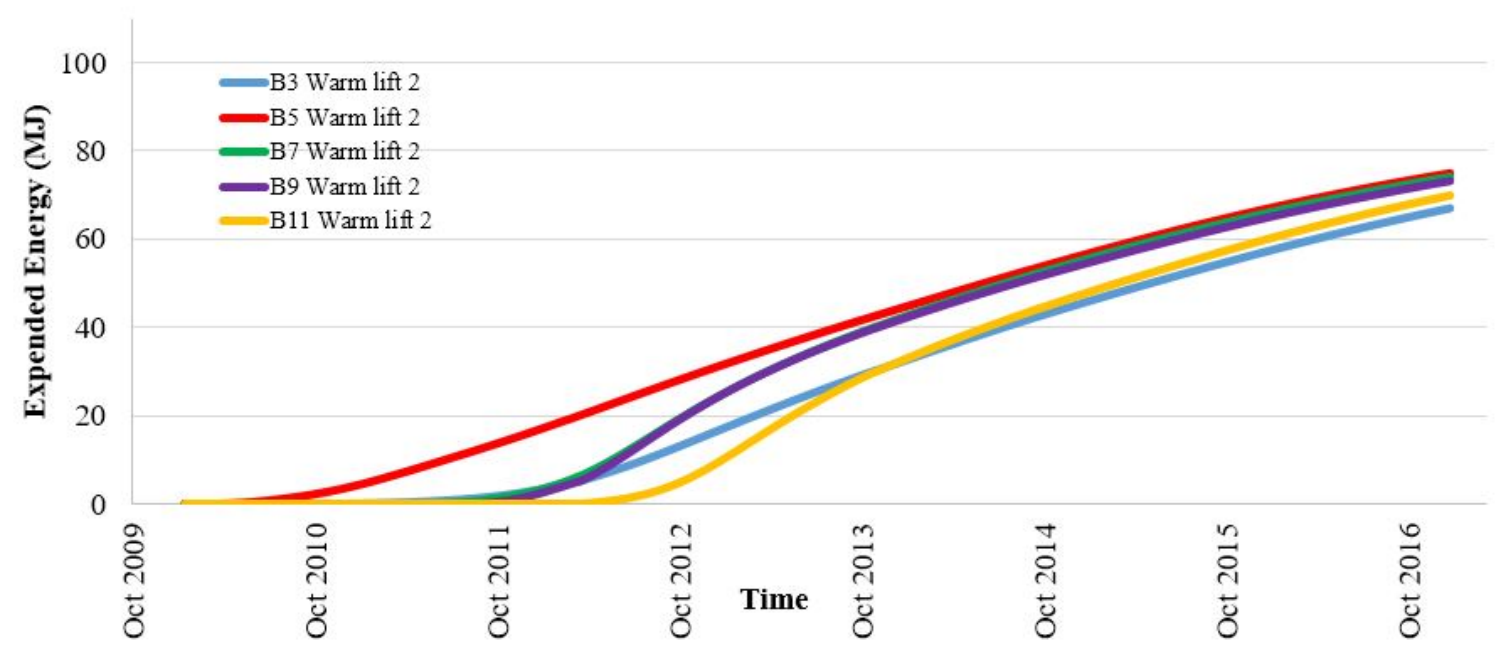

Figure 6.3: Warm waste lift 2 sequence modelled expended energies. 


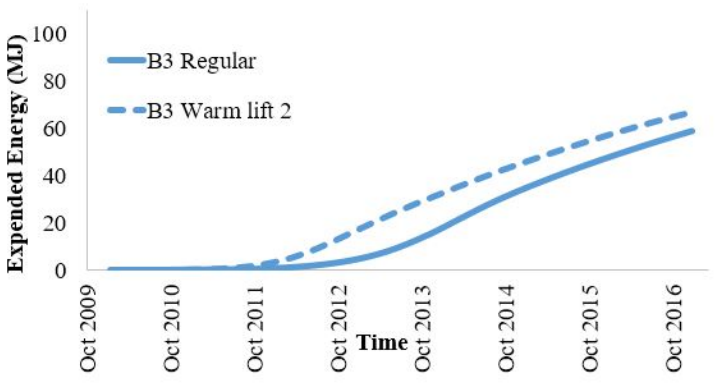

(a) Simulated expended energies at bundle 3 .

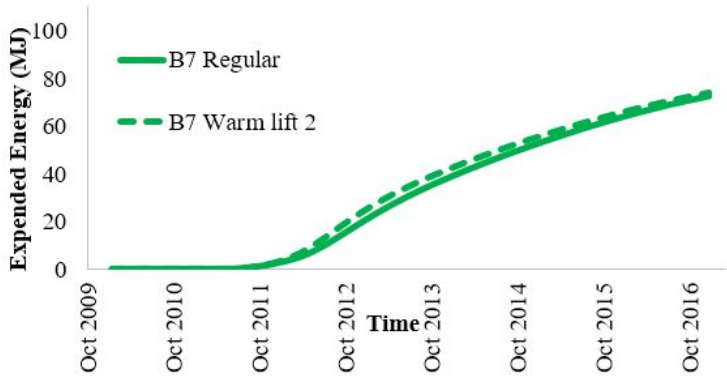

(c) Simulated expended energies at bundle 7 .

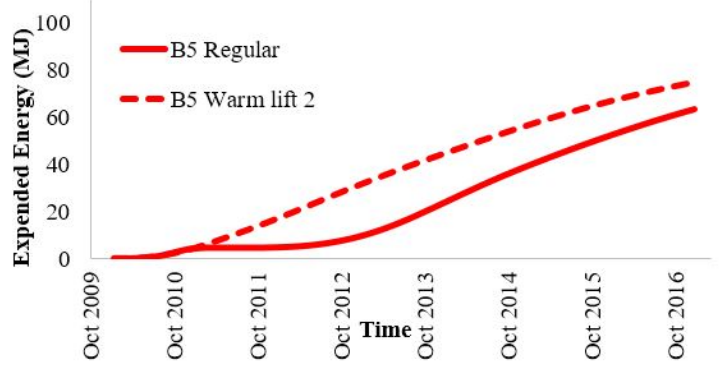

(b) Simulated expended energies at bundle 5 .

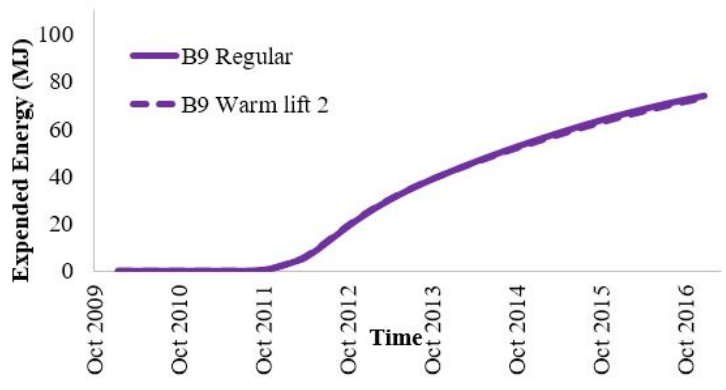

(d) Simulated expended energies at bundle 9 .

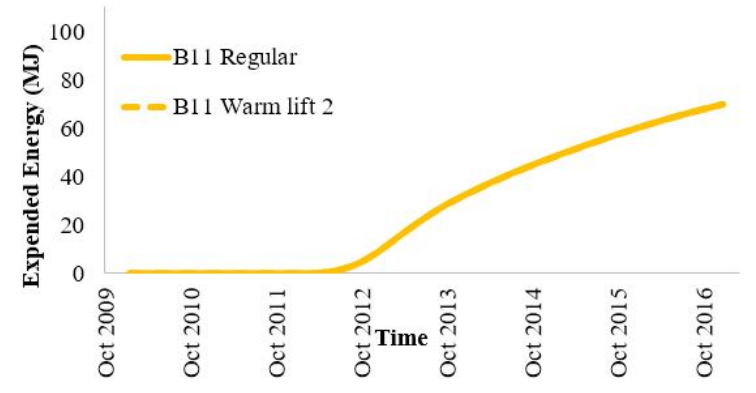

(e) Simulated expended energies at bundle 11 .

Figure 6.4: Comparison of simulated expended energies for actual waste lift sequence and warm waste lift 2 sequence. 
From the comparison plots of expended energies at each of the individual bundles (Figure 6.4), it can be seen that the results at bundles 3, 5 and 7 differ to varying degrees, but that the results at bundles 9 and 11 are very similar. As such, the difference in settlement at bundles 9 and 11 will be dictated by the lower bundles only, and will not differ due to biological decomposition in the upper waste lifts as these lifts were placed under warm conditions. The expended energy with time at bundles 3, 5 and 7, however, do differ due to biological decomposition. The expended energies for the warm lift 2 simulation are greater than the regular sequenced model. Greater expended energies are attributed to greater temperatures generated in the waste due to the placement of waste lift 2 during the summer months rather than the winter. The greatest difference in settlement occurs in June 2013. At bundle 11, the difference in settlement between the regular waste lift sequence and the warm lift 2 waste lift sequence is $0.337 \mathrm{~m}$. This means that by placing waste lift 2 during the summer rather than the winter could have resulted in $33.7 \mathrm{~cm}$ of additional settlement by June 2013. Waste Management began placing the final cover on Zone 4 at the Ste. Sophie landfill in 2014.

Zone 4 at the Ste. Sophie landfill is approximately $600 \mathrm{~m}$ by $400 \mathrm{~m}$. Assuming that, through an optimal placement strategy, $0.337 \mathrm{~m}$ of airspace was gained over the entire landfill footprint and assuming an average waste density of 1 tonne $/ \mathrm{m}^{3}$, approximately 80 000 tonnes of additional waste could have been placed in Zone 4 before the final cover was placed. With tipping fees of approximately $\$ 50$ per tonne, this would generate an additional \$4 million in revenue. More importantly, however, is the environmental benefit. This is a significant amount of waste, and if more waste can be placed into existing landfills, then fewer new landfills need to be opened. 


\section{Chapter 7}

\section{Conclusions and Contributions}

Data have been collected from the instrument bundles located in the Ste. Sophie landfill since January 2010. Temperature, oxygen, and settlement data have provided insight into the relative importance of the processes and parameters that impact the heat generation and transfer in landfills operated in northern climates. A few research groups have attempted to place sensors within waste with limited success as the sensors do not survive the harsh conditions in the waste. The data presented in this thesis represent one of the most comprehensive temperature data sets available. Therefore, the data itself is a significant contribution to the literature. The following sections summarize the conclusions and contributions presented in this thesis.

\section{Chapter 4: Ste. Sophie Heat Budget Model}

- The heat or energy budget for a landfill is a complex system to asses. The specific heat (and latent heat for frozen waste) and thermal conductivity store and transfer the heat generated by aerobic and anaerobic biodegradation which in turn impact the waste temperature and settlement with time. 
- The optimization of the thermal conductivity and specific heat supported the assumption that these parameters should increase with depth and time as assumed by Megalla et al. (2016). Other than Megalla et al. (2016), no previous research efforts have been presented in literature to study thermal conductivity with depth in a landfill. In addition, this study also allowed the specific heat to vary with depth in a landfill, which better reflects conditions expected in the field.

- As more field data were collected for the Ste. Sophie landfill, model parameters were further calibrated to improve the model fit and improve our understanding of the relative importance of various parameters and processes. Extending the simulation of Megalla et al. (2016) and optimizing the thermal conductivity and specific heat still resulted in simulated temperatures higher than those measured in the field during the last 2 to 3 years of simulation. To improve the model fit at later times, the latent heat and anaerobic heat generation rate were decreased.

- A heat budget was calculated for the vertical waste profile simulated, and it was found that aerobic heat accounted for $25 \%$ of the total heat generated, compared to $75 \%$ generated by anaerobic biodegradation. Several studies in the literature concluded that aerobic heat generation was the primary heat source, raising temperatures to optimal conditions for biodegradation and methane generation. However, the $25 \%$ aerobic heat generation rate vs. $75 \%$ anaerobic heat generation rate calculated in this thesis is significant as it highlights the major contribution of anaerobic heat generation throughout the life of the landfill.

- Of the total heat generated by aerobic and anaerobic biodegradation, $4 \%$ was needed 
to thaw the frozen waste, and $55 \%$ was stored as sensible heat and increased the waste temperatures. The remaining heat generated was lost to the surrounding environment: $38 \%$ was lost at the top of the landfill through longwave radiation and convection at the surface, and 3\% was lost through conduction at the base of the landfill. Aerobic heat generation was assumed to only occur in the top metre of waste for periods 4, 5 and 6 where field data indicated oxygen was present in the waste. As such, all the heat lost due to longwave radiation and convection at the surface of the landfill during these periods is likely heat generated via aerobic activity. The loss of aerobic heat to the atmosphere again emphasizes the significant contribution of anaerobic heat generation throughout the 7 year simulation period.

\section{Chapter 5: Temperature-Dependent Biodegradation-Induced Settlement Model}

- The proposed TDBI settlement model is an effective way to incorporate temperature-dependent biodegradation-induced settlement provided the waste temperatures are either simulated or measured with time.

- The TDBI settlement model was able to simulate the trends in temperature data observed in the field. This is the only proposed landfill settlement model which links biodegradation-induced settlement to waste temperatures and the corresponding heat generation rate, which reflects the gas generation and biodegradation rates. The TDBI settlement model allows a better simulation of the biodegradation-induced settlement as the waste transitions from low temperatures, at which degradation is negligible, to warm temperatures approaching optimal conditions for anaerobic 
biodegradation.

\section{Chapter 6: Simulation of Strategic Waste Lift Placement}

- An optimized waste lift placement strategy can improve the airspace utilization within a landfill. For the case study of the Ste. Sophie landfill presented in this thesis, placing waste lift 2 under warm ambient conditions could have resulted in $33.7 \mathrm{~cm}$ of additional settlement before placement of the final cover. Assuming similar gains over the entire Zone 4 footprint, this would have allowed approximately 80000 tonnes of additional waste to be placed in Zone 4, and would have generated an additional $\$ 4$ million in revenue assuming a tipping fee of $\$ 50$ per tonne. 


\section{References}

Alkaabi, S., Geel, P. V., \& Warith, M. (2009). Effect of saline water and sludge addition on biodegradation of municipal solid waste in bioreactor landfills. Waste Management \& Research, 27, 59-69.

Andersland, O., \& Anderson, D. (1978). The principles of quantum mechanics. New York, N.Y.: McGraw-Hill Book Co,.

Babu, G., Reddy, K., Chouskey, S., \& Kulkarni, S. (2010). Prediction of long-term municipal solid waste landfill settlement using constitutive model. Practice Periodical of Hazardous, Toxic and Radioactive Waste Management, 14, 139-150.

Bolyard, S., \& Reinhart, D. (2016). Application of landfill treatment approaches for stabilization of municipal solid waste. Waste Management, 55, 22-30.

Bonany, J., Van Geel, P., Gunay, B., \& Isgor, B. (2013a). Heat budget for a waste lift placed under freezing conditions at a landfill operated in a northern climate. Waste Management, 33(5), 1215-1228.

Bonany, J., Van Geel, P., Gunay, B., \& Isgor, B. (2013b). Simulating waste temperatures in an operating landfill in Quebec, Canada. Waste Management \& Research, 31(7), 692-699. 
Cao, Y., \& Staszewska, E. (2013). Role of landfill cover in reducing methane emission. Archives of Environmental Protection, 39(3), 115-126.

Durmusoglu, E., Corapcioglu, M., \& Tuncay, K. (2005). Landfill settlement with decomposition and gas generation. Journal of Environmental Engineering, 131(9), 1311-1321.

Edil, T., Ranguette, V., \& Wuellner, W. (1990). Settlement of municipal refuse. Geotechniques of Waste Fills- Theory and Practice, ASTM STP 1070, 1-25.

El-Fadel, M. (1991). Modeling gas and heat generation and transport in sanitary landfills. (PhD Thesis, Stanford University, California, USA)

El-fadel, M., Fayad, W., \& Hashisho, J. (2013). Enhanced solid waste stabilization in aerobic landfills using low aeration rates and high density compaction. Waste Management \& Research, 31(1), 30-40.

El-fadel, M., Findikakis, A., \& Leckie, J. (1997). Gas simulation models for solid waste landfills. Critical Reviews in Environmental Science and Technology, 27(3), 237-283.

El-fadel, M., Findikakis, A., \& Leckie, J. (1997b). Environmental impacts of solid waste landfilling. Journal of Environmental Management, 50(1), 1-25.

El-Fadel, M., Findikakis, N., \& Leckie, J. (1996a). Numerical modelling of generation and transport of gas and heat in landfills i. Model formulation. Waste Management Research, 14, 483-504.

El-Fadel, M., Findikakis, N., \& Leckie, J. (1996b). Numerical modelling of generation and transport of gas and heat in landfills ii. Model application. Waste Management Research, 14, 537-551. 
El-Fadel, M., Findikakis, N., \& Leckie, J. (1997a). Numerical modelling of generation and transport of gas and heat in landfills iii. Sensitivity analysis. Waste Management Research, 15, 87-102.

El-fadel, M., \& Khoury, R. (2000). Modeling settlement in MSW landfills: A critical review. Critical Reviews in Environmental Science and Technology, 30(3), 327-361.

El-fadel, M., Shazbak, S., Saliby, E., \& Leckie, J. (1999). Comparative assessment of settlement models for municipal solid waste landfill applications. Waste Management Research, 17(5), 347-368.

Erses, A., Onay, T., \& Yenigun, O. (2008). Comparison of aerobic and anaerobic degradation of municipal solid waste in bioreactor landfills. Bioresource Technology, 99, 5418-5426.

Faitli, J., Magyar, T., Erdelyi, A., \& Muranyi, A. (2014). Characterization of thermal properties of municipal solid waste landfills. Waste Management, 36, 213-221.

Farquhar, G., \& Rovers, F. (1973). Gas production during refuse decomposition. Water, Air \& Soil Pollution, 2(4), 483-495.

Finger, S., Hatch, R., \& Regan, T. (1976). Aerobic microbial growth in semisold matrices: Heat and mass transfer limitation. Biotechnology and Bioengineering, 18, 1193-1218.

Gholamifard, S., Eymard, R., \& Duquennoi, C. (2008). Modeling anaerobic bioreactor landfills in methanogenic phase: Long terma and short term behaviors. Water Research, 42, 15061-5071. 
Gibson, R., \& Lo, K. (1961). A Theory of Soils exhibiting Secondary Compression. Acta Polytechnica Scandinavica.

Giroux, J. (2014). State of waste management in canada. Canadian Council of Ministers of the Environment.

Hanson, J., Edil, T., \& Yesiller, N. (2000). Thermal properties of high water content materials. ASTM Special Technical Publication 1374 Geotechnics of High Water Content Materials, 1-8.

Hanson, J., Liu, W.-L., \& Yesiller, N. (2008). Analytical and numerical methodology for modeling temperatures in landfills. In Selected sessions of geocongress 08: Geotechnics of waste management and remediation. New Orleans, Louisiana.

Hanson, J., Yesiller, N., Howard, K., Liu, W.-L., \& Cooper, S. (2006). Effects of placement conditions on decomposition of municipal solid wastes in cold regions. In Proc. 13th annual cold regions engineering conference, asce (Vol. 2(2)).

Hanson, J., Yesiller, N., Onnen, M., Liu, W.-L., \& Oettle, N. (2013). Development of a numerical model for predicting heat generation and temperautres in MSW landfills. Waste Management, 33, 1993-2000.

Hanson, J., Yesiller, N., Onnen, M., \& Oettle, N. (2010). Spatial and temporal temperature distributions in municipal solid waste landfill. Journal of Environmental Engineering, 136(8), 804-814. 
Hunte, C., Hettiarachchi, C., Meegoda, J., \& Hettiarachchi, J. (2012). The City of Calgary biocell landfill: Data collection and settlement predictions using a multiphase model. GeoCongress, 4202-4211.

Incropera, F., Dewitt, D., Bergman, T., \& Lavine, A. (2013). Principles of heat and mass transfer (7th ed.). John Wiley \& Sons, Inc.

Kasali, G., \& Senior, E. (1989). Effects of temperature and moisture on the anaerobic digestion of refuse. Journal of Chemical Technology \& Biotechnology, 44, 31-41.

Lanini, S., Houi, D., Aguilar, O., \& Lefebvre, X. (2001). The role of aerobic activity on refuse temperature rise: II. Experimental and numerical modelling. Waste Management \& Research, 19, 58-69.

Lee, H.-J. (1996). Waste composition and characteristics as predictors of landfill stabilization., PhD Thesis, University of Florida, USA.

Lefebvre, X., Lanini, S., \& Houi, D. (2000). The role of aerobic activity on refuse temperature rise I. Landfill experimental study. Waste Management \& Research, 18, 444-452.

Lutz, W., \& Samir, K. (2010). Dimensions of global population projections: what do we know about future population trends and structures? Philosophical Transactions of the Royal Society, 365, 2779-2791.

Marques, A., Filz, G., \& Vilar, O. (2003). Composite compressibility model for municipal solid waste. Journal of Geotechnical and Geoenvironmental Engineering, 129(4), 372378. 
Megalla, D. (2015). Heat transfer model for an engineered landfill in Sainte-Sophie, Quebec, Canada. (MASc Thesis, Carleton University, Ottawa, CA)

Megalla, D., Van Geel, P., \& Doyle, J. (2016). Simulating the heat budget for waste as it is placed within a landfill operating in a northern climate. Waste Management, 55, $108-117$.

Neusinger, R., Drach, V., Ebert, H.-P., \& Fricke, J. (2005). Computer simulations that illustrate the heat balance of landfills. International Journal of Thermophysics, 26(2), 519-530.

Ontario Ministry of Environment. (1998). Landfill standards: A guideline on the regulatory and approval requirements for new or expanding landfill sites.

Park, H., \& Lee, S. (2002). Long-term settlement behaviour of msw landfills with various fill ages. Waste Management \& Research, 20(3), 259-268.

Pommier, S., Chenu, D., Quintard, M., \& Lefebvre, X. (2008). Modelling of moisturedependent aerobic degradation of solid waste. Waste Management, 28, 1188-1200.

Rees, J. (1980). Optimisation of methane production and refuse decomposition in landfills by temperature control. Journal of Chemical Technology and Biotechnology, 30, 458465.

Reinhart, D., Townsend, T., \& McCreanor, P. (2002). Florida Bioreactor Demonstration Project- Instrumentation. Coral Springs, Florida: Proceedings of Waste Tech 2002.

Rendra, S., Warith, M., \& Fernandes, L. (2007). Degradation of municipal solid waste in aerobic bioreactor landfills. Environmental Technology, 28(6), 609-620. 
Rich, C., Gronow, J., \& Voulvoulis, N. (2008). The potential for aeration of MSW landfills to accelerate completion. Waste Management, 28(6), 1039-1048.

Rowe, R. (2005). Long-term performance of barrier systems. Geotechnique, 55(9), 631678.

Rowe, R., Hoor, A., \& Pollard, A. (2010). Numerical examination of a method for reducing the temperature of municipal solid waste landfill lienrs. Journal of Environmental Engineering, 136(8), 794-804.

Sowers, G. (1973). Settlement of waste disposal fills. In Proc. 8th int. conf. on soil mechanics and foundation engineering (Vol. 2(2)). Moscow.

Statistics Canada. (2012). Human activity and the environment. http://www.statcan.gc.ca. (Accessed: 2017-06-16)

Townsend, T., Kumar, D., \& Ko, J. (2008). Bioreactor Landfill Operation: A Guide for Development, Implementation and Monitoring: version 1.0. Gainesville, Florida: Prepared for the Hinkley Center for Solid and Hazardous Waste Management.

United States Environmental Protection Agency. (2017). Greenhouse gas emissions. https://www.epa.gov/ghgemissions. (Accessed: 2017-09-12)

Van Geel, P., \& Murray, K. (2015). Simulating settlement during waste placement at a landfill with waste lifts placed under frozen conditions. Waste Management, 46, 352361.

Wall, D., \& Zeiss, C. (1995). Municipal landfill biodegradation and settlement. Journal of Environmental Engineering, 121(3), 214-224. 
Warith, M. (2003). Solid waste management: New trends in landfill design. Emirates Journal for Engineering Research, 8(1), 61-70.

Watmuff, J., Charters, W., \& Proctor, D. (1977). Solar and wind induced external coefficients- solar collectors. Cooperation Mediterraneanne pour L'Energie Solaire,Revue Internationale d'Heliotechnique, 2nd Quarter.

Yesiller, N., Hanson, J., \& Liu, W. (2005). Heat generation in municipal solid waste landfills. Journal of Geotechnical and Geoenvironmental Engineering, 131(11), 13301344.

Yesiller, N., Hanson, J., \& Yee, E. (2015). Waste heat generation: A comprehensive review. Waste Management, 42, 166-179.

Yoshida, H., \& Rowe, R. (2003). Consideration of landfill liner temperature. In Proc. 9th international waste management and landfill symposium. Cagliari, Italy.

Yun, D., Yoon, K. J., Gu-Yeon, K., \& Gea-Jae, J. (2014). Importance of closed landfills as green space in urbanized areas: Ecological assessment using carabid beetles. Landscape Ecology Engineering, 10, 277-284.

Zambra, C., \& Moraga, N. (2013). Heat and mass transfer in landfills: Simulation of the pile self-heating and of the soil contamination. International Journal of Heat and Mass Transfer, 66, 324-333.

Zambra, C., Moraga, N., \& Escudey, M. (2011). Heat and mass transfer in unsaturated porous media: Moisture effects in compost piles self-heating. International Journal of Heat and Mass Transfer, 54(13-14), 2801-2810. 